AEC RESEARCH AND

DEVELOPMENT REPORT

PUBLIC SERVICE COMPANY OF COLORADO

330-MW(E) HIGH-TEMPERATURE GAS-COOLED REACTOR

RESEARCH AND DEVELOPMENT PROGRAM

QUARTERLY PROGRESS REPORT

FOR THE PERIOD ENDING

MARCH 31, 1966

Prepared under

Contract AT $(04-3)-633$

for the

San Francisco Operations office

U.S.Atomic Energy Commission

\title{
IEGAL NOTICE
}

May 11, 1966

This report was prepared as an account of Government sponsored work. Neather the Tasted States, nor the Commisston, nor any person actng on behalf of the Commission:

A. Makes any warranty or representation, expressed or impied, wh th respect to the accuracy, completeness, or usefulness of the information contamed in thrs report, or that the use of any tnformation, apparatus, method, or process disclosed in this report mas not infrnge of avy tely owned rights; or
vrivate ivately owned rights; or

B. Assumes any liabilities with respect to the use of, or for damages resultung from the use of any information, apparatus, method, or process disclosed in this report.

As used in the above, "person acting on behalf of the Conmission" nnelucies any entpioyee or contractor of the Commission, or employ ee of such contractor, to the extent that such employee or contractor of the Commisston, or employes of such contractor prepares, 


\section{DISCLAIMER}

This report was prepared as an account of work sponsored by an agency of the United States Government. Neither the United States Government nor any agency Thereof, nor any of their employees, makes any warranty, express or implied, or assumes any legal liability or responsibility for the accuracy, completeness, or usefulness of any information, apparatus, product, or process disclosed, or represents that its use would not infringe privately owned rights. Reference herein to any specific commercial product, process, or service by trade name, trademark, manufacturer, or otherwise does not necessarily constitute or imply its endorsement, recommendation, or favoring by the United States Government or any agency thereof. The views and opinions of authors expressed herein do not necessarily state or reflect those of the United States Government or any agency thereof. 


\section{DISCLAIMER}

Portions of this document may be illegible in electronic image products. Images are produced from the best available original document. 
QUARTERLY REPORT SERIES

GA-6850-July, 1965, through September, 1965

GA-6950-October, 1965, through December, 1965 


\section{INTRODUCTION}

The objective of the research and development program work reported here is to develop and verify the information required to design, construct, operate, and maintain the Public Service Company of Colorado power plant as provided in U.S.Atomic Energy Commission Contract AT(04-3)-633.

Part I of this report includes the work described in Appendix $B$ of the contract; this work consists largely of component development and test-ing, nuclear analysis, and fuel development and testing. Part II covers the work described in Appendix $\mathrm{K}$ of the contract; this work includes the development of the fuel transfer machine, the series-steam-turbine-driven circulator, the control rod drives, the steam generator, and coated particles. 


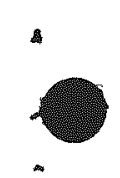

○

. 


\section{CONTENTS}

INTRODUCTION $0 \ldots \ldots 00000000000000000000000000000000000000000000$ i

\section{Part I}

TASK I. COMPONENT DEVELOPMENT 0000000000000000000000000000000000000001

Reactor Vesse1. .000000000000000000000000, . . 000000000000.0.0 1

PCRV Mode1 No, 2 Tests o o c000000000000000000000000000. 1

Reactor Thermal Barrier.000000000000000.0000000000000000000000 2

Primary Coolant System Flow $0000000000, \ldots 0000000000000000002$

Compressors and Auxiliary Circulators.000600000000000000000000 3 Compressors.000000000000000000000000000000000000000000003 3 Auxiliary Circulator.0000000000000000000000000000000000000 4

Valves.00000000000000000000000000000000000000000000000000000000004 4 Steam/Water Dump Valves 00000000000000000000000000000000.4 Helium Service Valves 00000000000000000000000000000000000077

Instrumentation and Electrica1.0000000000000000000000000000000007 7 Moisture Detectors.0000000000000000500000000000000000000000006 7

TASK II。 NUCLEAR ANALYSIS 00000000000000000000000000000000000010

Fuel Cycle Analysis. $\ldots 0000000000000000000000000000000000000010$

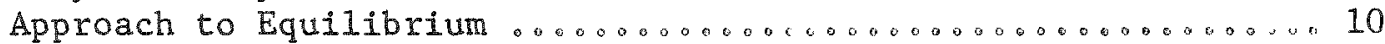

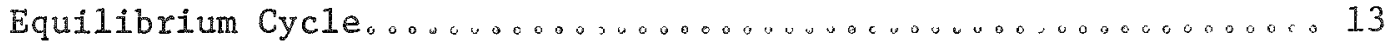

Power Shaping. 000000000000000000000000000000000000000000013 Transverse Power Distribution in the Initial Core.0.0.0.00... 13 Transverse Power Distribution in the Equilibrium Core Axial Power Distribution in the Equilibrium Core.0.0.0.... 16 Fue1 Feed Compositions in the Equilibrium Core. $000000000 \% 18$

Kinetic Analysis 00000000000000000000000000000000000000000000,18 Control Requirements 000000000000000000000000,100000000000018 Control System Worth 0000000000000000000000000000000000,0018 Reserve Shutdown System.00000000000000000000000000000000 20 Temperature Coefficient 0000000000000000000000000000000,22 Transient Analysis $0000000000000,1000000000000,00000000022$

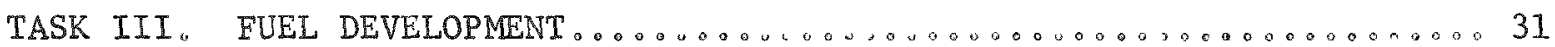

Design

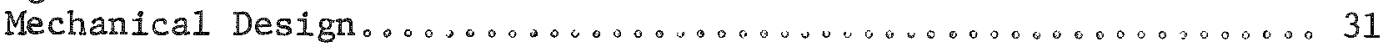

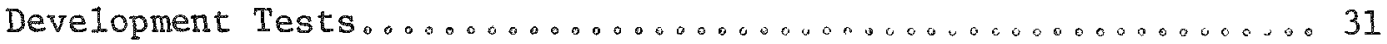

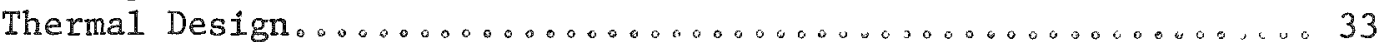

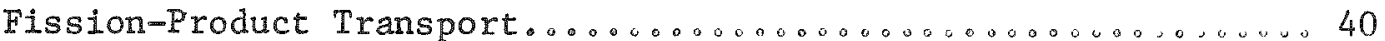

Materials onooco00000000000000000000000000000000000000000000 47

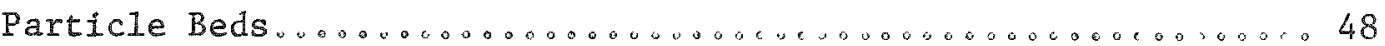

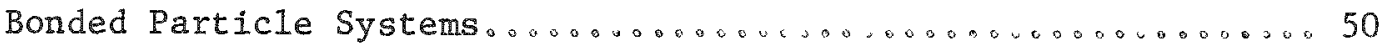




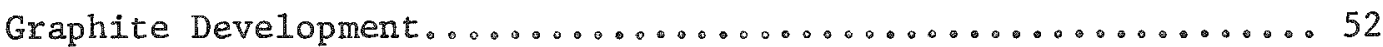

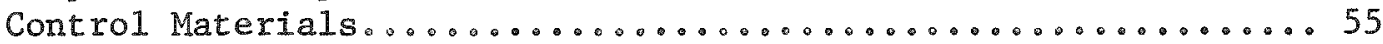

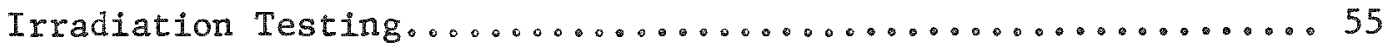

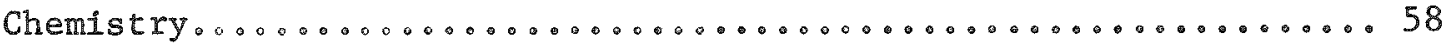

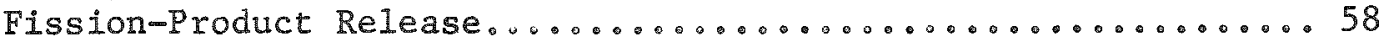

Sorption and Diffusion of Fission Products.............. 60

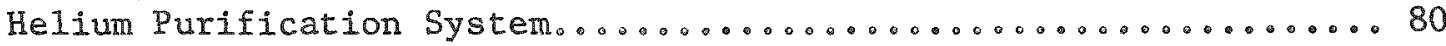

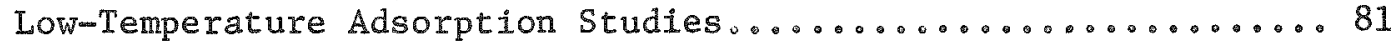

High-Temperature Adsorption Studies . . . . . . . . . . . . . . 81

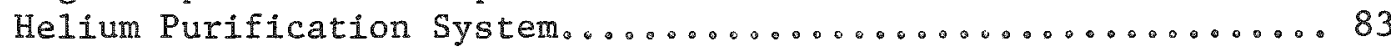

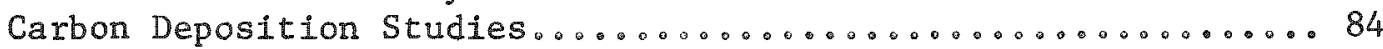

Part II

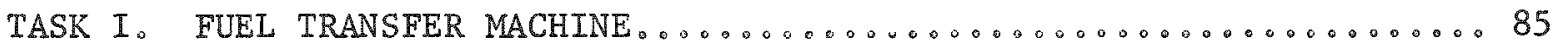

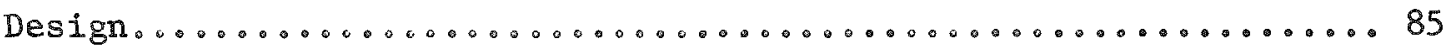

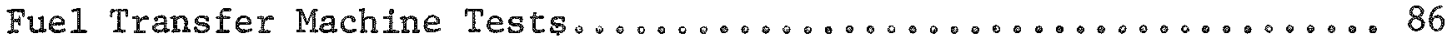

TASK II。 SERIES-STEAM-TURBINE-DRIVEN CIRCULATOR_............. 87

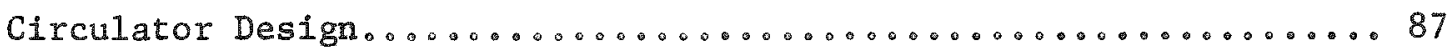

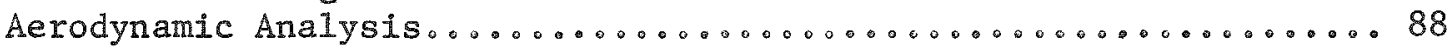

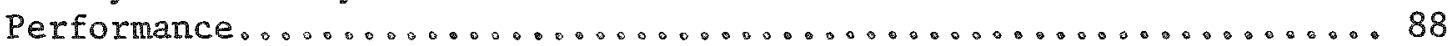

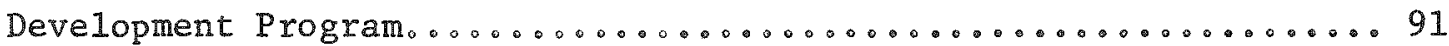

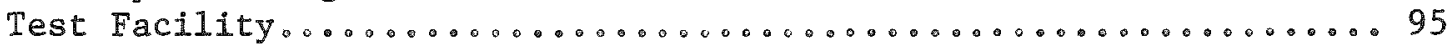

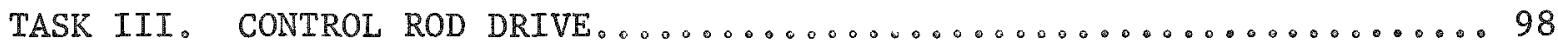

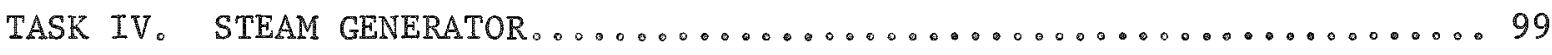

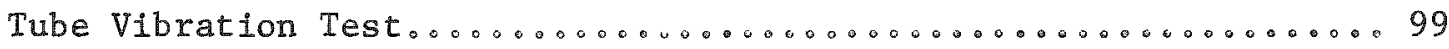

Steam/Water Flow Stability. .......................

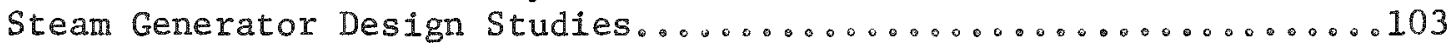

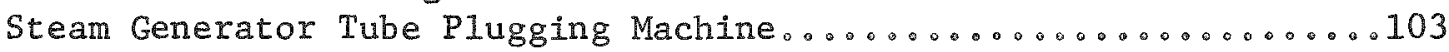

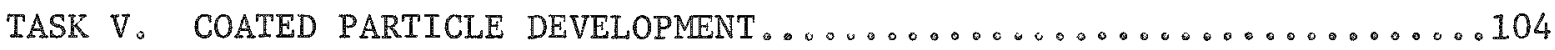

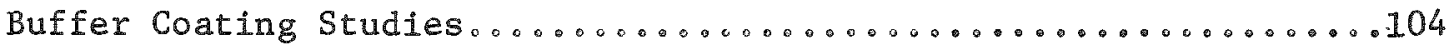

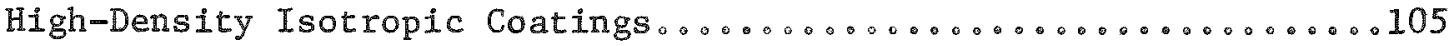

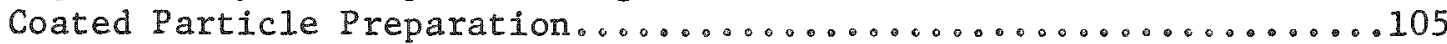

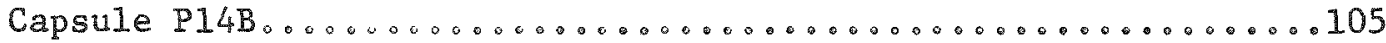

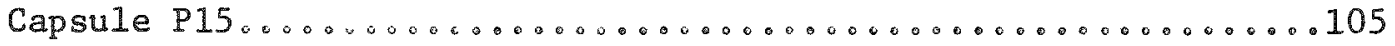

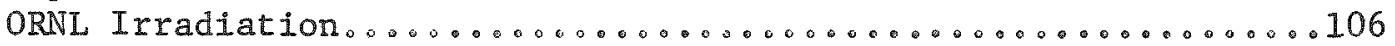

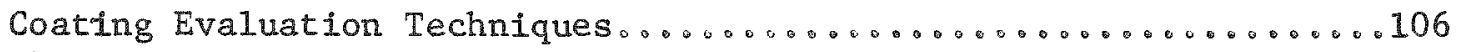

Thermal Stability Studies....

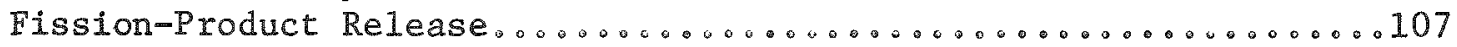




\section{PART I}


TASR I

COMPONENT DEVELOPMENT

\section{REACTOR VESSEL}

The objective of this subtask is to acquire information necessary to develop and specify the design of the prestressed concrete reactor vessel. (PCRV) for the plant and to provide a technical basis for obtaining necessary approvals of regulatory bodies and insurance groups, by means of conceptual design, analyses, and testing of materials, scale models of the vessel, and full-scale parts of the vessel, such as tendons and penetrations: where necessary.

Model testing will include internal heating to produce appropriate temperature differences across the concrete, test to destruction, longterm tests, measurement of leakage through the concrete resulting from a simulated crack in the liner, and test to demonstrate the adequacy of the double containment on penetrations. Representatives of interested technical societies, regulatory bodies and insurance groups will be kept informed of the progress of the program and encouraged to witness key tests.

PCRV Mode1 No, 2 Tests

Construction work on Model No. 2 has progressed to a point at which tendon tensioning has started. In the first part of the quarter, the remainder of the embedments for the bottom head and part of the side walls were installed. Dry aggregate was then placed in preparation for intrusion grouting, and the side forms were erected. The intrusion grouting was carried out and work immediately started on placement of the remainder of the embedments in the cylinder walls and in the top head. Side forms were also erected, and the remaining concrete was job-mixed and placed. During the curing time, the tendons were installed in preparation for tensioning.

More than 1000 embedded tendon ducts and reinforcing steel bars were fabricated to adequate tolerances, as was demonstrated by the small amount of rework required to allow placement. The model space interrelationship resulting from minimizing the volume of steel embedments, the total lap lengths, the many redundant elements, and the many large closely spaced penetrations made the placing sequence and fabrication tolerances important. Embedment placement was further complicated by the approximately 800 sensors embedded in the concrete and attached to the outside of the liner as well as by their lead out wiring。

The installation of vibrating wire and electrical resistance strain gauges, moisture monitors, and thermocouples proceeded concurrent with embedment placement. Formouts were provided for the vibrating wire gauges 
to be installed at the concrete surface. Tendon load cell installation was concurrent with tendon placement.

Work has proceeded on establishing the requirements for data reduction and display. As the sensors were installed, the identification of each sensor and its data input form were programmed into a code for computing reduction of the electrical signal to a numerical form of the physical equivalent. The sensor location used was thus the actual location of installation.

The tendon forces are being finalized based on as-built dimensions and field determinations of friction and tendon modulus of elasticity. The theoretical forces were first developed by the use of unit-load techniques whereby the stress distribution throughout the idealized structure was predicted by analyses in which it was assumed that unit loads were individually applied at representative locations. The same analyses were utilized in developing the sequence of tendon tensioning and the number of stages. The force requirements were then modified in order to adapt to variations from the idealized conditions assumed by the analyses.

\section{REACTOR THERMAL BARRIER}

The objective of this subtask is to establish the suitability and reliability and to predict the maintainability of thermal barrier materials and designs for predicted operating conditions of the plant PCRV by means of analyses, conceptual designs, fabrication development, materials testing, thermal testing, and accelerated life testing where meaningful, on thermal barriers under simulated environmental conditions (in helium, at temperatures up to or greater than those predicted in the reactor and, where analyses indicate necessary, at reactor pressure)。

A reevaluation of the test program requirements for the Class A multilayer metallic thermal barrier was completed. The tests now proposed include include:

1. Conductivity measurements in air for a single gas layer with spacers and leakage convection flows present.

2. Thermal cycling in pure helium to determine friction and wear characteristics of typical panel configurations.

3. Attachment stud reliability。

4. Cooling coil thermal contact evaluation.

5. Flow permeation tests to find pressure drop characteristics of a typical as-assembled panel.

\section{PRIMARY COOLANT SYSTEM FLOW}

The objective of this subtask is to determine the pressure-drop coefficients in the primary system and to verify the distribution and stability 
of the coolant flow in the primary coolant system under normal and emergency cooling conditions of the plant by means of analyses and model test(s) simulating the PCRV cavity and/or pertinent internal structures thereof.

The additional pumping facilities and instrumentation for flow testing of the primary coolant system components have now been installed. These comprise two additional $14,000 \mathrm{cfm}$ blowers, new interconnecting ducting, manifolds, and valves, and venturis for flow measurements. A separate system for providing heated air, which will be used for flow distribution and mixing tests of the reactor core exit plenum, has also been completed. The thermocouple instrumentation, which includes a 400-point data acquisition system with tape punching, has also been installed.

The model for the tests of the region between the outlet from the core and the inlet to the steam generators, designated Region $I_{\text {g }}$ has been designed, and is partly constructed. The 0.285-scale model, which is cons tructed of plywood and aluminum, is a realistic representation of the whole of this region in the reactor. Provision is made in the model for varying the height of the mixing plenum. The flow resistance of the steam generators is simulated by screens in the model, and provision is made for measuring flow into each of the simulated steam generator modules. The steel shell for the model is already installed, and connected to the pumping facility.

The hot-air source can provide a flow of heated air from any one or two of the simulated core refueling regions to permit tests to be made on flow mixing and distribution in the plenum.

During April, the model will be installed and testing begun. Measurements will be made of flow, pressure, and temperature within the plenum and in the simulated steam generator module inlets.

\section{COMPRESSORS AND AUXILIARY CIRCULATORS}

The objective of this subtask is to establish the suitability and reliability of the compressors and emergency circulator and their related operating controls and instrumentation for expected operating conditions, except radiation, in the plant by means of testung and analysis of such items as over-al1 equipment performance, operational limitations, maintenance requirements, shielding requirements, fission-product contamination, and helium leak rates.

Testing will include the low-pressure transfer compressor, the purified helium compressor, and the emergency circulator. Other compressors will be tested if necessary.

\section{Compressors}

Based on the current reactor plant reference design, the anticipated requirements for a low-pressure sink to collect miscellaneous small helium streams has not developed. Therefore, the need for the low-pressure transfer 
compressor (a nonlubricated, single-stage reciprocating compressor) has also not developed. As a result, the research and development program originally proposed for such a machine is being held in abeyance

The inquiry specification for the purified heluum compressor (a lowflow. high-head centrifugal machine) has been distributed for technical review, and comments are being incorporated Potential vendors have indicated that the development of such a machine specifically for PSC would be very expensive A study has therefore been initiated to determine whether a commercially available compressor that could be adapted to HTGR needs already exists The extent of vendor gas-bearing, centrifugal compressors and the degree to which these machines could be used in the HTGR is being investigated.

\section{Auxiliary Circulator}

A decision has been made to eliminate separately denominated auxiliary circulators from the plant design and instead to provide the main helium circulators with auxiliary drives and each primary coolant loop with a spare circulator. Consequently, effort on the auxiliary circulator has been terminated.

\section{VALVES}

The objective of this subtask is to determine the operating characterm istics of the steam-water dump valve(s) and associated system, including related instrumentation, and critical-service helium valves, and their suitability, reliability, and maintainability for service in the plant by leak, performance, and accelerated life testing of full-size valves and analyses.

\section{Steam/Water Dump Valves}

The computer code WOOSH was revised to consider a single-tube rupture in the steam generator. Two new subroutines, RUPIN and RUPCAL, were written to accomplish this change. RUPIN reads and writes the input necessary and sets up initial values of constants for the calculation. RUPCAL calculates the ruptured tube flow to the primary system Since an offset rupture with steam/water flow out of both ends was to be considered, RUPCAL was written to handle this type of case. The calculation can also include the effect of an orifice at the inlet or outlet end of the ruptured tube. The removal of energy and mass from the steam generator because of the rupture was not considered in the dump calculation, and the results are therefore approximate. For a single-tube rupture, this approximation will have a negligible effect on the over-all results.

A number of WOOSH cases were run for a single-tube rupture in the steam generator. The rupture was assumed to occur in an economizerevaporator tube, just downstream of the inlet orifice. The orifices were sized to restrict the rupture flow to $10 \mathrm{1b} / \mathrm{sec}$ out of the feedwater inlet 
side of the rupture at full pressure operation. The cases run considered 2-, 3-, 4-, 6-, 8-, and 10-in. dump lines and valves, with a dump tank pressure of 200 psia. The dump was terminated when the pressure in the steam generator reached 725 psia. The valve opening time considered was 0.5 sec. From these runs, the following parameter was derived to relate the dumpline and valve-loss coeficient, steam generator inventory, and the area of the dump line to the steam/water inleakage during dump, for a singletube rupture:

$$
\frac{\text { Water inventory (1b) } \times \sqrt{\text { Dump line and valve loss coefficient }}}{\text { Dump line area }\left(\mathrm{in}^{2}\right)}
$$

This parameter is plotted versus water inleakage during the dump in Fig. 1.1. Using this figure, the steam/water inleakage during dump for various dump line and valve combinations was calculated. These results and the total inleakages to the primary system are shown in Table 1.1. For a dual dump line and valve combination, the inleakage during dump would be approximately one-half of the values shown.

Table 1.1

TOTAL INLEARAGE INTO THE PRIMARY SYSTEMa

\begin{tabular}{c|c|l|l|c}
\hline $\begin{array}{c}\text { Line Size } \\
\text { Nominal IPS } \\
\text { (in.) }\end{array}$ & $\begin{array}{c}\text { Valve Size } \\
\text { Nominal IPS } \\
\text { (in.) }\end{array}$ & Valve Type & $\begin{array}{c}\text { Inleakage During } \\
\text { Dump (1b) }\end{array}$ & $\begin{array}{c}\text { Tnleakage } \\
\text { (1b) }\end{array}$ \\
\hline 8 & 8 & Roto & 37.5 & 146.5 \\
8 & 8 & Globe & 44 & 153 \\
8 & 6 & Roto & 40 & 149 \\
8 & 6 & Globe & 55 & 164 \\
8 & 4 & Roto & 55 & 164 \\
8 & 4 & Globe & 89 & 198 \\
6 & 6 & Roto & 48 & 157 \\
6 & 6 & Globe & 59 & 168 \\
6 & 4 & Roto & 58 & 167 \\
6 & 4 & Globe & 90 & 199 \\
6 & 3 & Roto & 79 & 188 \\
6 & 3 & Globe & 138 & 197 \\
4 & 4 & Roto & 89 & 219 \\
4 & 4 & Globe & 110 & 206 \\
4 & 3 & Roto & 97 & 257 \\
4 & 3 & Globe & 148 & 257 \\
4 & 2 & Roto & 148 & \\
\hline
\end{tabular}

a For a single rupture with various dump line and valve combinations, eight modules dumping together.

b Includes the tube inventory $(2141 \mathrm{~b})$, rupture flow prior to the dump (15 $\mathrm{lb} / \mathrm{sec}$ for $5 \mathrm{sec}=\sim 75 \mathrm{lb}$ ), and the flow after dump from 725 psia to 675 psia $(201 \mathrm{~b})$; total $=109.01 \mathrm{~b}$ plus the inleakage during dump. 


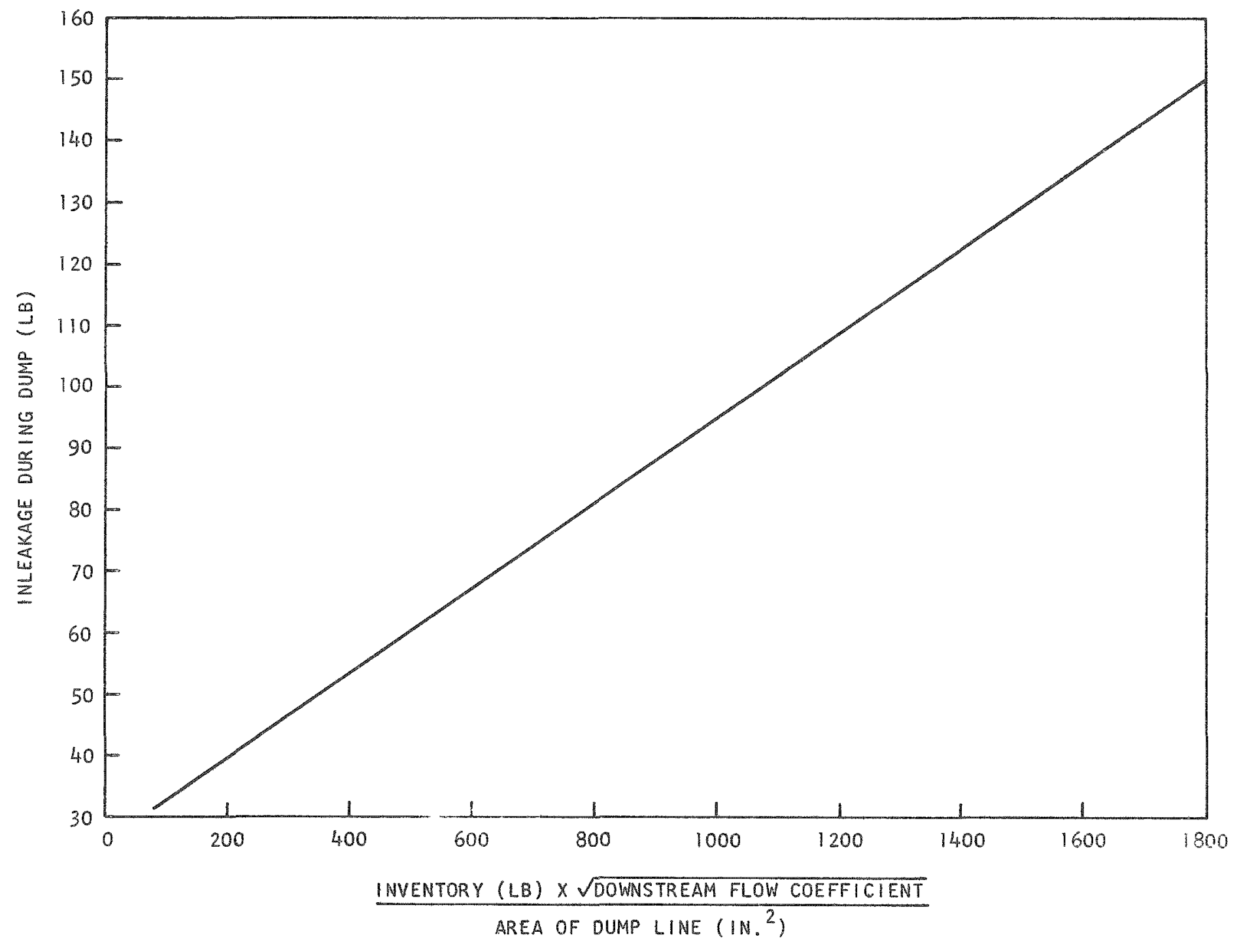

Fig. 1.1--Inleakage during dumping 
These results indicate that a 3 -in. rotovalve in a 4 -in. dump line provides a sufficiently rapid steam/water dump.

Helium Service Valves

Gas purity requirements for the proposed helium valve tests have been reviewed. Impurity levels are significant because seizing and cold welding are more likely to occur in high-purity helium. A literature review on these subjects showed that cold welding of metal surfaces can occur when protective oxide coatings are removed from the surfaces, as might happen in a high-purity helium atmosphere. There are not sufficient data, however, to establish any quantitative relationship with impurity levels.

\section{INSTRUMENTATION AND ELECTRICAL}

The objective of this subtask is to develop thermometers for measureing fuel element temperatures and moisture detectors and electrical penetrations, and to establish their operating characteristics, reliability and maintainability in the plant by means of analysis and testing in helium, at temperature and, where analyses and/or preliminary tests indicate a necessity, at pressure and other environmental conditions.

\section{Moisture Detectors}

The preliminary design of the dewpoint moisture detector and construction of the moisture detector laboratory test facility are nearing completion.

Preliminary calculations were performed to determine the dose rate which may prevail at the light detectors due to the coolant activity in the space surrounding the mirror. The dose rate was estimated at $10 \mathrm{r} / \mathrm{hr}$. As a result, it has been tentatively decided to utilize vacuum photocells instead of solid state light sensors because the former are less subject to radiation damage.

Figure 1.2 illustrates the moisture detector as presently conceived. The detector incorporates two sets of mirrors, one light source, and two photocells per mirror, one set being used as a spare. One photocell picks up the 1ight reflected by the mirror from the source; the other, the light scattered by the mirror surface. Under ideal conditions, the output of the former is maximum and that of the latter zero. If the mirror surface gets covered with a film of dust or volatile matter, the reflectivity of the mirror decreases. The output of the photocell receiving the reflected light (which serves as the trip signal detector) decreases toward the trip setting whereas the output of the second photocell increases because of light scatter and serves as an indication of the cleanness of the mirror. The presence of moisture in the sample stream, above the moisture trip setting, will also result in the actions previously described with the exception that they will rapidly result in a moisture trip rather than a quasistatic situation. 


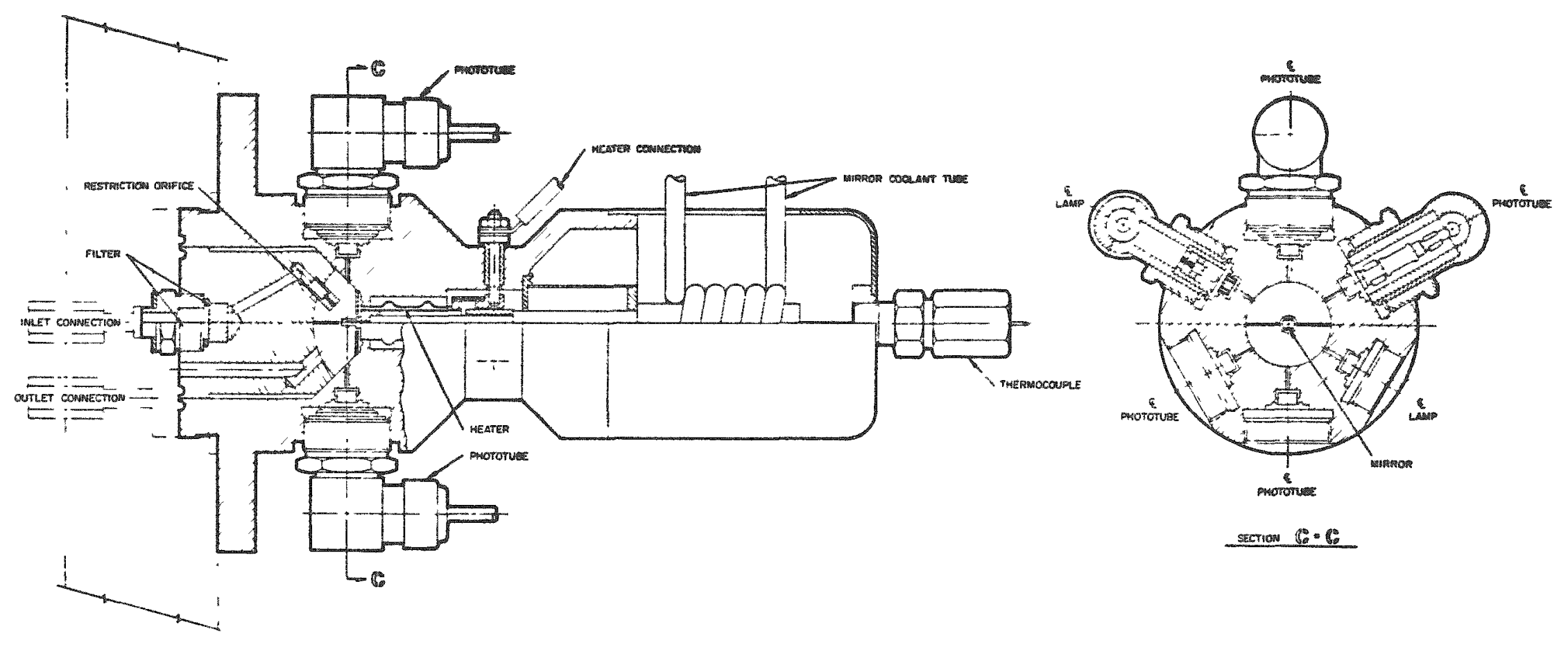

Fig 1.2-moisture Detector

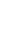


A heater capable of raising the temperature of the mirror to $250^{\circ} \mathrm{F}$ is provided to remove as much of the matter deposited on the mirror as possible upon indication of significant scatter.

The detector is provided with two gas connections that are engaged when the detector is plugged into the partition plate separating the primary containment from the interspace of the moisture monitor penetration. The penetration is located in the side of the PCRV and contains a sample gas flow loop established between the outlet of the helium circulators and the cold helium plenum. Upon plug-in, a small amount of sample gas flows through a coarse filter into the detector mirror cavity and back into the main sample 10op.

The best means of cooling the mirror has not yet been determined. The possibility of using Freon compressors or the plant liquid-nitrogen system are presently being investigated. No work has been done in connection with the coolant control system, since this is contingent upon selection of the coolant.

The light source is a miniature tungsten-filament bulb with a rated lifetime of $100,000 \mathrm{hr}$. It is planned to energize the bulb from an alternating current source at a frequency of about $10 \mathrm{cps}$ in order to reduce background and noise at the output of the photocell and allow alternating current amplification. The circuitry to achieve the above is presently being developed.

The laboratory moisture monitor test facility consists of a oncethrough (open-10op) flow system. Helium from a helium cylinder source is routed through two lines. One line is cooled by liquid nitrogen to provide a bone-dry helium source. The other line is bubbled through water at $150^{\circ} \mathrm{C}$, and the wet helium is then cooled in an ice bath to provide gas at a dewpoint of $0^{\circ} \mathrm{C}$. A heat exchanger equalizes the temperature of the dry and the wet helium. A flow meter and needle valve control the flow of helium in each line. The two streams are then mixed and heated to the desired temperature. By adjusting the two needle valves, mixing rates can be controlled and moisture content adjusted to the desired dewpoint up to $0^{\circ} \mathrm{C}$. For higher moisture content, the ice bath is heated to the desired dewpoint temperature. Helium mass flow and pressure are controlled by a needle valve at the exhaust of the dewpoint meter and by the pressure regulator at the helium source. Adequate heaters are provided to maintain the gas system well above the dewpoint. 
TASK II

NUCLEAR ANALYSIS

\section{FUEL CYCLE ANALYSIS}

The objective of this subtask is to establish the fuel management program for the reactor based on analyses of the effects of the loadings in the initial and replacement segments, including a recycle segment in an equilibrium core, on local power generation, reactor safety, and economics.

\section{Approach to Equilibrium}

The adoption of coolant orificing in the reference design permits the use of lighter loadings which result in more economic fuel cycles. Age peaking factors corresponding to lighter loadings up to a C/Th ratio of 225 have been examined for an equilibrium core, and the maximum fuel temperature is maintained well below $1500^{\circ} \mathrm{C}$. The loading for the initial core is heavier, and this results in conservatively low fuel temperatures during the first years of operation. The contents of the core during the approach to equilibrium are shown in Table 2.1 and the quantities of discharged fuel are shown in Table 2.2. The initial core is partially mocked up with some of the excess reactivity associated with the low fission-product inventory taken up by excess thorium in the zones discharged after 2, 3, and 4 years. It is this variation in thorium content that produces the fluctuations in the quantity of $U^{23}$ discharged each year. The light loading in the replacement segments results in quite low age peaking factors (1ess than 1.25) for the first five years; in the following five years the age peaking factor climbs rapidly to its equilibrium value of 1.45 .

It should be pointed out that the uncertainty in the epithermal value of the capture-to-fission ratio for $U^{-233}(\alpha)$ requires that some calculational inconsistancies occur if a conservative position is to be maintained. All loading and end-of-cycle reactivities are therefore computed with the pessimistic value $(a \simeq 0.25)$, and maximum excess reactivities that determine shutdown margins are computed with the more widely accepted value $(\alpha=0.17)$. Figure 2.1 shows the effective multiplication constant for (1) unrodded operating condition, (2) unrodded at $300^{\circ} \mathrm{K}$ with all $\mathrm{Xe}^{135}$ and $\mathrm{Pa}^{233}$ decayed, and (3) rodded at $300^{\circ} \mathrm{K}$ with all $\mathrm{Xe}^{135}$ and $\mathrm{Pa}^{233}$ decayed, during several cycles in the approach to equilibrium. To date only unshielded boron has been used as a burnable poison; it is clear that this is adequate after the initial two-year cycle. The feed fuel composition has been maintained constant; however, the replacement of seven refueling regions at every sixth reload introduces a perturbation that will be accommodated by loading adjustments each year. Because of a limitation of the one-dimensional depletion program (FEVER-7), the $\mathrm{Np}^{237}$ could not be included; this results in the multiplication values shown being high by about $0.5 \% \mathrm{k}$. When these details 
Table 2.1

MATERIAL CONTENT OF CORE DURING APPROACH TO EQUILIBRIUM

\begin{tabular}{|c|c|c|c|c|c|c|}
\hline \multirow{2}{*}{$\begin{array}{l}\text { Years of } \\
\text { operation }\end{array}$} & \multicolumn{6}{|c|}{ Quantities (kg) } \\
\hline & $\mathrm{Th}^{2} 32$ & $\mathrm{~Pa}^{233}+\mathrm{U}^{233}$ & $\mathrm{U}^{235}$ & Total U & Fissile $\mathrm{Pu}$ & Total Pu \\
\hline 0 & 20,000 & 0 & 1150 & 1230 & 0 & 0 \\
\hline 1 & 19,800 & 180 & 840 & 1170 & 2 & 2 \\
\hline 2 & 19,600 & 310 & 610 & 1120 & 3 & 4 \\
\hline $2^{a}$ & 18,400 & 250 & 760 & 1210 & 2 & 3 \\
\hline 3 & 18,200 & 350 & 550 & 1140 & 3 & 4 \\
\hline $3 \stackrel{a}{=}$ & 17.100 & 280 & 700 & 1190 & 3 & 4 \\
\hline 4 & 16,900 & 350 & 500 & 1120 & 3 & 4 \\
\hline $4 \stackrel{a}{-}$ & 16,000 & 270 & 650 & 1160 & 3 & 4 \\
\hline 5 & 15,900 & 340 & 460 & 1070 & 3 & 4 \\
\hline $5 \stackrel{a}{-}$ & 15,400 & 260 & 620 & 1110 & 2 & 4 \\
\hline 6 & 15,200 & 330 & 430 & 1030 & 3 & 4 \\
\hline $6 \stackrel{a}{a}$ & 14,700 & 250 & 600 & 1080 & 2 & 3 \\
\hline 7 & 14,500 & 310 & 410 & 990 & 3 & 4 \\
\hline $7 \underline{a}$ & 14,100 & 230 & 590 & 1050 & 2 & 3 \\
\hline 8 & 13,900 & 290 & 400 & 950 & 2 & 4 \\
\hline $8 \stackrel{\mathrm{a}}{ }$ & 14.100 & 230 & 580 & 1040 & 2 & 3 \\
\hline Equilibrium & 14.100 & 230 & 550 & 1010 & 2 & 3 \\
\hline Equilibrium & 13,900 & 290 & 360 & 930 & 2 & 4 \\
\hline
\end{tabular}

a After refueling.

Table 2.2

QUANTITIES OF MATERIAL DISCHARGED DURING THE APPROACH TO EQUILIBRIUM

\begin{tabular}{c|c|c|c|c|c|c}
\hline \multirow{2}{*}{$\begin{array}{c}\text { Years of } \\
\text { operation }\end{array}$} & \multicolumn{7}{|c}{ Quantities $(\mathrm{kg})$} \\
\cline { 2 - 7 } & $\mathrm{Th}^{232}$ & $\mathrm{~Pa}^{233}+\mathrm{U}^{233}$ & $\mathrm{U}^{235}$ & Tota1 U & Fissile Pu & Total Pu \\
\hline \multirow{2}{*}{2} & 3630 & 58 & 53 & 130 & 0.2 & 0.3 \\
3 & 3450 & 71 & 62 & 170 & 0.4 & 0.6 \\
5 & 3310 & 78 & 55 & 180 & 0.5 & 0.8 \\
5 & 2920 & 75 & 45 & 180 & 0.5 & 0.9 \\
7 & 2880 & 78 & 33 & 170 & 0.5 & 0.9 \\
8 & 2880 & 80 & 24 & 170 & 0.5 & 0.8 \\
& 2250 & 61 & 25 & 140 & 0.4 & 0.7 \\
Equilibrium & 2240 & 60 & 19 & 130 & 0.4 & 0.7 \\
\hline
\end{tabular}




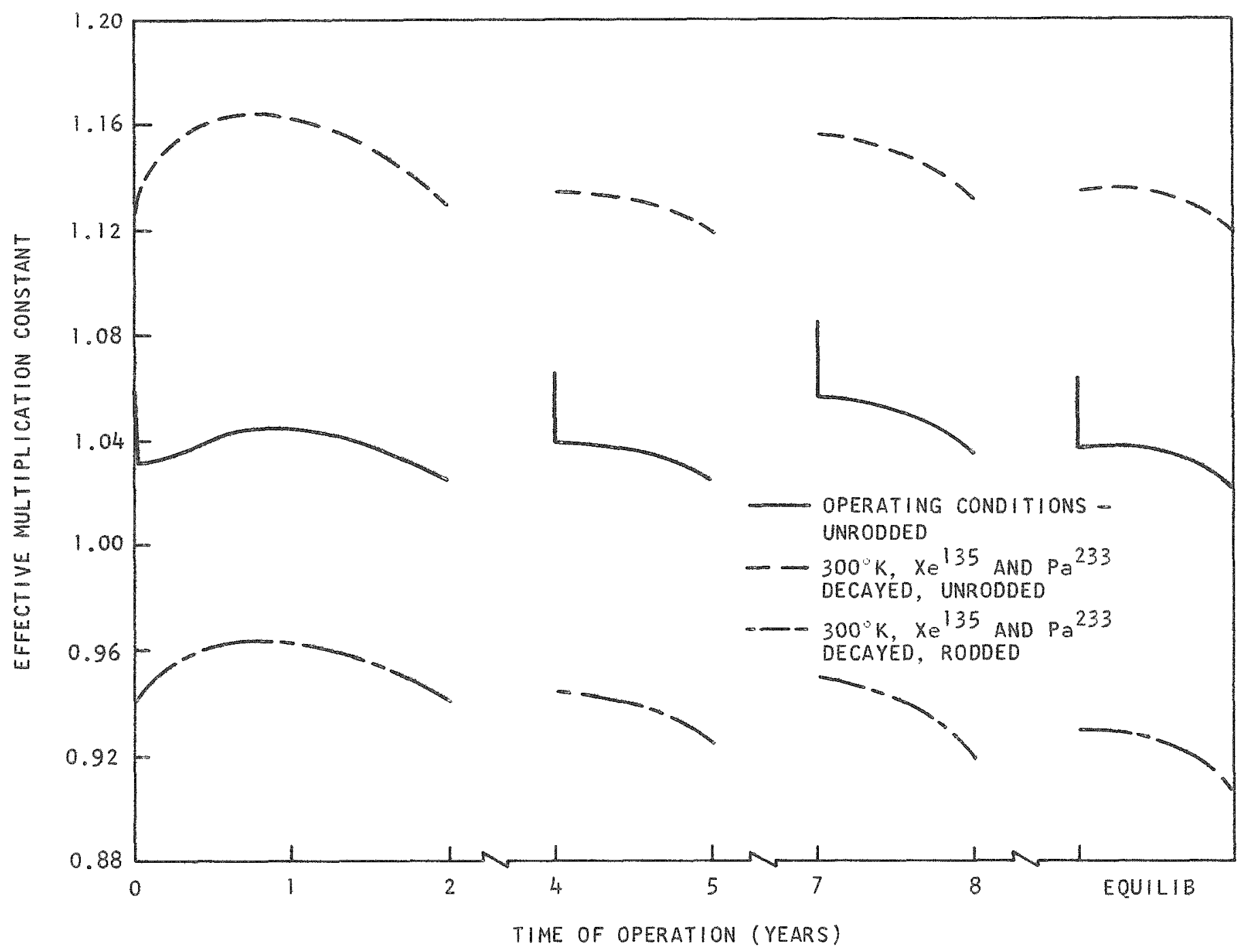

Fig, 2.1-Tariation in effective multiplication constant during approach to equilibrium 
are included, it should be possible to keep the maximum excess multiplication at $300^{\circ} \mathrm{K}$ to less than 0.14 . With present core loading, the minimum shutdown margin occurs after about one year of operation and amounts to about $4 \% \Delta \mathrm{k}$. With adjusted loadings and shielded burnable poison, the minimum shutdown margin would be increased to about $6 \% \Delta \mathrm{k}$. In actual operation, the reactor is shut down to the refueling temperature of $470^{\circ} \mathrm{K}$, rather than $300^{\circ} \mathrm{K}$. Because of the negative temperature coefficient, this will add a further $2 \% \Delta \mathrm{k}$ to the shutdown margin.

Equilibrium Cycle

The equilibrium cycle occurs after about 10 years of operation, and the contents of the core during one of these cycles are shown in Table 2.3. In developing the beginning-of-cycle values, it was assumed that the reactor had been shut down for two weeks for refueling. Consequently, about $40 \%$ of the $\mathrm{Pa}^{233}$ is removed either by decay to $\mathrm{U}^{233}$ or by removal for refueling. The contents of one-sixth of the core during equilibrium operation are shown in Table 2.4 and the neutron balance at the beginning and end of the cycle is shown in Table 2.5. The values shown in Tables $2.3,2.4$, and 2.5 are nominal, in that they do not reflect the replacement of seven refueling regions every sixth year and only six refueling regions at all other times.

The maximum fuel burnup in any fuel particle currently obtains in the equilibrium core and amounts to $20 \%$ of the atoms in uranium particles. This particle contains four thorium atoms per uranium atom. The maximum burnup in the all-thorium particle is $6 \%$ of the atoms. The thickness of the fuel coatings is sized to accommodate these burnups. The average burnup in the equilibrium core is $100,000 \mathrm{Mwd} / \mathrm{t}$.

\section{POWER SHAPING}

The objective of this subtask is to establish the fuel and burnable poison distribution and the control rod programming based on analyses of the transverse and axial power distribution as a function of fuel and poison loading, burnup, and control rod positions and considerations of fuel temperatures and economics.

Transverse Power Distribution in the Initial Core

The radial fuel zoning of the initial core was not affected by the lighter loading of the replacement segments. Since there are four radial zones, each containing four mocked-up fuel ages, plus the central refueling region, all of which contain two axial zones, there are potentially 34 different fuel compositions. In a single transverse plane there are 17 fuel compositions; by associating compositions within $10 \%$ of each other, the number of compositions can be reduced to 11 in a plane. Investigation thus far has indicated no apparent degradation in the power distribution because of this association of fuel zones. Figure 2.2 shows the maximum and average normalized power in each of the 55 core regions at the beginning of life with no control rods inserted. The maximum values usually occur at the boundaries of zones and often at corner points in the $X-Y$, multigroup layout; these 
Table 2.3

MATERIAL CONTENT OF EOUTLIBRTUA CORF

\begin{tabular}{|c|c|c|}
\hline \multirow[b]{2}{*}{ Maceral } & \multicolumn{2}{|c|}{ Welght (kg) } \\
\hline & $\begin{array}{l}\text { Reglnning } \\
\text { of Cycle }\end{array}$ & $\begin{array}{l}\text { End of } \\
\text { Cycle }\end{array}$ \\
\hline $\mathrm{Th}^{232}$ & 1.4 .669 & 13,870 \\
\hline $\mathrm{Pa}^{233}$ & 14 & 24 \\
\hline$U^{2}+3$ & 220 & 270 \\
\hline $0^{23^{5}}$ & 550 & 360 \\
\hline Toeal IV & 1010 & 930 \\
\hline $\mathrm{Pu}^{239}$ & 1.4 & 1.6 \\
\hline $\mathrm{Pu}^{24 !}$ & 0.6 & 0.7 \\
\hline Sotal Ru & 3.1 & 3.8 \\
\hline
\end{tabular}

Tanle 2.4

MATERTAL CONTFNTS OF ONE-STXTH OF CORE DURING EQUTLTBRTUM OPERATTON

\begin{tabular}{|c|c|c|c|c|c|c|}
\hline \multirow{2}{*}{$\begin{array}{c}\text { Resldence } \\
\text { Time } \\
\text { (Vears) }\end{array}$} & \multicolumn{6}{|c|}{ Weight (kg) } \\
\hline & $\mathrm{Th}^{2}=3 ?$ & $\mathrm{~Pa}^{3} 3$ & {$\left[0^{23}\right.$} & $y^{3} 3^{x_{0}}$ & Total U & Total Pu \\
\hline 0 & 2420 & 0.0 & 0.0 & 207 & 220 & 0.0 \\
\hline 1 & 2390 & 4.2 & 22 & 134 & 190 & 0.6 \\
\hline 2 & 2360 & 4.1 & 38 & 89 & 170 & 0.6 \\
\hline 3 & 2330 & 4.1 & 47 & 58 & 150 & 0.7 \\
\hline 4 & 2300 & 4.0 & 52 & 38 & 140 & 0.7 \\
\hline 5 & 2260 & 4.0 & 55 & 26 & 140 & 0.7 \\
\hline 6 & 2240 & 3.9 & $5 h$ & 19 & 130 & 0.7 \\
\hline
\end{tabular}

Table 2.ry

NEUTRON BALANCE TOR TUE EQUTLIBRTUM CYCLL

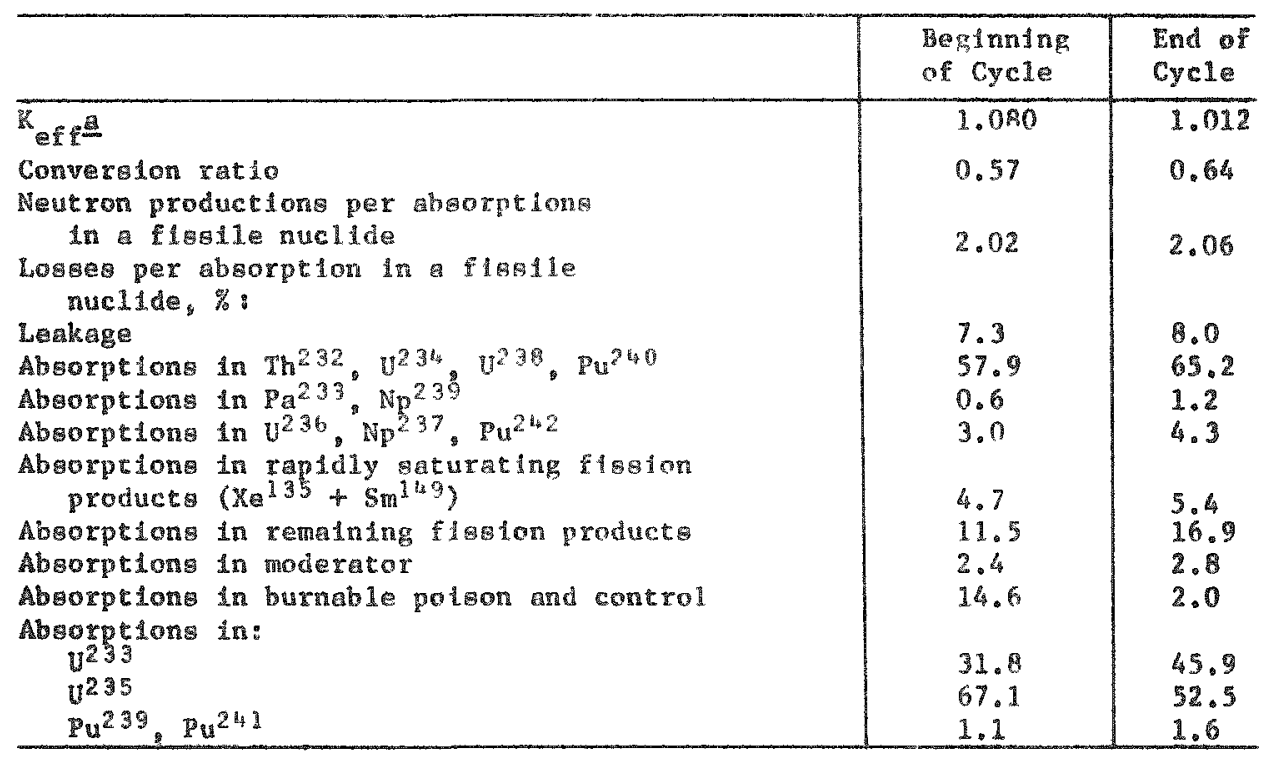

a Wtiout burnable polson or comar polaon and whthe rapldy acurating fiaston products. 


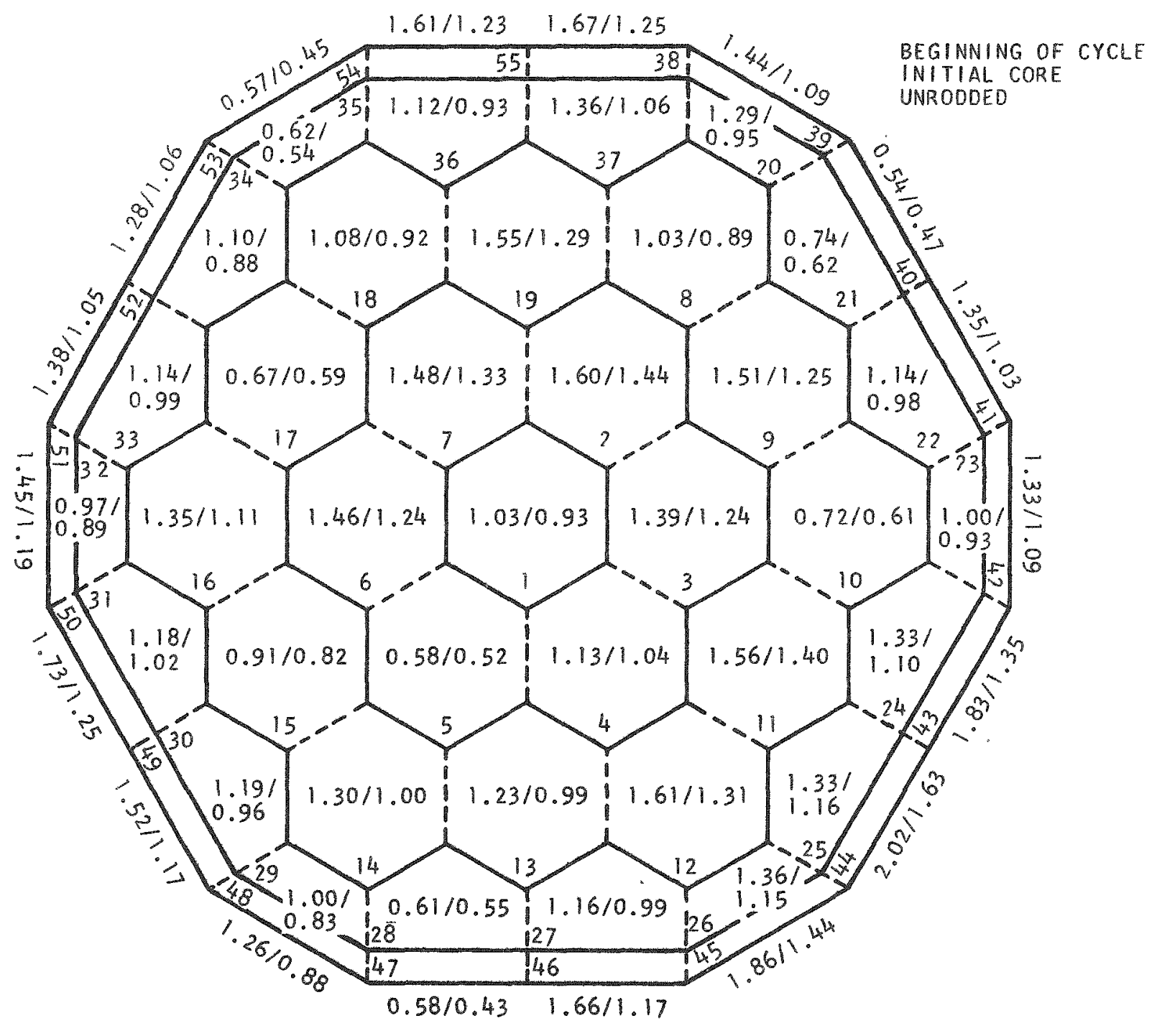

Fig. 2.2--Maximum and average power in each core zone 
values are very localized and are of questionable reliability. The maximum power density outside the edge zone is 1.60 and occurs in region 2. A calculation of the fraction of the initial core operating above any given normalized power level indicates that less than $3 \%$ of the core attains power levels above 1.5 and less than $1 \%$ above 1.6 .

A two-dimensional burnup calculation for the first two years of operation was synthesized and very little shift in the over-all power distribution was indicated. Control rod configurations that will introduce little change in the gross power distribution are currently being investigated.

\section{Transverse Power Distribution in the Equilibrium Core}

The radial fuel zoning in the equilibrium core was changed to reflect the lighter fuel loading. At the beginning of the cycle, the maximum value of the average normalized power is about 1.5 and occurs in the one-year-old refueling regions at the edge of the core. At the end of the cycle, the maximum value of the average normalized power density has increased to about 1.8 and again occurs in the one-year-old refueling regions at the edge of the core. The fraction of the equilibrium core operating above any given normalized power level was calculated. The resulting values represent an increase of about 0.2 over the heavier loadings previously considered and are roughly what one would expect from the increase in age peaking factor. At the beginning of the cycle, about $1 \%$ of the core operates above a 1.6 peak and at the end of the cycle the fraction above 1.6 increases to $4 \%$ 。

With the maximum powers occurring toward the edge of the core, the control patterns will have to be such that the flux is not pushed up in this region. A pattern that would maintain the central rod and three outer rods at about the same level of insertion is currently being investigated. The central rod will operate from the automatic controller while the other three are periodically shimmed manually.

Axial Power Distribution in the Equilibrium Core

The use of coolant orifices results in considerably lower fuel temperatures and thus makes the axial power shaping less necessary. Previously an exponential power distribution was considered necessary. This type of power distribution has the disadvantages of increased neutron leakage, the complexity of five axial core zones, and some very heavily loaded regions that are difficult to fabricate and that obtain poor neutron economy because of their hard spectra. When the fuel tempratures were lowered, several alternative axial fuel zoning schemes were considered; the resulting power distributions are shown in Fig. 2.3. Case 2, which is a uniform zoning, has the poorest power distribution in that it peaks up toward the outlet end where the coolant is hot. The other cases are all fairly similar and obtain maximum fuel temperatures $100^{\circ} \mathrm{F}$ below that of Case 1 . Case 2, the two equal-lengths case, was chosen for the reference because of its simplicity and good neutron economy. 


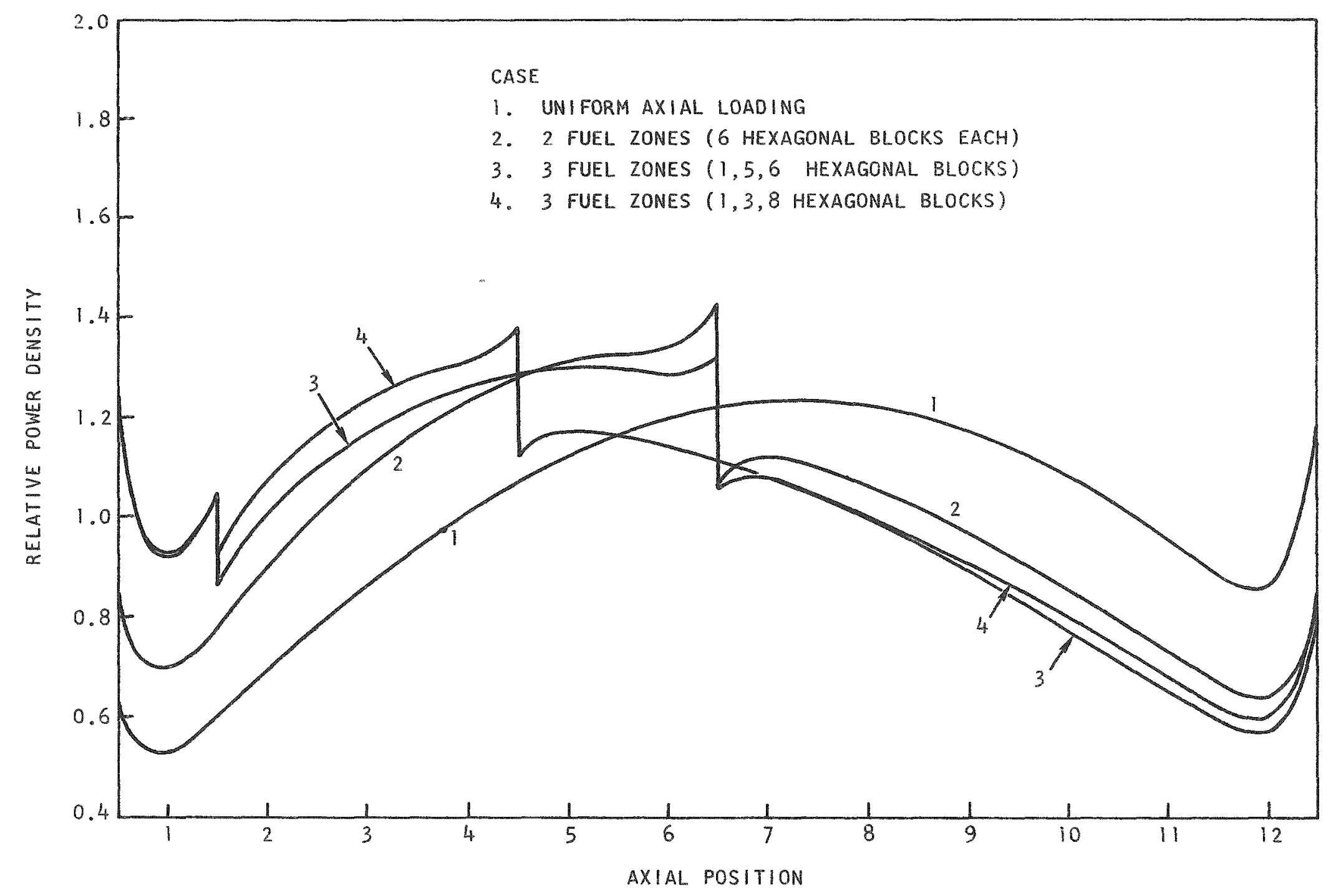

Eig. 2.3- Axial power distribution 
Fuel Feed Compositions in the Equilibrium Core

The feed compositions for the equilibrium core are shown in Table 2.6. With the current fuel element and fuel particle specifications, it should be possible to utilize fuel holes up to 06 in in diameter It is clear that with the lighter fuel loading and less severe axial zoning, there are no problems of adequate space for the fuel in the equilibrium core, This is not the case for the initial core because of some very heavily loaded zones. However, as these zones are the first to be removed, it may be possible to use a thinner coating thickness and thus eliminate this difficulty.

\section{KINETIC ANALYSIS}

The objective of this subtask is to predict the required strength of the control system, the control rod worth, the magnitude of the temperature coefficients, and the kinetic behavior of the core including insertions of reactivity and spatial xenon stabılity by means of analyses under normal operating and accident condrtions.

\section{Control Requirements}

The maximum excess reactivity occurs after one year of irradiation in the initial core if unshielded burnable boron poison is used. If shielded poisons are used and if the replacement fuel is tallored to the individual yearly requirements, the maximum excess reactivity in each cycle will be approximately $3 \% \Delta \mathrm{k}$ 。 However, the maximum control requirements will still occur in the initial core since the heavy loading of thorzum markedly increases the temperature coefficient and, correspondingly, the temperature defect. The control requirements for several conditions are listed in Table 2.7; the maximum value is $13.7 \% \Delta k$ to lower the initial core to room temperature for an indefinite period. Since the refueling equipment will normally be operated at $470^{\circ} \mathrm{K}\left(2400^{\circ} \mathrm{F}\right)$ and some unloading could be carried out within a month of shutdown, it is reasonable to assume that the maximum reactivity to be controlled is only $11 \% \Delta k$. The maximum worth rod is about $1 \% \Delta \mathrm{k}$; the worth of all the rods which is smallest in the initial core, is $18.2 \% \Delta \mathrm{k}$ 。 The minimum shutdown margin w111 therefore occur in the initial core and amount to $4 \% \Delta \mathrm{k}$, even after a $10 \%$ uncertainty in the control system worth is deducted.

Under unusual conditions of a stuck rod palr, it might be necessary to open the nozzles and remove the control rods from three adjacent refueling zones. Aside from the regions actually being refueled, temporary absorber rods could be introduced when the regular rods and drives are removed. To investigate the need for temporary absorber rods, it was assumed that three of the maximum reactivity central refueling regions were simultaneously unrodded, which resulted in an increase of $3 \% \Delta \mathrm{k}$ Since the minimum shutdown margin to refueling conditions is $5 \% \Delta k$, temporary absorber rods will probably be unnecessary.

\section{Control System Worth}

The basic configuration of the control rod absorber sections is a hollow cylinder 3,2 in. $O D$, and 2,0 in. ID, and about $17 \mathrm{in,} \mathrm{1ong.} \mathrm{These}$ 
Table 2.6

FEED COMPOSITION FOR EQUILIBRIUM CORE

\begin{tabular}{|c|c|c|c|c|c|}
\hline \multirow{2}{*}{$\begin{array}{l}\text { Axial } \\
\text { Zone }\end{array}$} & $\begin{array}{c}\text { Radial } \\
\text { Zone }\end{array}$ & $\begin{array}{c}\text { Radial } \\
\text { Zone }\end{array}$ & $\begin{array}{c}\text { Radial } \\
\text { Zone }\end{array}$ & $\begin{array}{c}\text { Radial } \\
\text { Zone }\end{array}$ & $\begin{array}{c}\text { Radial } \\
\text { Zone }\end{array}$ \\
\hline & 1 & 2 & 3 & 4 & 5 \\
\hline \multicolumn{6}{|c|}{$\mathrm{C} / \mathrm{Th}$} \\
\hline $\begin{array}{l}1 \\
2\end{array}$ & $\begin{array}{l}224 \\
242 \\
\end{array}$ & $\begin{array}{l}213 \\
230 \\
\end{array}$ & $\begin{array}{l}220 \\
236 \\
\end{array}$ & $\begin{array}{l}241 \\
253\end{array}$ & $\begin{array}{l}151 \\
170\end{array}$ \\
\hline \multicolumn{6}{|c|}{$\mathrm{C} / \mathrm{U}$} \\
\hline $\begin{array}{l}1 \\
2 \\
\end{array}$ & $\begin{array}{l}2800 \\
3770 \\
\end{array}$ & $\begin{array}{l}2410 \\
3240 \\
\end{array}$ & $\begin{array}{l}2310 \\
3100 \\
\end{array}$ & $\begin{array}{l}1990 \\
2620 \\
\end{array}$ & $\begin{array}{l}2770 \\
3570 \\
\end{array}$ \\
\hline \multicolumn{6}{|c|}{$\mathrm{B} / \mathrm{C}(\mathrm{ppm})$} \\
\hline $\begin{array}{l}1 \\
2 \\
\end{array}$ & $\begin{array}{l}70 \\
50 \\
\end{array}$ & $\begin{array}{l}80 \\
60 \\
\end{array}$ & $\begin{array}{l}90 \\
60 \\
\end{array}$ & $\begin{array}{l}100 \\
80 \\
\end{array}$ & $\begin{array}{l}70 \\
60\end{array}$ \\
\hline \multicolumn{6}{|c|}{ Fuel Hole Diam. (in。) } \\
\hline $\begin{array}{l}1 \\
2\end{array}$ & $\begin{array}{l}0.450 \\
0.425\end{array}$ & $\begin{array}{l}0.465 \\
0.439\end{array}$ & $\begin{array}{l}0.462 \\
0.437\end{array}$ & $\begin{array}{l}0.453 \\
0.431\end{array}$ & $\begin{array}{l}0.553 \\
0.519\end{array}$ \\
\hline
\end{tabular}

Table 2.7

REACTIVITY REQUIREMENTS

\begin{tabular}{|c|c|c|c|c|c|c|}
\hline & \multicolumn{6}{|c|}{ Reactivity $(\% \Delta k)$} \\
\hline & \multicolumn{2}{|c|}{ Initial Core } & \multicolumn{2}{|c|}{ Third Reload } & \multicolumn{2}{|c|}{ Equilibrium Core } \\
\hline & $\begin{array}{c}300^{\circ} \mathrm{K}, \\
\text { Complete } \\
\text { Decay }\end{array}$ & $\begin{array}{l}470^{\circ} \mathrm{K} \text { a } \\
30-\text { day } \\
\text { Shutdown }\end{array}$ & $\begin{array}{c}300^{\circ} \mathrm{K} \\
\text { Complete } \\
\text { Decay }\end{array}$ & $\begin{array}{c}470^{\circ} \mathrm{K}_{2} \text { a } \\
30-\text { day } \\
\text { Shutdown }\end{array}$ & $\begin{array}{c}300^{\circ} \mathrm{K}, \\
\text { Complete } \\
\text { Decay }\end{array}$ & $\begin{array}{c}470^{\circ} \mathrm{K}, \text { a } \\
30-\mathrm{day} \\
\text { Shutdown }\end{array}$ \\
\hline $\begin{array}{l}\text { Temperature } \\
\text { defect } \\
\mathrm{Xe}^{135} \text { decay } \\
\mathrm{Pa}^{233} \text { decay } \\
\text { and sub- } \\
\text { sequent } \\
\mathrm{U}^{233}\end{array}$ & $\begin{array}{l}6.5 \\
2.6\end{array}$ & $\begin{array}{l}4.4 \\
2.6\end{array}$ & $\begin{array}{l}4.6 \\
2.7\end{array}$ & $\begin{array}{l}3.0 \\
2.7\end{array}$ & $\begin{array}{l}4.3 \\
2.9\end{array}$ & $\begin{array}{l}2.6 \\
2.9\end{array}$ \\
\hline $\begin{array}{l}\text { buildup } \\
\text { Maximum ex- } \\
\text { cess re- } \\
\text { activity }\end{array}$ & 2.2 & 1.0 & 2.0 & 0.9 & 2.4 & 1.1 \\
\hline TOTAL & 14.3 & 11.0 & 12.3 & 9.6 & 12.6 & 9.6 \\
\hline
\end{tabular}

a Refueling occurs at about $200^{\circ} \mathrm{C}\left(\sim 400^{\circ} \mathrm{F}\right)$. 
sections are joined with an attendent gap between sections of about 0.75 in., which results in a $4 \%$ loss in absorber. The two rods forming a pair travel in in holes in the central fuel element of each refueling region; the centerlines of the holes are located 9.72 in. apart. The mutual shadowing of the rod pair, which has been computed using two-dimensional multigroup transport methods, amounts to about $2 \%$. The neutron-flux shielding factors for a single control rod and a pair of rods have been compared and found to be essentially the same. Therefore the shielding factors are computed for a single rod at the center of the region. The worth of a pair of control rods is computed by using these shielding factors and a 5\% reduction in absorber content to account for joints and mutual shielding. No explicit credit is taken for the metal structural material.

In the initial core, at the beginning of cycle, the control system worth is $18.2 \% \Delta k$ and subsequently increases to about $19 \% \Delta k$ at the end of cycle. The worth of the control system continues to increase with burnup, and, at the end of the equilibrium cycle, it reaches $21 \% \Delta \mathrm{k}$.

The fractional reactivity worth of the entire control system, six (of the seven) scram rod pairs, and a single control rod pair as a function of distance inserted is show in Fig. 2.4. The banked rods tend to push the flux downward before them and therefore introduce only $12 \%$ of their worth when half inserted. However, when the rods are about three-quarters inserted they introduce $25 \%$ of their worth per foot. The scram system and a single rod pair obtain a much more constant reactivity introduction per foot because they are not strong enough to significantly alter the flux distribution.

\section{Reserve Shutdown System}

The reserve shutdown system is designed to operate with complete independence of the normal control system and thus introduces both redundancy and extra shutdown margin. This reserve system alone should be capable of holding the reactor subcritical at refueling temperature for a minimum of 30 days while the control system is being repaired. If the control system fails with the complete withdrawal of the maximum worth rod pair, it should have a minimum of $9 \% \Delta k$. A study was made of several poison materials and configurations. From the results of this study, it was concluded that $B_{4} C$ was the most advantageous material considering its low cost and availability, and any one of several configurations would provide the needed reactivity. To maximize the reliability of the reserve shutdown system, it was decided that small spheres containing $B_{4} C$ would be randomly dropped into holes provided in the fuel elements. To maximize the reliability of this system, the receiver hole should be as large as possible, and thus a 3.75-in. hole filled with balls providing the control equivalent of a 3.75-in. graphite cylinder containing 30 $w t-\% \mathrm{~B}_{4} \mathrm{C}$ was chosen as the reference design. 


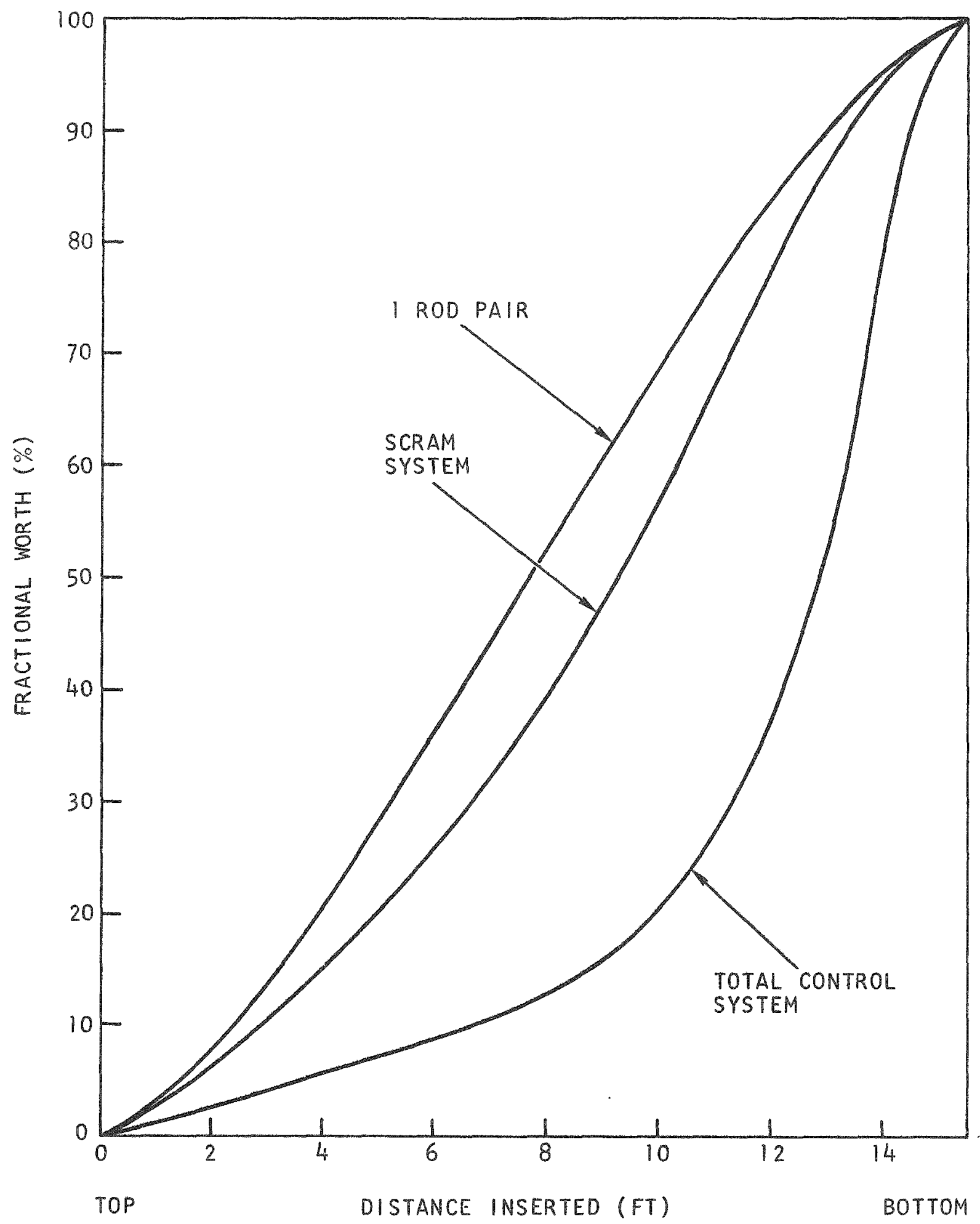

Fig. 2.4--Fractional worth of various groups of control rods 
Temperature Coefficient

The temperature coefficients for the initial core have been computed and are shown in Fig. 2.5. As is usual, the fuel coefficient is dominated by the Doppler broadening of the $\mathrm{Th}^{232}$ resonances. The isothermal coefficient is more negative than the fuel coefficient, primarily because of the non-1/v absorption characteristics of $\mathrm{U}^{235}$. Both the isothermal (with and without $\mathrm{Xe}^{135}$ ) and the fuel coefficients are negative to $3500^{\circ} \mathrm{K}$ and at operating conditions are $-4.7 \times 10^{-5}{ }^{\circ} \mathrm{C}^{-1}$ and $-4.3 \times 10^{-5}{ }^{\circ} \mathrm{C}^{-1}$, respectively.

The temperature coefficients for the beginning and end of the equilibrium cycle are shown in Fig. 2.6. The fuel coefficient changes very little during the yearly cycle whereas the isothermal coefficient gets slightly less negative with burnup primarily due to the buildup of $U^{233}$. These coefficients are considerably less negative than the initial core, primarily because of the lighter thorium loading, the higher $\mathrm{U}^{233}$ content, and the higher fission-product content. The isothermal temperature coefficients at beginning and end of cycle and the fuel coefficients are, again, all negative to $3500^{\circ} \mathrm{K}$, and at operating conditions are $-2.2 \times 10^{-5}{ }^{\circ} \mathrm{C}-1,-1.7 \times 10^{-5}$ ${ }^{\circ} \mathrm{C}^{-1}$, and $-3.1 \times 10^{-5}{ }^{\circ} \mathrm{C}^{-1}$, respectively. Since the end-of-equilibrium cycle obtains the smallest temperature coefficients, most of the succeeding kinetic analyses used these values.

\section{$\underline{\text { Transient Analyses }}$}

Transient analyses have been performed on the assumption that the highest worth control rod pair $(1 \% \Delta \mathrm{k})$ is completely withdrawn at its maximum rate. The reactor is presumed to be critical and operating initially at its full power of $833 \mathrm{Mw}$. The transients are terminated by a scram occurring either at $140 \%$ of full power with a $200-\mathrm{msec}$ delay or by a coolant overtemperature scram at $1525^{\circ} \mathrm{F}$ with a $15-\mathrm{sec}$ delay. The scram system consists of seven (with at least six operable) rod pairs with a reactivity worth of $3 \% \Delta \mathrm{k}$ and require only $3.6 \mathrm{sec}$ for complete insertion. The withdrawn control rods are also inserted by the scram signal and are inserted at their normal operating speed of about $4 \mathrm{in} . / \mathrm{sec}$. The reactivity of the withdrawn control rods will generally be 0.12 or greater, but, for these calculations, only 0.10 has been used.

The prompt neutron lifetime and the delayed neutron parameters are shown in Table 2.8 for the initial core, the third reload (fourth year of operation), and the equilibrium cycle. As the lighter loaded replacement segments are inserted, the prompt neutron lifetime increases; however, the $\mathrm{U}^{23} 3$ level simultaneously increases, which results in a considerable decrease in the delayed neutron fraction.

The rod runout accident was considered for two withdrawal times, 46.8 sec and $100 \mathrm{sec}$; for a $46.8-\mathrm{sec}$ withdrawal time, it was clear that, with a 15-sec delay in the temperature scram, this transient was first stopped by the temperature coefficient and subsequently shut down by the scram. However, with a 100-sec withdrawal time, the scram terminates the transient and reduces the maximum coolant temperature $170^{\circ} \mathrm{F}$, the maximum moderator temperature $150^{\circ} \mathrm{C}$, and the maximum fuel temperature $220^{\circ} \mathrm{C}$. On this basis a withdrawal 


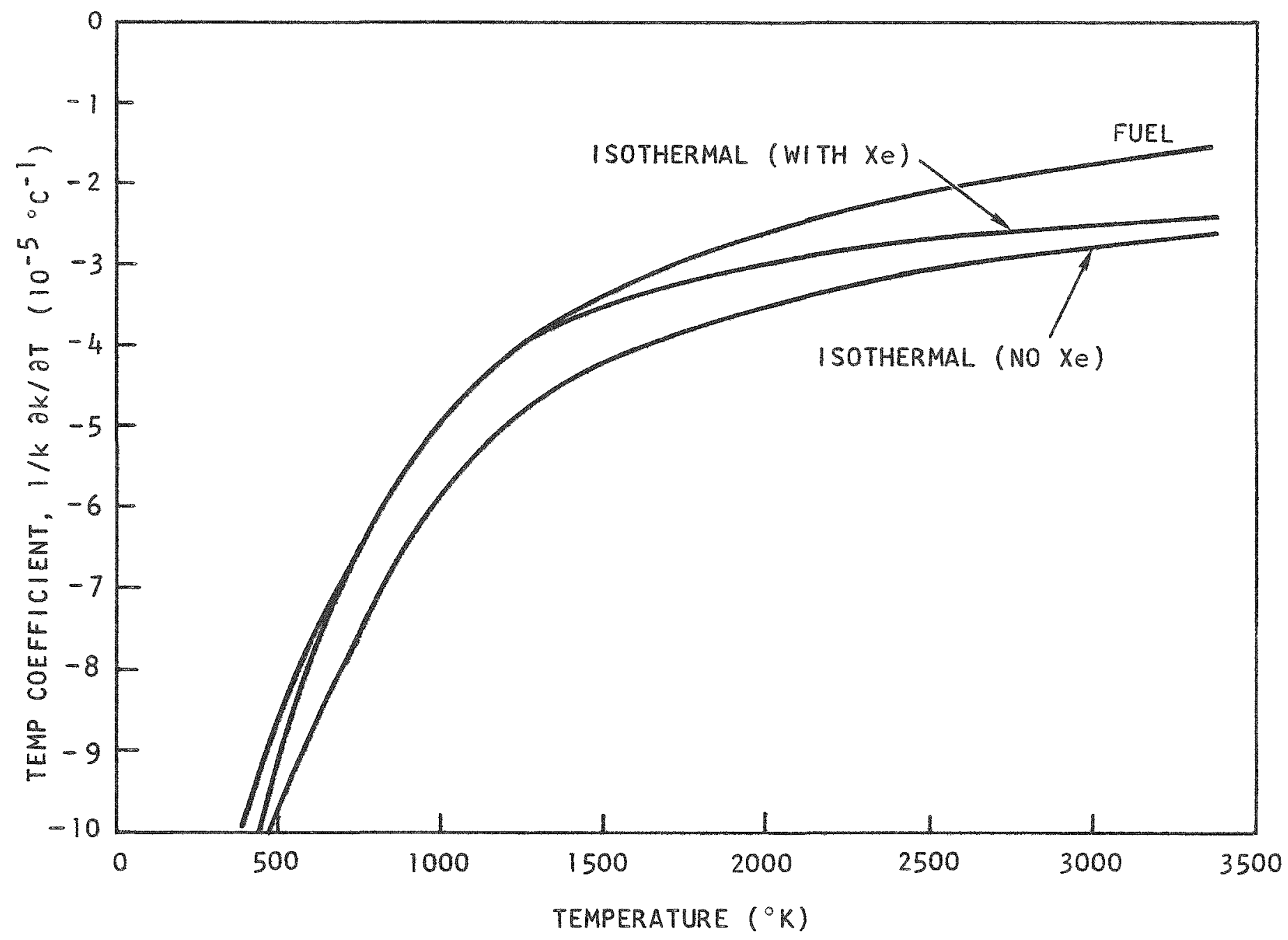

Fig, 2,5-Tenperature coefficient versus temperature in the initial core 


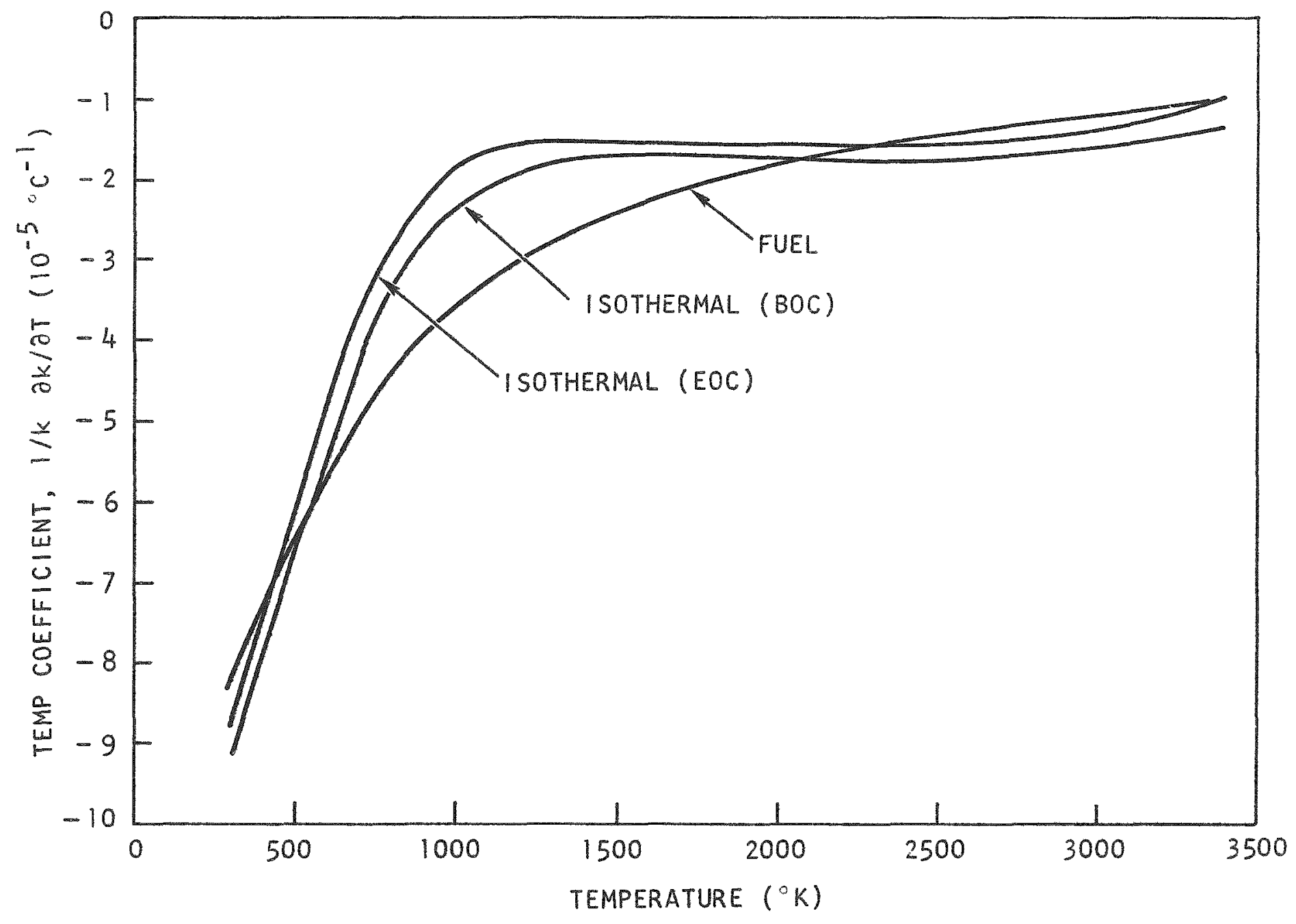

Fig。2.6--Temperature coefficient versus temperature in the equilibrium cycle 
Table 2.8

KINETIC PARAMETERS FOR THE VARIOUS CORES

\begin{tabular}{|c|c|c|c|c|c|c|}
\hline & \multicolumn{2}{|c|}{ Initial Core } & \multicolumn{2}{|c|}{ Reload 3} & \multicolumn{2}{|c|}{ Equilibrium } \\
\hline & $\begin{array}{l}\text { With Xe } \\
\mathrm{BOC}^{\mathrm{a}} \\
\end{array}$ & $\operatorname{EOC}^{\mathrm{b}}$ & $\begin{array}{c}\text { With } \mathrm{Xe} \\
\mathrm{BOC} \\
\end{array}$ & $\operatorname{EOC} \frac{\mathrm{b}}{}$ & $\begin{array}{c}\text { With Xe } \\
\mathrm{BOC}^{\mathrm{a}} \\
\end{array}$ & $\mathrm{EOC}^{\mathrm{b}}$ \\
\hline \multicolumn{7}{|l|}{ Fractional productions: } \\
\hline From $\mathrm{U}^{233}$ & 0.0 & 0.385 & 0.347 & 0.476 & 0.347 & 0.493 \\
\hline From U U 235 & 1.0 & 0.615 & 0.653 & 0.524 & 0.653 & 0.507 \\
\hline $\begin{array}{l}\text { Prompt neutron lifetimes } \\
\text { sec. }\end{array}$ & $1.80 \times 10^{-4}$ & $1.90 \times 10^{-4}$ & $2.05 \times 10^{-4}$ & $2.17 \times 10^{-4}$ & $2.39 \times 10^{-4}$ & $2.63 \times 10^{-4}$ \\
\hline $\begin{array}{l}\text { Effective delayed-neutron } \\
\text { fraction }\end{array}$ & 0.00650 & 0.00503 & 0.00517 & 0.00468 & 0.00517 & 0.00461 \\
\hline \multicolumn{7}{|l|}{$\begin{array}{l}\text { Delayed-neutron half life } \\
\lambda_{i} \text {, sec: }\end{array}$} \\
\hline 1 & 55.72 & 55.45 & 55.47 & 55.38 & 55.47 & 55.37 \\
\hline 2 & 22.72 & 22.16 & 22.23 & 22.00 & 22.23 & 21.96 \\
\hline 3 & 6.22 & 5.92 & 5.95 & 5.82 & 5.95 & 5.80 \\
\hline 4 & 2.30 & 2.27 & 2.28 & 2.26 & 2.28 & 2.26 \\
\hline 5 & 0.61 & 0.61 & 0.61 & 0.61 & 0.61 & 0.61 \\
\hline 6 & 0.23 & 0.24 & 0.24 & 0.24 & 0.24 & 0.24 \\
\hline \multicolumn{7}{|l|}{$\begin{array}{l}\text { Delayed neutron fraction } \beta \\
\text { Precursor }\end{array}$} \\
\hline 1 & $2.145 \times 10^{-4}$ & $2.203 \times 10^{-4}$ & $2.198 \times 10^{-4}$ & $2.217 \times 10^{-4}$ & $2.198 \times 10^{\mathrm{m}-4}$ & $2.220 \times 10^{-4}$ \\
\hline 2 & $1.424 \times 10^{-3}$ & $1.183 \times 10^{-3}$ & $1.207 \times 10^{-3}$ & $1.126 \times 10^{-3}$ & $1.207 \times 10^{-3}$ & $1.115 \times 10^{-3}$ \\
\hline 3 & $1.274 \times 10^{-3}$ & $1.043 \times 10^{-3}$ & $1.065 \times 10^{-m-3}$ & $9.879 \times 10_{-3}^{-4}$ & $1.065 \times 10^{-m}-3$ & $9.775 \times 10^{-4}$ \\
\hline 4 & $2.568 \times 10^{-3}$ & $1.865 \times 10^{-3}$ & $1.934 \times 10^{-3}$ & $1.699 \times 10^{-3}$ & $1.934 \times 10^{-4}$ & $1.667 \times 10^{-4}$ \\
\hline 5 & $7.480 \times 10^{-4}-4$ & $5.121 \times 10^{-4}$ & $5.354 \times 10^{-4}$ & $4.565 \times 10^{-4}$ & $5.354 \times 10^{-4}$ & $4.460 \times 10^{-4}$ \\
\hline 6 & $2.730 \times 10$ & $2.029 \times 10^{-7}$ & $2.098 \times 10^{\mathrm{T}}$ & $1.863 \times 10^{-7}$ & $2.098 \times 10^{-}$ & $1.831 \times 10^{-4}$ \\
\hline
\end{tabular}

a Beginning of cycle (BOC).

b End of cycle (EOC). 
time of $100 \mathrm{sec}$ was chosen for the reference design as resulting in both a reasonable plant startup time and improved kinetics behavior. Figs. 2.7 , $2.8,2.9$, and 2.10 show the power level, the maximum and average coolant outlet temperature, the average moderator temperature in the maximum and average channel, and the maximum and average fuel temperature, respectively, as a function of time during the transient.

It is quite clear from the results of the transient analyses that a scram at $140 \%$ rated power results in a very mild transient and the temperature coefficient plays little part. However, because of the long delay with coolant overtemperature scram, considerable quantities of energy are generated and the magnitude of the temperature coefficient would be more important. As a test, the temperature coefficient was arbitrarily reduced by $50 \%$. Under these conditions with a $1 \% \Delta p$ rod runout transient, the maximum coolant temperature is $2040^{\circ} \mathrm{F}$, the maximum moderator temperature is $1260^{\circ} \mathrm{C}$, and the maximum fuel temperature is $2240^{\circ} \mathrm{C}$. Although these represent significant increases over the results with the computed temperature coefficient, they should be acceptable considering the ceramic nature of the core.

The conditions during a loss-of-flow transient have been calculated for the reactor initially at full power. The flow is assumed to decrease from $100 \%$ to $0 \%$ in $10 \mathrm{sec}$. At $5 \%$ flow a scram signal is activated with a $1-\mathrm{sec}$ delay and the circulators are started on auxiliary power with a 5-sec delay. The flow rate then increases linearly to about $14 \%$ of full flow in 60 sec. A second scram signal is initiated if the coolant outlet temperature exceeds $1525^{\circ} \mathrm{F}$. The results of the transient are shown in Table 2.9 .

Table 2.9

RESULTS OF A LOSS-OF-FLOW TRANSIENT

\begin{tabular}{l|c|c}
\hline & \multicolumn{2}{|c}{ Scram Initiation } \\
\cline { 2 - 3 } & $\begin{array}{l}\text { Low } \\
\text { Flow }\end{array}$ & $\begin{array}{c}\text { High Coolant } \\
\text { Outlet Temp. }\end{array}$ \\
\hline Maximum thermal power, Mw & 840 & 840 \\
Coolant outlet temperature, ${ }^{\circ} \mathrm{F}:$ & & \\
Maximum channel & 1560 & 1760 \\
Average channe1 & 1500 & 1600 \\
Moderator temperature, ${ }^{\circ} \mathrm{C}$ & & \\
Maximum & 830 & 990 \\
Average & 760 & 850 \\
Time moderator temperature exceeds & 110 & 350 \\
initial value, sec & & \\
Fuel temperature, ${ }^{\circ} \mathrm{C}:$ & 1140 & 1250 \\
Maximum & 810 & 870 \\
Average &
\end{tabular}




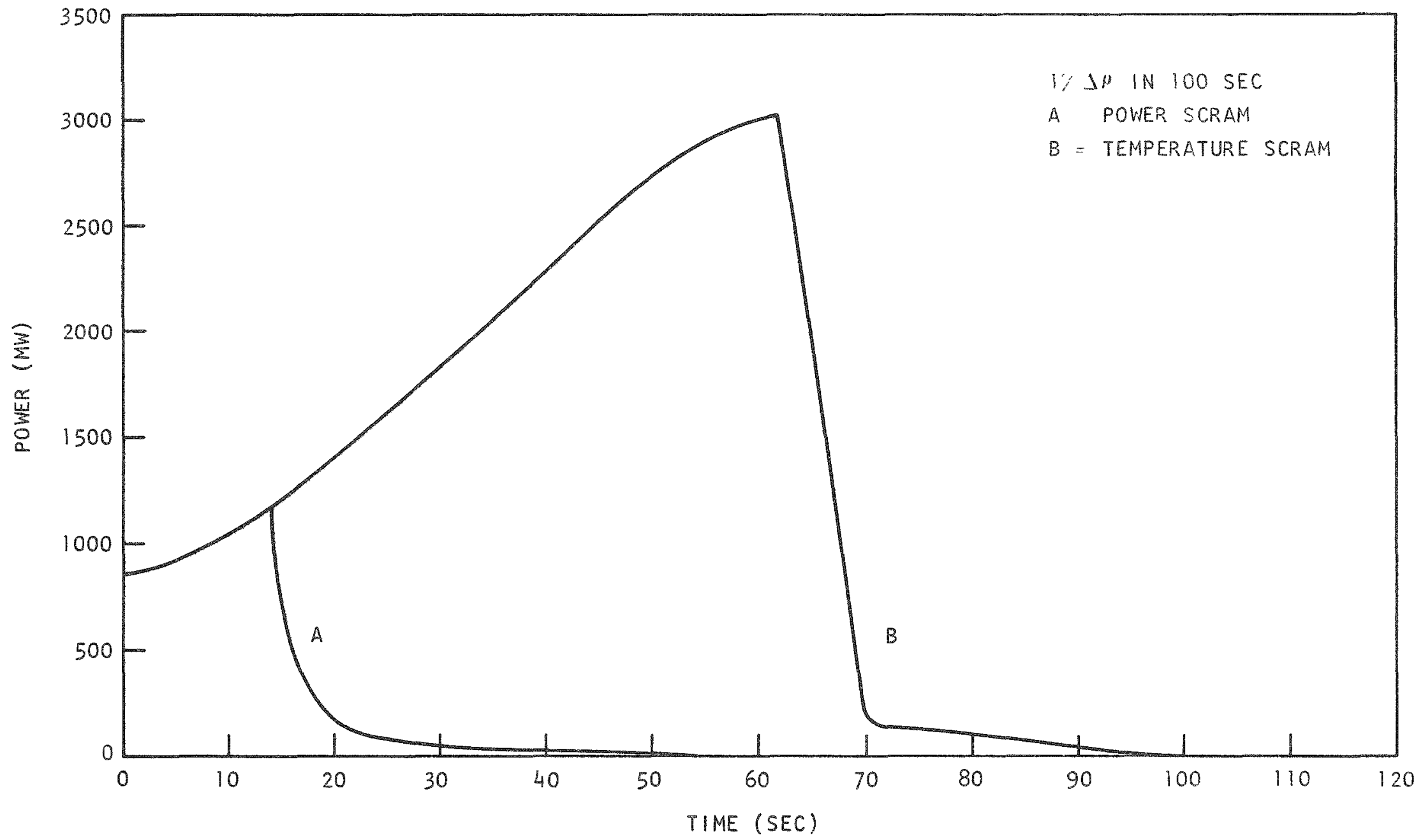

N

Fig, 2.7 --Power level versus time for rod runout transient 


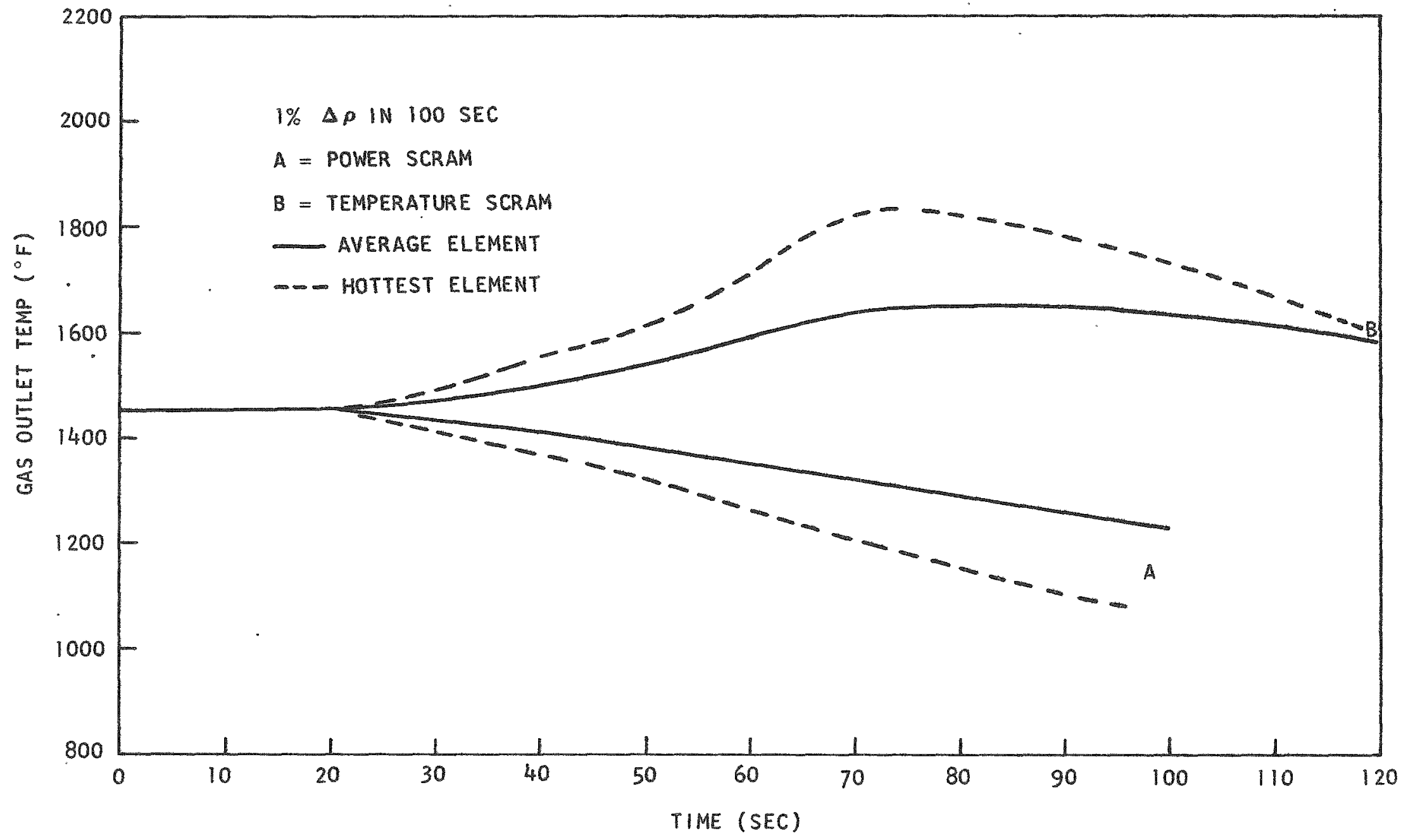

Fig. 2.8- Gas outlet temperature versus time during a rod runout transient 


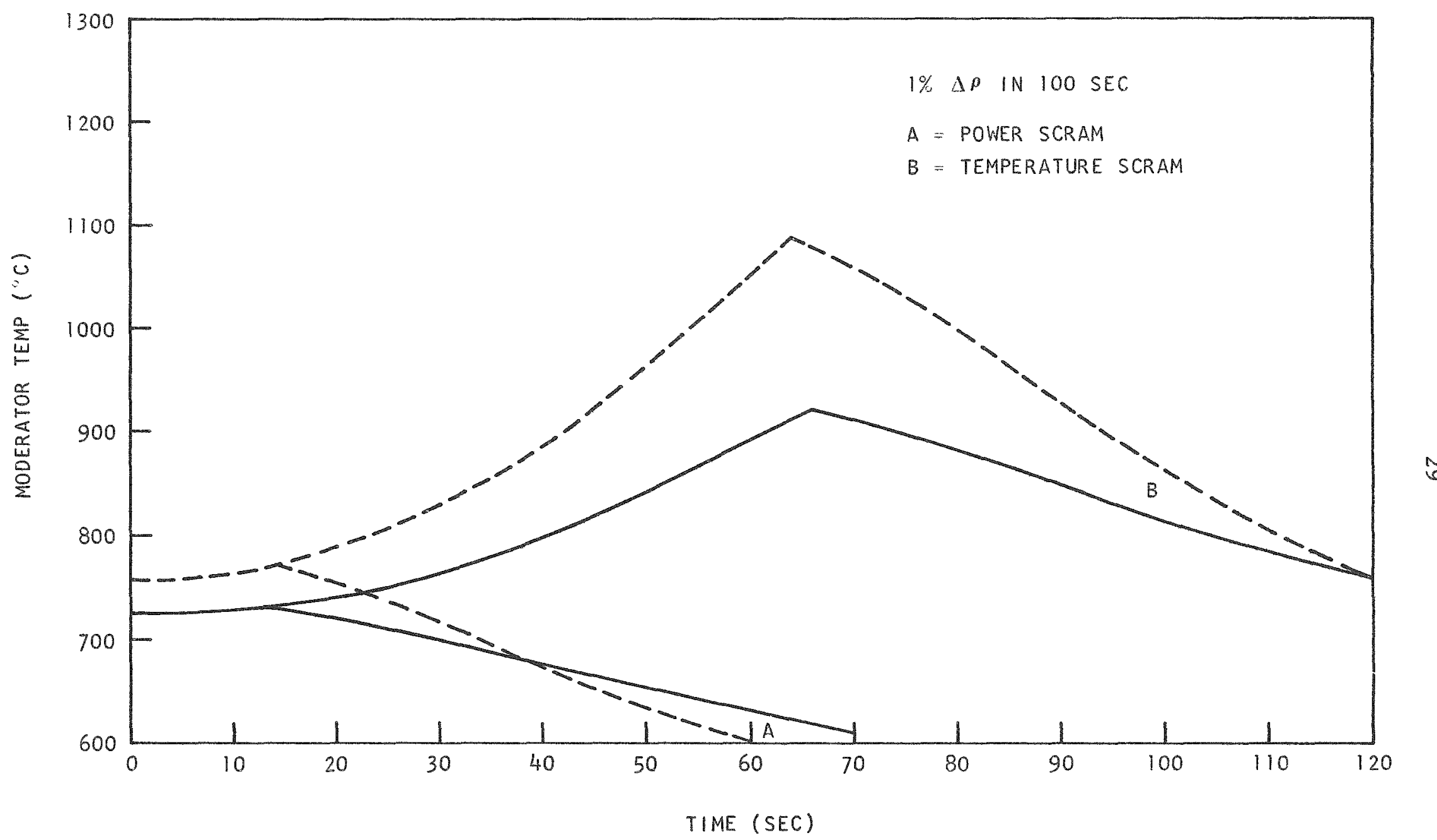

Fig 29 -Moderator temperature versus time during a rod runout transient 


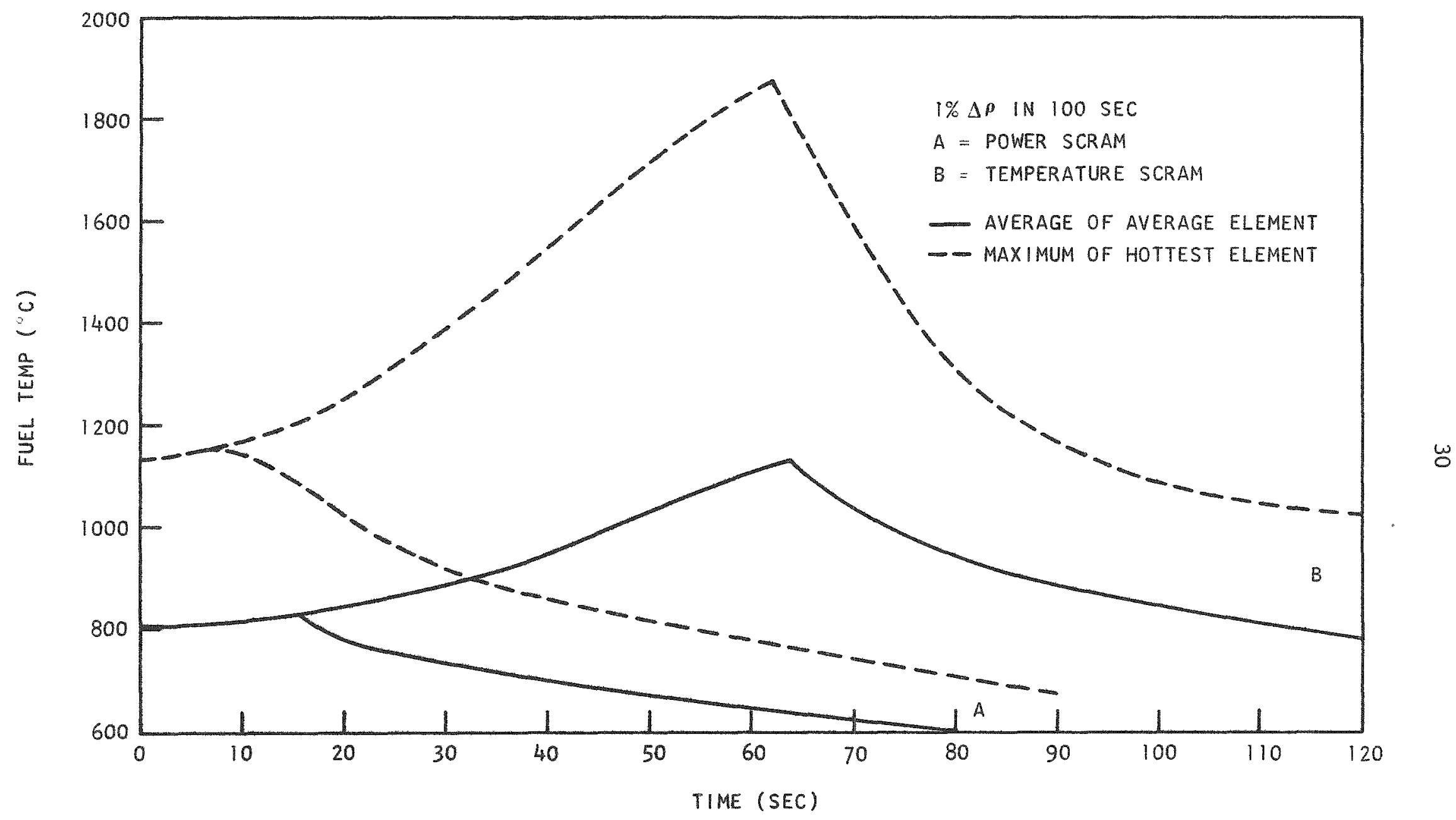

Fig. 2.10--Fuel temperature versus time during a rod runout transient 
TASR III

FUEL DEVELOPMENT

\section{DESIGN}

The objective of this subtask is to develop the design of the fuel elements to be used in the plant by means of mechanical and flow testing, analysis of temperature under normal and accident conditions, analyses of stress, including effects of temperature, irradiation and creep, and analysis of fission-product concentrations in the reactor systems.

\section{Mechanical Design}

Based on results of the core parameter study discussed in the previous quarterly report (GA-6950) and on additional detailed temperature and fuel loading analyses, the fuel and coolant holes within the fuel elements have been rearranged to produce an array containing two fuel holes for each coolant hole. The previous design utilized three fuel holes for each coolant hole $(3 \mathrm{FH} / \mathrm{CH})$. A layout of the new reference design is show in Fig. 3.1.

The major advantages for the $2 \mathrm{FH} / \mathrm{CH}$ arrangement are lower temperature differences within the graphite structure and a lower peak graphite temperature. Preliminary calculations indicate that the reduced temperature differences and lower peak graphite temperatures will significantly reduce the differential contraction strains within the graphite and thus further enhance the structural integrity of the fuel element. For equivalent fuel loadings, the $2 \mathrm{FH} / \mathrm{CH}$ pattern increases the graphite web thickness between the fuel and coolant holes. The thicker webs will provide greater over-al1 structural ruggedness and provide a greater capacity for accepting attack from oxidizing coolant impurities.

The only apparent disadvantage to the $2 \mathrm{FH} / \mathrm{CH}$ pattern is that a slightly larger coolant channel area fraction is required for an equivalent core $\Delta P$ than with the $3 \mathrm{FH} / \mathrm{CH}$ design. This will decrease the moderator content of the core. However, the decrease is relatively small, and it is generally outweighed by the advantages described above.

An additional change in the reference design of the fuel elements is the use of binder to bond the fuel particles within the fuel element. The primary purpose of the change is to prevent loose fuel particles from spilling into the primary system following the unlikely event of a fuel element fracture during fuel handling.

\section{Development Tests}

Impact Strength Test for the Handling Hole Lifting Ledge. A test program has been initiated to determine the structural characteristics of the 


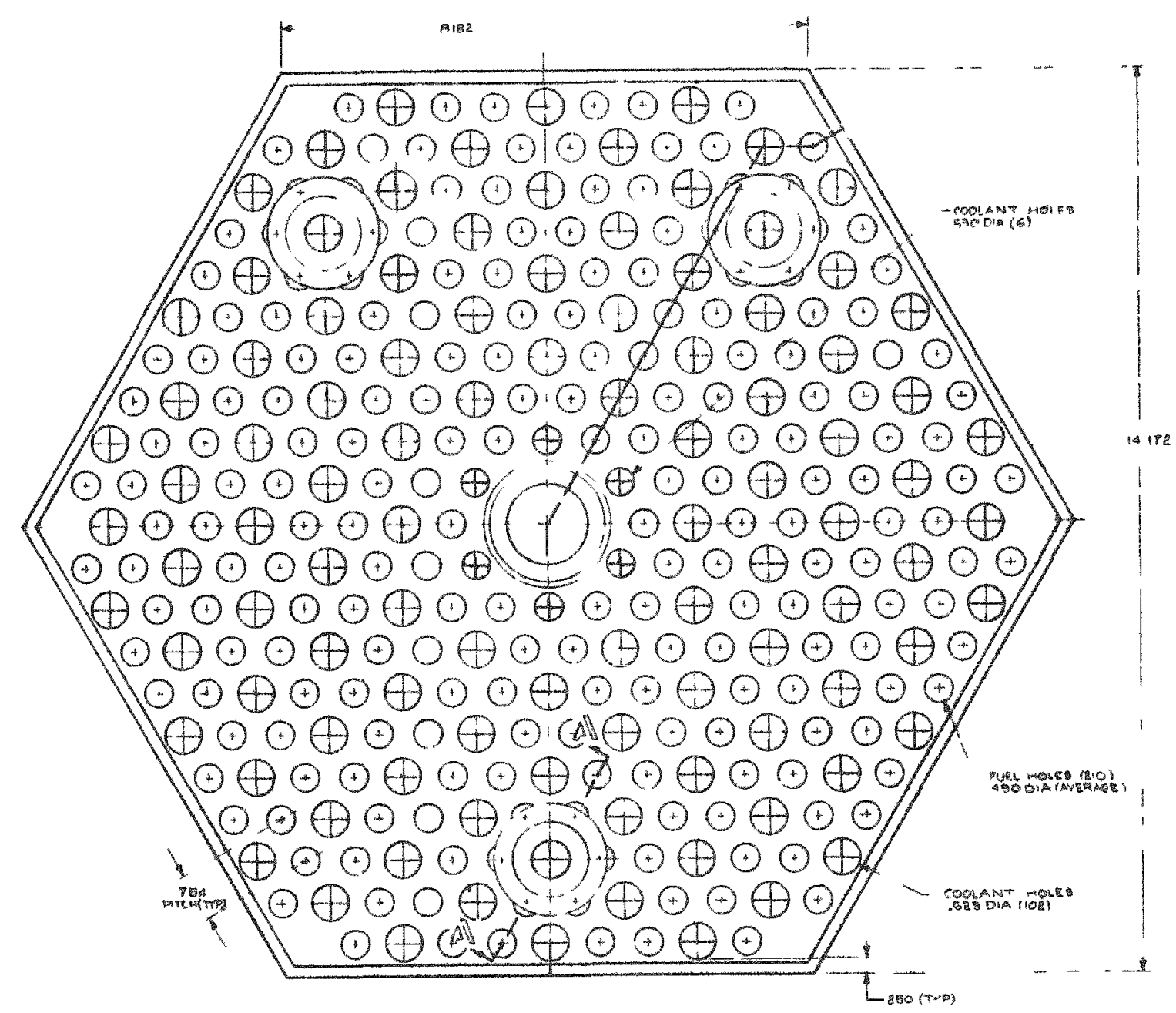

Fig. 3.1--Fuel element arrangement with 2 fuel holes per coolant hole

liftung ledge within the ruel element handling hole Direct tensile and shock load tests are planned The test equipment has been fabricated and testing is in process

Dowel-pin Shear-strength Test. A test program has been initiated to determine the shear strength of the fuel element dowel pins. The purpose of the test is to optimize the dowel geometry for maximum strength characteristics and to establish design load capability.

Core Multicolumn Flow and Vibration Iest Rig. Work was iniciated this quarter on the design of a multicolumn flow and vibration test rig. The present design concept contains 24 columns of scaled simulated fuel or reflector elements within an adjustable barrel type of structure. The two main objectives for the test program are (1) to demonstrate the operation 
of an orificed core and to study orifice characteristics over the range of expected coolant flow conditions and (2) to demonstrate the vibrational stability of the core. A preliminary analysis of flow distribution and dynamic simulation indicates a scale size of about 0.45 for the test $r$ g with the head and flow rate characteristics of the available air blowers. The fuel and reflector elements will be fabricated from graphite and will contain about 30 coolant flow holes in each element.

Thermal Design

Performance Studies. Further thermal studies of orificed core performance with modified cosine power distributions were completed during the quarter. Several axial fuel loading profiles producing modified cosine power shapes were analyzed with the objective of reducing the number of different axial fuel zones to a minimum without significantly compromising fuel thermal performance.

Axial fuel temperatures were calculated using the RAT code for four cases of axial fuel zoning: (1) uniform loadıng, (2) two fuel zones of six fuel elements each, (3) three fuel zones of 1, 5, and 6 elements, respectively, and, (4) three fuel zones of 1,3 , and 8 elements, respectively. The maximum fuel temperature profiles for each case are shown in Fig. 3.2 for the average power in region 25 at the end of one year of life (region average peaking factor of $1.53 . \%$ A simplified, axisymmetric geometry was used for the calculation to allow the use of RAT in $\mathrm{R}-\mathrm{Z}$ coordinates.

The two-axial-zone loading utilizing six fuel elements for each zone was selected for further design work. Little reduction in peak fuel temperature is obtained by the additional complexity of the other three cases.

Thermal design studies completed during the quarter were used to compare the performance of the $2 \mathrm{FH} / \mathrm{CH}$ fuel element design with that of the $3 \mathrm{FH} / \mathrm{CH}$ design. The comparative thermal performance characteristics for the two arrangements are shown in Table 3.1. The calculations were based on expected conditions with core orificing (no srossflow) and the two-axialzone cosine power distribution shown in $\mathrm{Fig} .3 .2$, curve number 2 , for an equilibrium core loading with a C/Th ratio of 200 .

The major advantages for the $2 \mathrm{FH} / \mathrm{CH}$ arrangement are lower temperature differences within the graphite and lower graphite temperature levels at the coolant hole surfaces. Also, a reduction in maximum fuel temperature of about $50^{\circ} \mathrm{F}$ was calculated for the $2 \mathrm{FH} / \mathrm{CH}$ design.

*The region peaking factor used was representative of the maximum power region for a carbon to thorium ratio (C/Th) of 200 for the equilibrium core fuel loading. To utilize the advantage of the lower fuel temperature experienced with core orificing, a lighter core fuel loading, corresponding to a $\mathrm{C} / \mathrm{Th}$ ratio of 225 , has been established for the reference design equilibrium core. Fuel cycle costs are reduced with the lighter loading. Region peaking factors will be increased for the lighter fuel loading and modest increases in peak fuel temperatures are expected. 


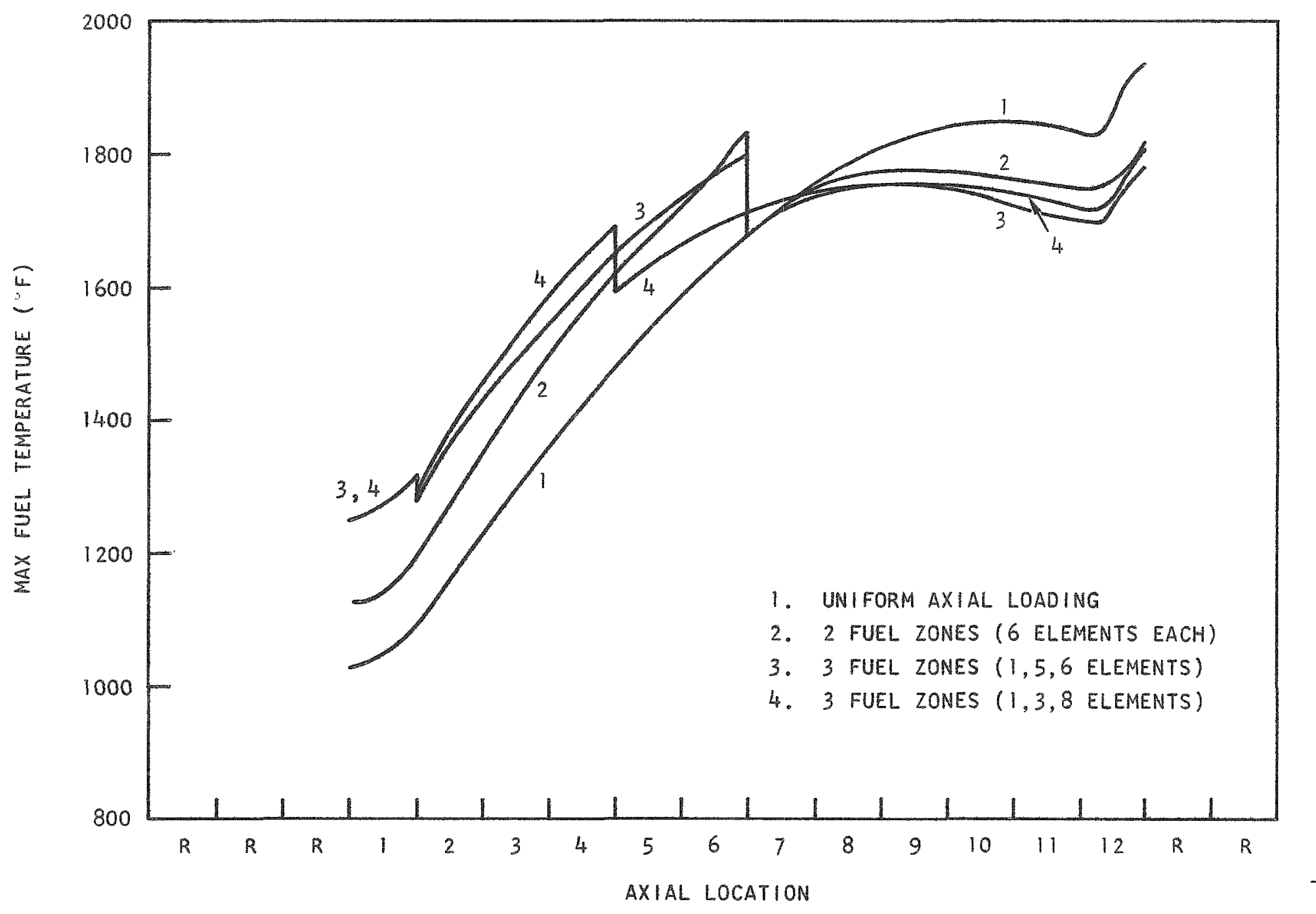

Fig. 3,2--Axial temperature distribution in region 25 (average power) 
Table 3.1

THERMAL PERFORMANCE COMPARISON FOR TWO FUEL ELEMENT ARRANGEMENTS

\begin{tabular}{|c|c|c|}
\hline & $2 \mathrm{FH} / \mathrm{CH}^{\mathrm{a}}$ & $3 \mathrm{FH} / \mathrm{CH}^{\mathrm{a}}$ \\
\hline $\begin{array}{l}\text { Fuel element coolant channel area fraction } \\
\text { used for analyses, } \%\end{array}$ & 16.4 & 15.3 \\
\hline $\begin{array}{l}\text { Orificed core press. drop ( } 675 \text { psia, } \\
3.41 \times 10^{6} \mathrm{lb} / \mathrm{hr} \text { reactor flow rate), psi }\end{array}$ & 7.14 & 7.42 \\
\hline $\begin{array}{l}\text { Temps within area of symmetry, region 25, } \\
1 \mathrm{yr} \text { age, } \mathrm{P} / \overline{\mathrm{P}}=1.53 \text { (region average), } \\
{ }^{\circ} \mathrm{F}: \\
\text { Max fuel temp } \\
\text { Max graphite temp } \\
\text { Min graphite temp } \\
\text { Max graphite temp difference }\end{array}$ & $\begin{array}{l}1846 \\
1439 \\
1334 \\
105\end{array}$ & $\begin{array}{l}1897 \\
1540 \\
1377 \\
163\end{array}$ \\
\hline $\begin{array}{l}\text { Max fuel temp in corner fuel hole of } \\
\text { region } 25,1 \text { yr age, local peaking } \\
\text { factor 1.73, }{ }^{\circ} \mathrm{F}\end{array}$ & 2000 & Not applicable \\
\hline $\begin{array}{l}\text { Graphite temp near corner fuel hole of } \\
\text { region } 25,1 \text { yr age, peaking factor } \\
1.73,{ }^{\circ} \mathrm{F}: \\
\text { Max graphite temp } \\
\text { Min graphite temp } \\
\text { Max graphite temp difference }\end{array}$ & $\begin{array}{l}1665 \\
1199 \\
466\end{array}$ & $\begin{array}{l}\text { Not applicable } \\
\text { Not applicable } \\
\text { Not applicable }\end{array}$ \\
\hline $\begin{array}{l}\text { By eliminating corner fuel hole from } \\
\text { element shown in Fig. } 3.1 \text {, follow- } \\
\text { ing temps evaluated for corner area } \\
\text { of an element assuming local peak- } \\
\text { ing factor of } 1.73 \text {; comparative } \\
\text { temps estimated for } 3 \text { FH/CH design, } \\
\text { of: } \\
\text { Max fuel temp } \\
\text { Max graphite temp } \\
\text { Min graphite temp } \\
\text { Max graphite temp difference }\end{array}$ & $\begin{array}{l}1971 \frac{b}{b} \\
1446 \frac{b}{b} \\
1187 \frac{b}{259}\end{array}$ & $\begin{array}{l}2020^{c} \\
1560^{c} \\
1200^{c} \\
360^{c}\end{array}$ \\
\hline $\begin{array}{l}\text { The following temps pertain to area } \\
\text { adjacent to fuel element edge } \\
\text { away from corner region; assumed } \\
\text { power peaking factor } 1.73,{ }^{\circ} \mathrm{F}: \\
\text { Max fuel temp } \\
\text { Max graphite temp } \\
\text { Min graphite temp } \\
\text { Max graphite temp difference }\end{array}$ & $\begin{array}{l}1996 \frac{b}{b} \\
1615 \frac{b}{b} \\
1333 \underline{b} \\
282 \underline{-}\end{array}$ & $\begin{array}{l}2000^{c} \\
1560^{c} \\
1300^{c} \\
260^{c}\end{array}$ \\
\hline
\end{tabular}

a FH/Cg means fuel holes per coolant hole.

b calculated.

c Estimated. 
Thermal performance along the flat edges of elements at resion boundaries where large power peaks are experienced, such as the edge of region 25 at one year age, is at best about the same as the $3 \mathrm{FH} / \mathrm{CH}$ design. The $2 \mathrm{FH} / \mathrm{CH}$ design may actually experience slightly higher peak temperatures. However, the estimated difference between the two designs is quite small and both calculations are believed conservative. A comparison of thermal performance for the two designs is shown in Table 3.1 .

Flow Distribution in the Reactor Core. The regions of the core are orificed for equal gas exit temperatures, and the flow rate in a region is established in accordance with the power generation within the region. The over-all core pressure drop is established by the pressure drop through the maximum power region, and all other regions are orificed to provide appropriate coolant flow rates. Generally, a pressure difference exists between the channels within a given region and those of the adjacent colder or hotter regions. This pressure difference causes leakage of coolant gas into the channels of older fuel elements and from the channels of newer colums at every element interface within the columns. Presumably the crossflow is not directly from the hot channels in one region to the cold channels in another, but rather from the channels to the narrow space between adjacent columns and vice versa. There will be a net flow, for example, from a hot region to its surroundings, but within the region there is crossflow among the individual flow channels. It is expected that only channels along the region periphery, perhaps several rows inwards, participate in the process of crossflow.

The amount of crossflow depends on the condition of the interface. New elements probably have very little crossflow, while old elements, which have suffered prolonged radiation and may have a somewhat distorted geometry, will experience greater flow exchanges.

The pressure drop and the flow rate distribution were first calculated assuming no crossflow. Included in the analysis were the flow bypass through the side reflector, flow through the gaps between adjacent fuel columns in the regions, and the flow through the control rod openings. The fuel element geometry is essentially as shown in Fig. 3.1, except that the coolant hole diameter used was $0.58 \mathrm{in}$. The control rod element contains three openings, two for control rods and one for reserve shutdown absorber. There are a total of 690 coolant holes each having a diameter of $0.580 \mathrm{in}$. and 42 coolant holes each having a diameter of 0.493 in. per region of seven columns. The small holes are dimensioned to receive $2 / 3$ of the flow rate of that for a large hole. It was assumed that $1 \%$ of the total core power is gemerated in the side reflector and that $4 \%$ of the total core flow rate is used for cooling of the control rods. This $4 \%$ control rod flow is distributed evenly among the 37 regions. It is further assumed that the control rod coolant exit temperature is $1450^{\circ} \mathrm{F}$ for each region.

In the calculation of the pressure drop a $\Delta P$ of 1.5 velocity heads was predicted at the core inlet. Of this, 1.0 is due to flow acceleration from essentially zero velocity in the plenum above the top reflector, and 0.5 is due to irreversible losses. No pressure recovery is taken into account at the core exit. At the interface between elements, the coolant holes may be offset somewhat owing to machining tolerances, and a pressure loss occurs. A conservative estimate of the loss coefficient is 0.2 at each element interface. 
Figure 3.3 shows the flow rates through each region, not including the $3687 \mathrm{lb} / \mathrm{hr}$ control rod flow per region. Table 3.2 summarizes the results.

Table 3.2

RESULTS OF PRESSURE DROP AND FLOW RATE DISTRIBUTION CALCULATION
ASSUMING NO CROSSFLOW

Total core thermal power, Mw $(t) \ldots \ldots \ldots \ldots . \ldots 33.4$

Total core helium flow rate, $1 \mathrm{~b} / \mathrm{hr} \ldots \ldots \ldots \ldots \ldots 3.410 \times 10^{6}$

Helium temperature at core inlet, ${ }^{\circ} \mathrm{F} \ldots \ldots \ldots \ldots 755$

Mixed-mean temperature in exit plenum, ${ }^{\circ} \mathrm{F} \ldots \ldots \ldots .1427$

Side reflector power generation, fraction

of total core power, \% ................. 1

Side reflector bypass flow, fraction of

total core flow rate, $\% \ldots \ldots \ldots \ldots \ldots \ldots \ldots .9$

Side reflector flow exit temperature, ${ }^{\circ} \mathrm{F} \ldots \ldots \ldots .892$

Control rod flow, fraction of total core

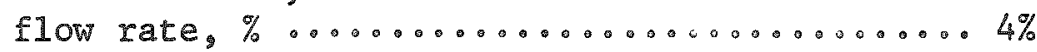

Control rod flow exit temperature, ${ }^{\circ} \mathrm{F} \ldots \ldots \ldots \ldots 1450$

Fraction of total power dissipated by

control rod flow, \%.....................

Mean exit temperature from each region, ${ }^{\circ} \mathrm{F} \ldots \ldots . .1455$

Average gap bypass flow within a region, $\% \ldots . .4$

Core inlet pressure, psia .............. 675

Over-all core pressure drop, psi............ 7.1

The problem of accurately evaluating crossflow in the entire reactor under expected conditions of operation becomes extremely complicated. Deve1opement of a computer program is in progress for the analysis of multiple parallel flow channels with multiple interconnects. To provide information about the loss coefficients for crossflow, a supplementary experimental program is planned.

Meanwhile, a simplified model has been used to determine values for preliminary performance analyses. The power peaking factors are a direct indication of the flow rate through each region and hence also of the orifice $\Delta \mathrm{P}^{\prime} \mathrm{s}$. Since the orifice $\Delta \mathrm{P}$ provides the pressure gradient that causes crossflow, it may be reasoned that the ratio between a region peaking factor and the average peaking factor of the surrounding ones is a relative measure of crossflow. For a ratio of one, no net cross flow takes place, for a ratio greater than one, crossflow leaves the region, and vice versa. This ratio, for convenience called crossflow factor, has been calculated for each region of the core.

Numerical values for the crossflow were computed by extrapolation from results obtained earlier for a two-channel model with multiple interconnects. For example, crossflow from a channel in region 25 at one year 


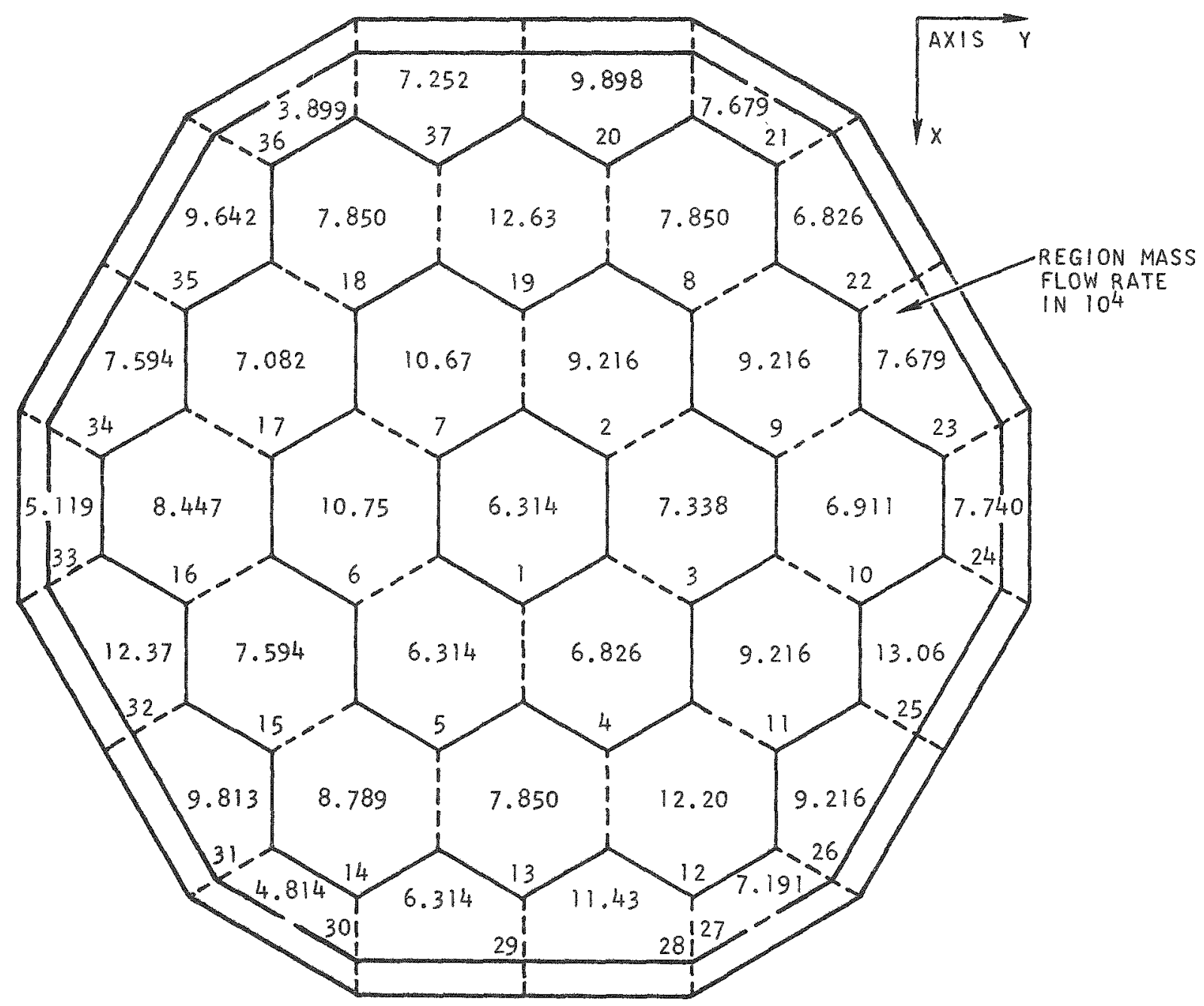

Fig. 3,3-Typical flow rate distrubution in reactor core; core orificed for equal gas exit temperature of $1455^{\circ} \mathrm{F}$ from all regions; no crossflow 
age, adjacent to a channel in region 10 at 6 year age (cross flow ratio 1.89) was 0.275 times the incoming flow rate to channel 25. Similarly, crossflow into a channel with a crossflow factor of 0.53 (channel $10 /$ channel 25) was calculated as 0.425 times the incoming flow rate. These two values were plotted on a graph of dimensionless crossflow versus crossflow factor, and a third point was obtained by reasoning that for a ratio of unity the crossflow is zero. The above values pertain to the two-channel calculations for a 0.010-in. interface gap height. When assuming a 0.020-in. gap for the calculations the total crossflow per channel remains the same, but it occurs over a much shorter distance from the entrance of the channel.

For each region the net flow loss or gain was computed by applying the above procedure to a number of channels in a region. It was arbitrarily decided to select four successive rows of coolant holes counted inward from the region boundary. For a seven-column region away from the side reflector this amounts to almost half of the total number of coolant holes.

To obtain the average effect of crossflow on the coolant and fuel element temperatures within a region, the total entering or leaving crossflow was averaged over all coolant channels within the region.

When crossflow is applied to a core orificed at conditions which would give a uniform gas exit temperature of $1455^{\circ} \mathrm{F}$ without crossflow, a decrease in core pressure drop results. This is because the hot channel, which determines the required pumping head, loses some coolant at each element interface along its length. A channel in region 25 at one year age, which has a normal incoming flow rate of $173 \mathrm{lb} / \mathrm{hr}$, loses about $10 \mathrm{lb} / \mathrm{hr}$ due to crossflow.

To calculate gas and fuel element temperatures with crossflow, one must first decide how the total inflow or outflow of coolant through the interface gaps is divided along the length of the channel. It was decided, based on the previously reported two-channel analysis results, to assume an exponential decrease of crossflow, with about $75 \%$ of the total taking place over the first half of the channel.

Generally, the temperature of crossflow gas entering a channel is different from that in the channel already, and a step change in bulk temperature takes place assuming instant mixing. A difficulty lies in predicting the temperature of the incoming crossflow, since the procedure defines only the estimated exchange with the six surrounding regions, all of which are operating at different conditions. However, by assuming that the entering flow is the same temperature as the local region coolant temperature it is estimated that the error in over-all performance is quite small.

For channels that lose flow, no such difficulty is present, and it was calculated that for a typical channel in region 25 , the gas exit temperature becomes $1484^{\circ} \mathrm{F}$ with crossflow as compared to $1455^{\circ} \mathrm{F}$ without. The maximum fuel temperature increases by about $30^{\circ} \mathrm{F}$ due to crossflow as predicted by this method.

The gas exit temperatures from the core described above may be adjusted back to a uniform value of $1455^{\circ} \mathrm{F}$ by resetting the orifices. This means that 
a channel in region 25 must start off with an excess in flow rate so that, after some amount of crossflow has been lost along the way, the exit temperature is just $1455^{\circ} \mathrm{F}$. Other channels have an initial flow rate that is less than the normal amount, but after gaining crossflow their exit temperatures are $1455^{\circ} \mathrm{F}$ as well.

Compared to the ideally adjusted orifices, a result of this "overorificing" is an increase in core $\Delta \mathrm{P}$. However, the increase appears to be equal to the decrease that crossflow brought about in the pressure drop of the no-crossflow-orificed core. Hence, the pressure drop in a core orificed for uniform gas exit temperatures with crossflow appears to be nearly equal to the $\Delta P$ for a core without crossflow, orificed for uniform gas exit temperatures.

Maximum fuel temperatures are, on the average, hardly affected by crossflow in this "over-orificed" core when comparing them to no-crossflow values. On the average, it appears that modest crossflow has little effect on core performance. However, the local effects of crossflow may still cause significant coolant loss from channels near element edges where local power peaking is severe, producing high local fuel and coolant temperatures. Analytical methods are currently being developed to provide for more accurate evaluation of over-all orificed core performance as well as local effects.

Transient Thermal Performance Studies. A study was made of the thermal behavior of the core during a 30 min period following scram from a loss of primary coolant flow. No cooling of the elements was assumed to take place during this time.

The analysis was performed using the RAT heat-transport code. The heat-transfer model was a simplified axisymmetrical geometry to allow the use of RAT in radial-axial coordinates. The fuel element design analyzed is shown in Fig. 3.1. Figure 3.4 shows results for the maximum power region. This region has an average power peaking factor of 1.83 , highest in the core for the $C / T h$ ratio of 225 equilibrium fuel loading. Figure 3.5 shows results for the average core condition.

Fission-product Transport

Preliminary calculations of fission-product activities in the primary coolant system were made. The RAD-2 code was used to calculate the fissionproduct activity data for the fuel and for the coolant gaseous activity, with the exception of $\mathrm{Sr}^{89}, \mathrm{Sr}^{90}, \mathrm{Cs}^{137}$, and $\mathrm{Ba}^{140}$ gaseous activity values, which include the contribution of release calculated by the FREVAP code.

Gaseous activities for $\mathrm{Sr}^{89}, \mathrm{Sr}^{90}, \mathrm{Cs}^{137}$, and $\mathrm{Ba}^{140}$ were calculated by a two-step method. The total gaseous activity for each of these isotopes was determined by adding the activity contribution from precursor decay as calculated by $\mathrm{RAD}=2$ to the direct release of the isotope as calculated by FREVAP. The total gaseous activity released was then subjected to the appropriate removal mechanism.

The exposure of coated fuel particle specimens to high-temperature steam is continuing. The purpose of this work is to study the oxidative reaction 


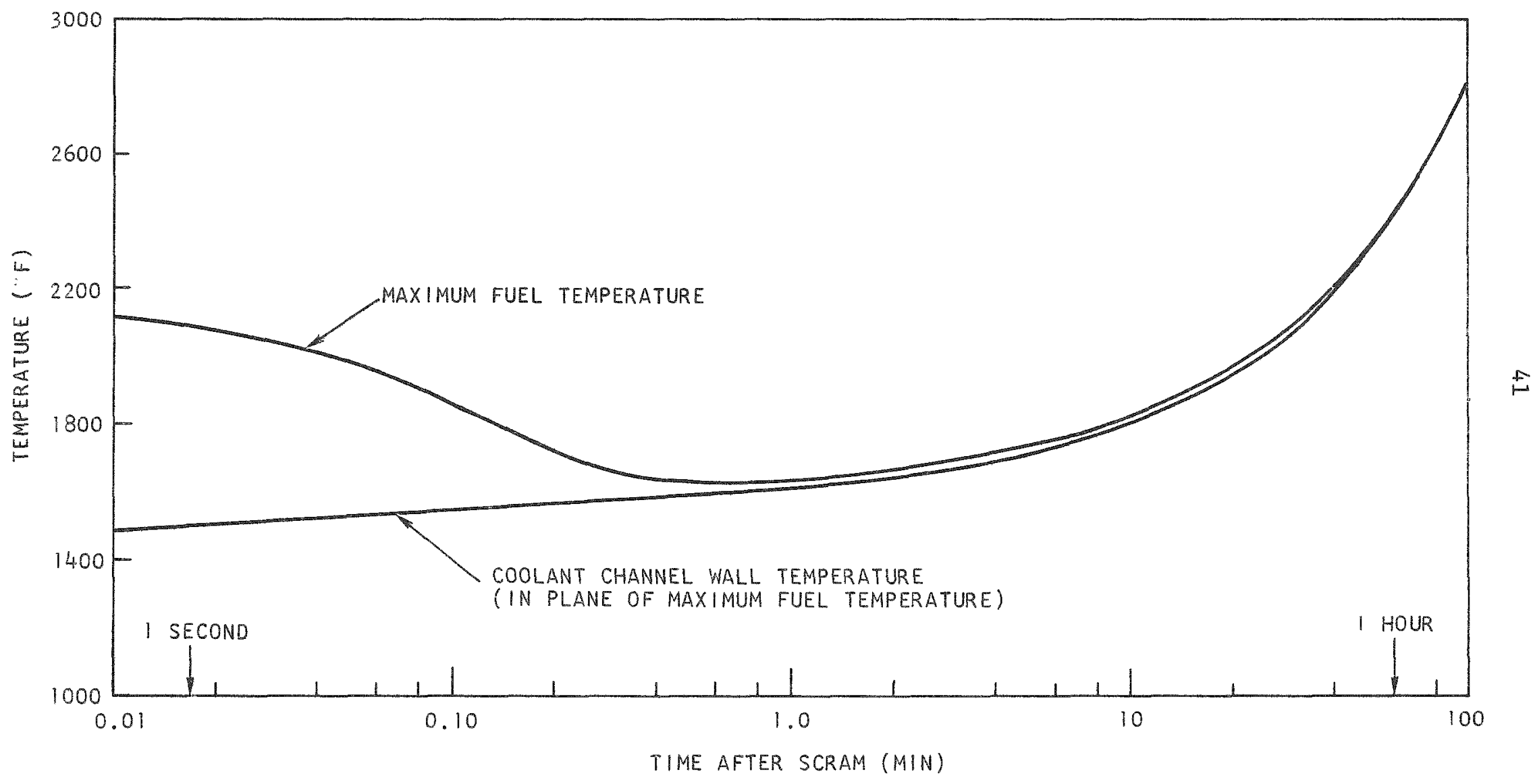

Fig. 3,4--Temperature history of the maximum power region after a scram initiated by loss of coolant flow 


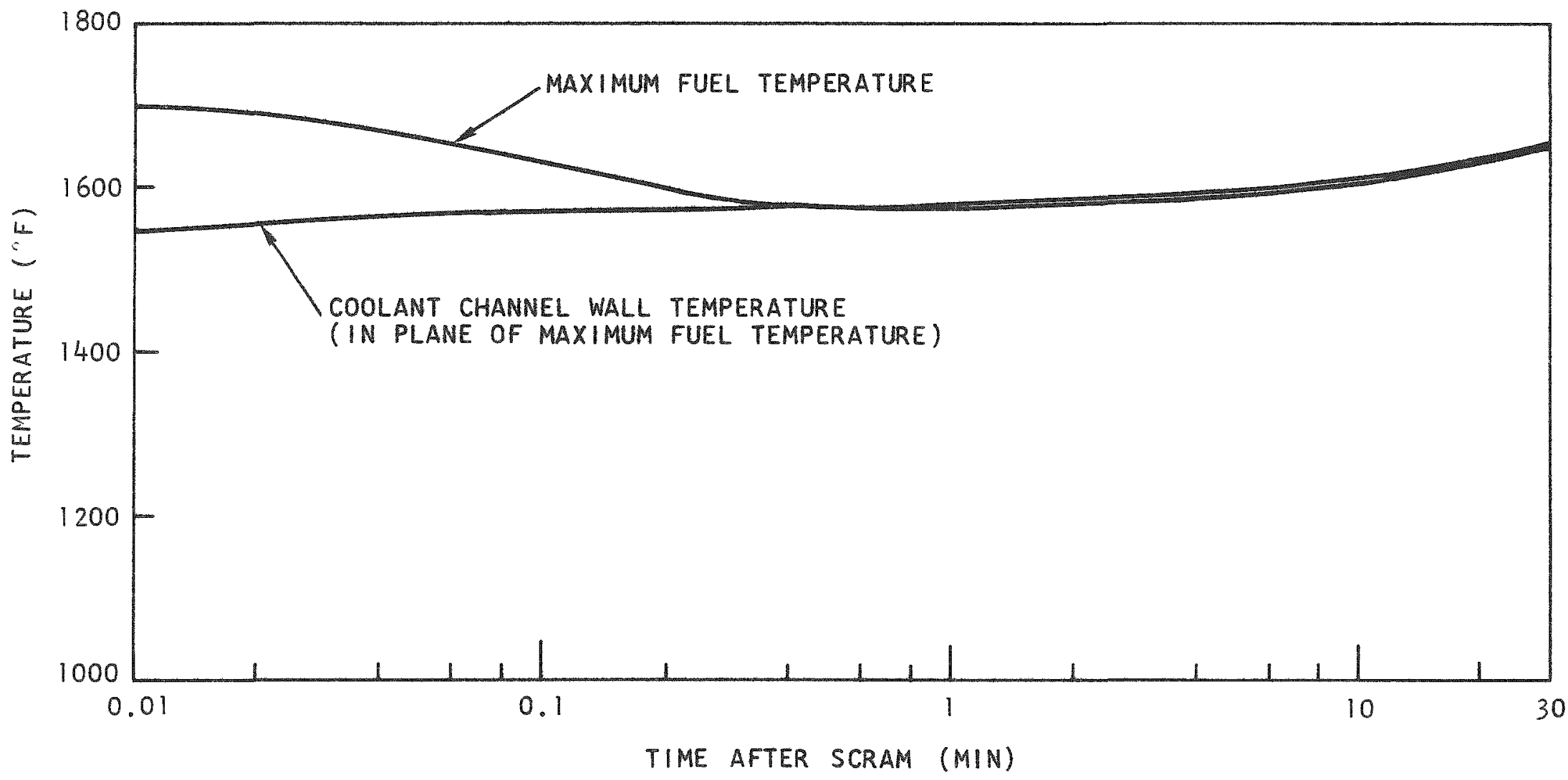

Fig. 3,5--Temperature history during a 30-min period after a scram initiated by loss of flow (core average) 
rate of fuel particles when exposed to conditions simulating a reactor steam-inleakage accident.

Particles are exposed to a steam-helium gas mixture at temperatures in the range $1000^{\circ}$ to $1400^{\circ} \mathrm{C}$. Steam concentrations of $2.5 \%, 16.5 \%$, and $22 \%$ in helium at $5 \mathrm{psig}$ and flowing at $300 \mathrm{~cm}^{3}$ (STP)/min have been used.

The effluent gas is first dried to remove excess moisture and then is passed through a gas chromatograph for oxidation product $\left(\mathrm{CO}, \mathrm{CO}_{2}\right)$ analysis. It then passes through an ionization chamber for the measurement of gaseous radioactive species that are released upon rupture of the particles. In the present experiments, samples of irradiated and unirradiated BISO-coated $(T h, U) C_{2}$ particles with a $100-\mu$ coating were used. One sample had a coating density of $1.97 \mathrm{~g} / \mathrm{cm}^{3}$, a kernel diameter of $300 \mu$, and a Th/U ratio of 3 ; the irradiated samples had a burnup of 3.7 FIMA. The other sample had a coating density of $1.91 \mathrm{~g} / \mathrm{cm}^{3}$, a kernel diameter of $215 \mu$, and a Th/U ratio of 4 ; the irradiated samples had a burnup of 4.0 FIMA.

Oxidation rates for unirradiated coatings are shown in an Arrhenius plot in Fig. 3.6. The apparent activation energy for the reaction, as determined from the slope, is $63 \mathrm{kcal} / \mathrm{mole}$.

Figure 3.7 is a similar plot for TS -688 graphite exposed to steam condition in the same apparatus. The activation energy appears to diminish at higher temperatures. It is believed that depletion of the reactant steam and subsequent increase in $\mathrm{CO}$ and $\mathrm{H}_{2}$ causes this effect. For example, at $1400^{\circ} \mathrm{C}$, and at the flow conditions of the test, $30 \%$ and $50 \%$ of the steam is reacted in a single pass for the 0.165 and 0.025 atm (steam) experiments, respectively. The slope of the lower-temperature portion of the curve in Fig. 3.7 indicates an activation energy of around $83 \mathrm{kcal} / \mathrm{mole}$.

The measurement of time to rupture for irradiated particles has proved interesting. Rupture times were measured for bare particles and for graphiteenclosed particles. Results show that the surrounding graphite is quite protective at higher tempratures. This is because steam must diffuse through and react with the graphite. Hence, the steam is quite depleted in concentration at the particle surface until a large portion of the sacrificial graphite is destroyed. At lower temperatures (i.e., $21000^{\circ} \mathrm{C}$ ) it appears that the surrounding graphite offers greatly reduced protection; however, the reaction rates of coatings and graphite are much lower at the lower temperature. These phenomena are best represented in Fig. 3.8, which is an Arrhenius plot of reciprocal rupture time against reciprocal temperature for irradiated particles. For the particles contained in graphite at higher temperatures, the average rupture time is seen to bend over much like the graphite reaction rate (see Fig. 3.7 ).

Activation energies for oxidative rupture were determined from the slopes of the curves in Fig. 3.8. For bare particles, $114 \mathrm{kcal} / \mathrm{mole}$ is calculated in the temperature range $1000^{\circ}$ to $1200^{\circ} \mathrm{C}$. 


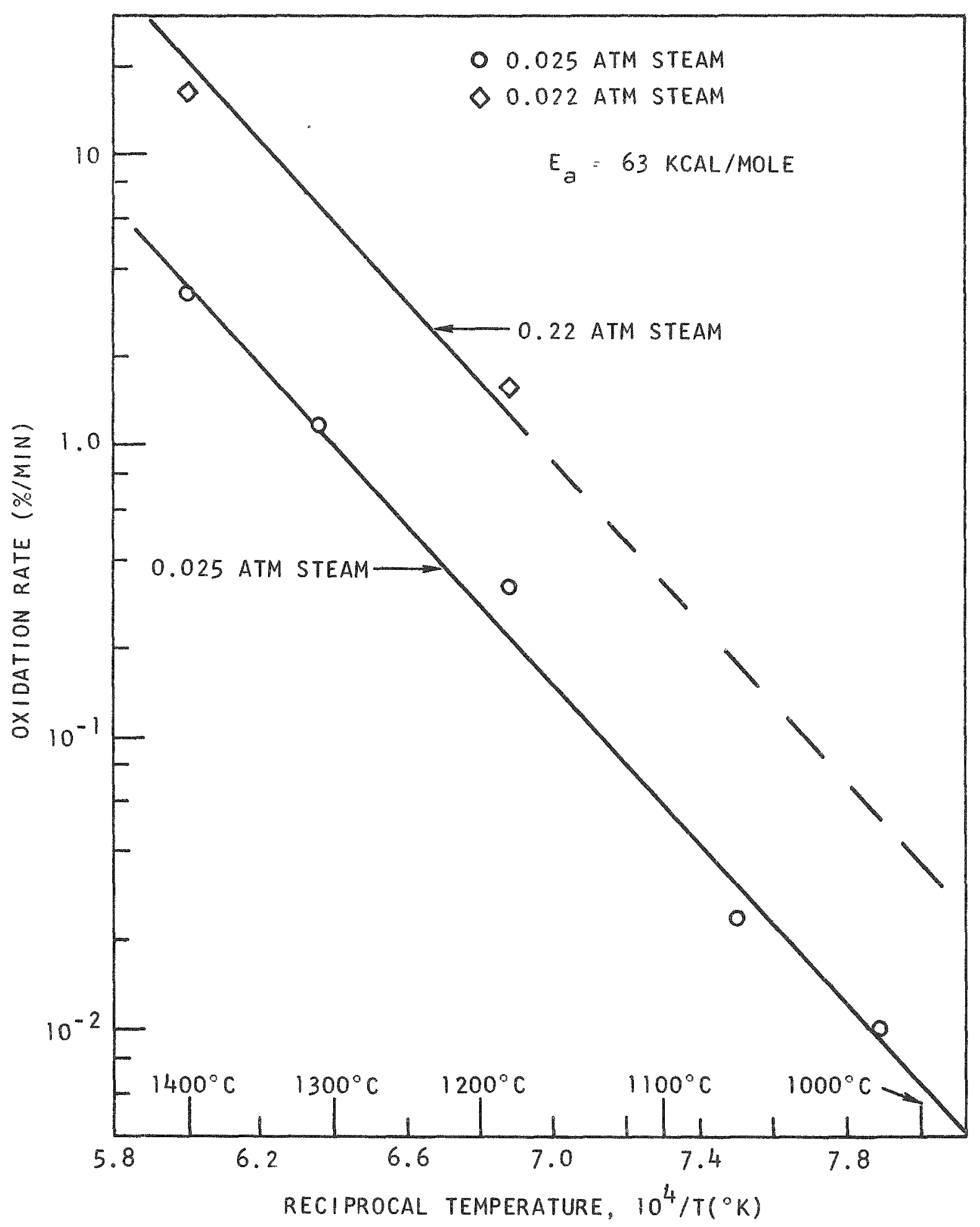

Fig. 3.6--Steam-particle coating reaction rate versus reciprocal temperature; unirradiated $\mathrm{BISO}$-coated $(\mathrm{Th}, \mathrm{U}) \mathrm{C}_{2}$ particles; sample weight $20.5 \mathrm{mg}$ 


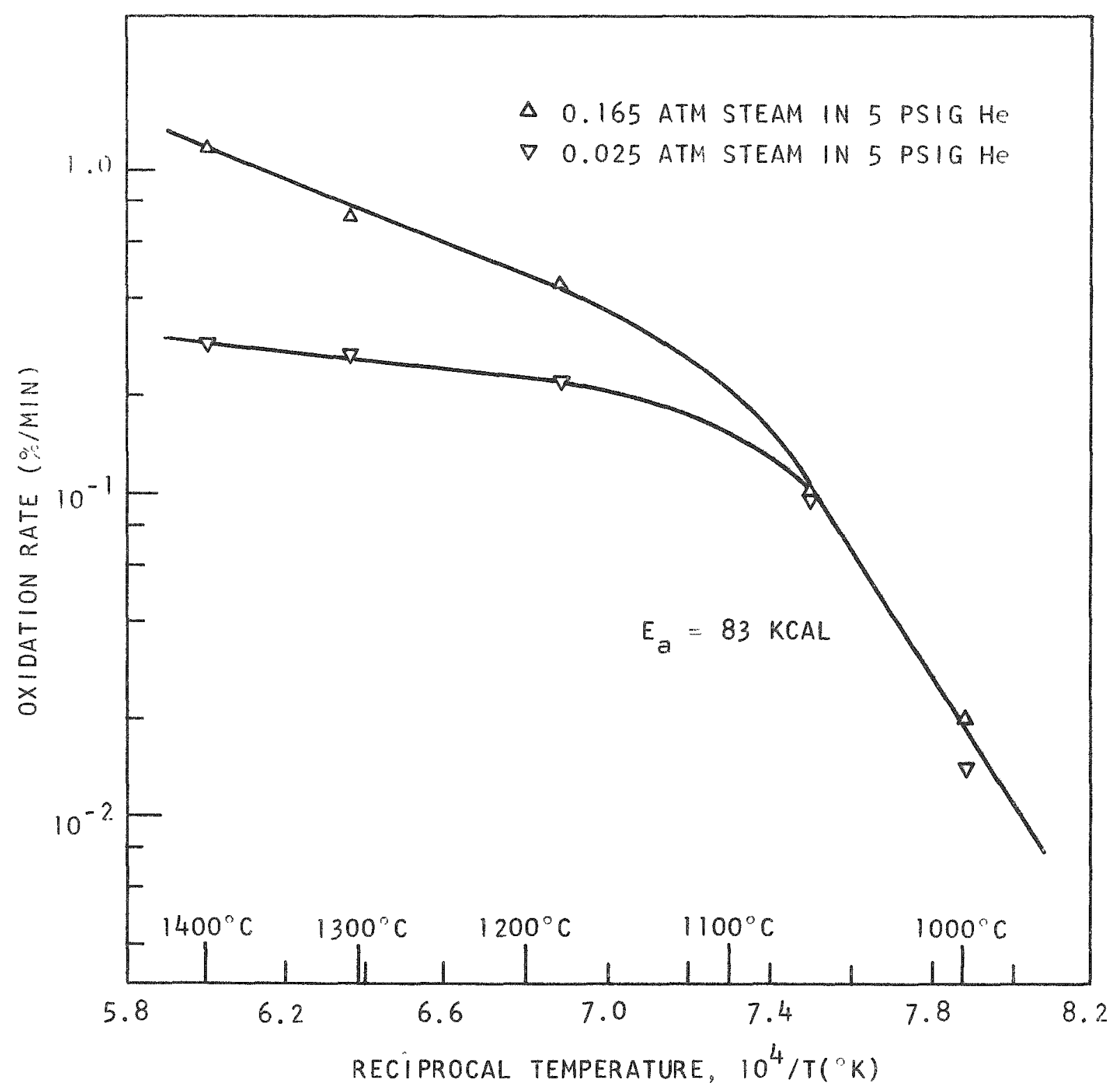

Fig。3.7--Steam-graphite reaction rate versus reciprocal temperature 


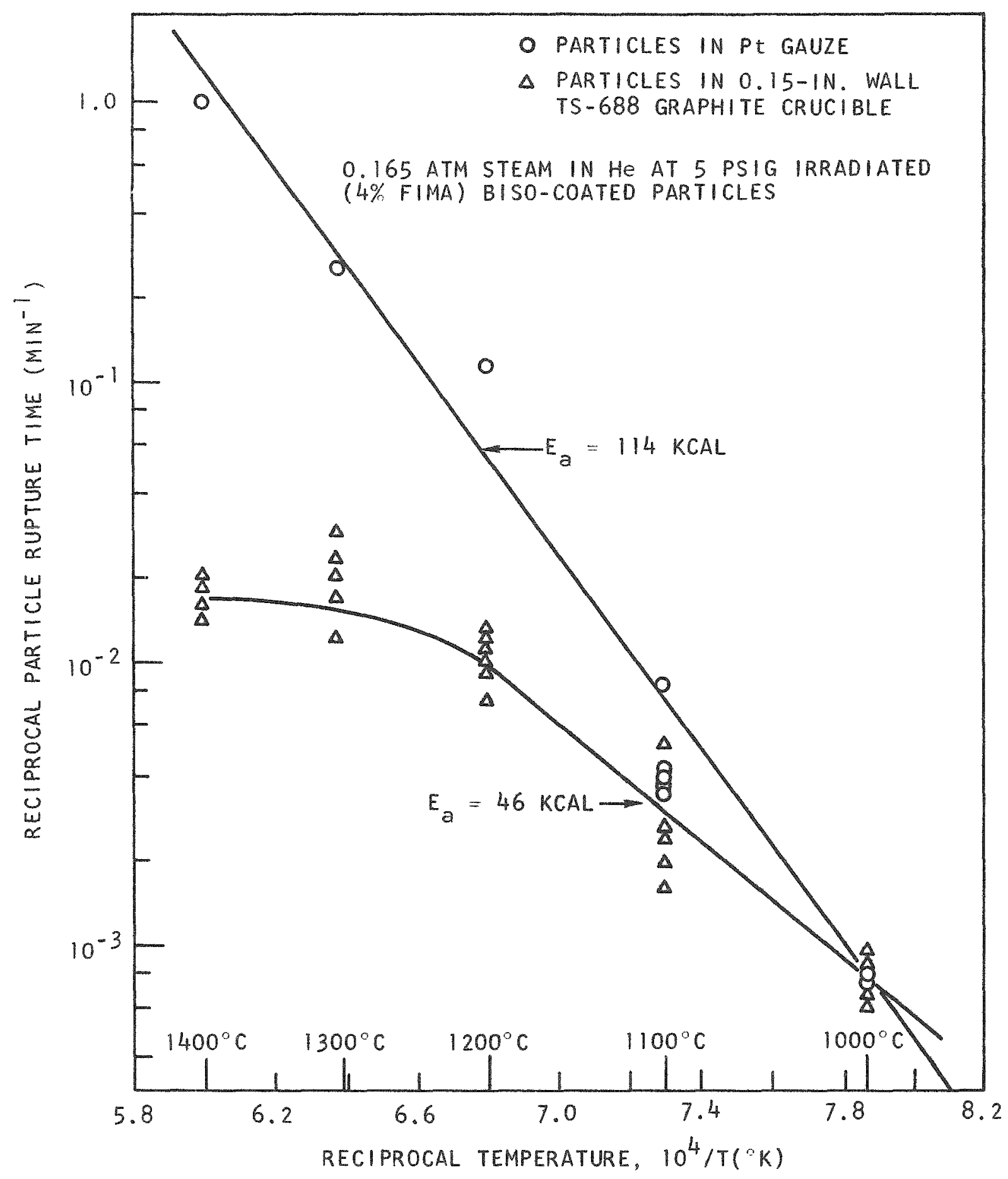

Fig. 3.8--Reciprocal particle rupture time versus reciprocal temperature 
The relatively high activation energy for bare particles may be associated with a difference in type of oxidative attack at each temperature. For instance, photomicrographs show that pinhole attack predominates at higher temperatures of $1300^{\circ}$ to $1400^{\circ} \mathrm{C}$. Moreover, particle reaction rate measurements indicate that particles fail at $1400^{\circ} \mathrm{C}$ after about $10 \%$ of the coating is consumed. At lower temperatures, however, photomicrographs indicate a generalized attack with some "pot holing." The reaction rate data indicates that at $1000^{\circ} \mathrm{C}$ particles fail after approximately $50 \%$ of the coatis destroyed.

\section{MATERIALS}

The objectives of this subtask are to:

1. Determine the characteristics of beds of loose coated particles by means of thermal conductivity tests, packing tests, and impact tests.

2. Determine the characteristics of beds of bonded particles (as an alternative to loose particles) by means of fabrication technique investigations, thermal conductivity tests, and impact tests.

3. Select the type of particle bed to be used in the reactor based on the above work and work carried out in other parts of the program, taking into account the expected characteristics and relative ease of reprocessing for the two types of beds, and determine the suitability of the selected system by means of further tests of the type described above.

4. Determine the characteristics of various candidate graphites for use in the reactor fuel elements by means of measurements of the physical, thermal, and mechanical properties of these graphites.

5. Determine the characteristics of various control materials by means of measurements of physical, mechanical, chemical, and thermal properties.

6. Determine the irradiation stability of candidate graphites for use in the reactor fuel elements by means of irradiation tests conducted in the Engineering Test Reactor (ETR) at the temperatures and to the integrated fast flux expected in the reactor, followed by postirradiation examination. Approximately five capsules are planned for this part of the program.

7. Establish the effect of fast flux on fuel particle coating structural integrity as a function of coating structure and exposure by means of irradiation tests in the ETR on unfueled samples of particle coatings, postirradiation measurements of coating properties such as dimensional changes, flexural strength, and crystallite spacing, and subsequent reirradiation to design integrated fast flux and remeasurement. These irradiations will be carried out in the graphite capsules used in item 6 above.

8. Determine the irradiation stability of coated fuel particles for use in the reactor by means of a series of short-term tests on coated fuel particles to select a coated fuel particle(s) having 
over its design life a high degree of structural integrity suitable for use in a nonvented fuel element, followed by longer-term irradiation tests conducted at the temperature and to design burnup and to a significant fraction of the integrated fast flux expected in the plant. The "significant" integrated fast dosage will be determined from the results obtained in item 7 above. Capsule tests will be followed by postirradiation examination of the particles. Approximately seven short-term and three longer-term capsules are planned for this part of the program.

Particle Beds

Fuel development studies in support of the PSC fuel materials program are intended to provide information on the properties and performance of coated particle fuel systems. The development and evaluation of candidate fuel systems are being used to aid in the design of fuel elements, and to aid in the selection of fuel that will meet the performance requirements of the PSC reactor. The reference fuel element design calls for the use of retentive coated particles in an unpurged graphite element. This reference design has been established wherein the coated fuel particles are bonded to themselves and to the graphite element. Bonded beds should prevent or minimize the loss of fuel should a fuel element become cracked.

Packing Studies. Packing studies are being performed to develop practical methods for preparing and loading uniform fuel blends. Methods are being developed for blending activated charcoal (for sorption of metallic fission products) into the coated particle bed. Packing densities are being measured for blends of coated particles with activated charcoal.

Several blends of charcoal and reference coated fertile particles were prepared. The charcoal was prepared by outgassing at $1500^{\circ} \mathrm{C}$ to $<10-\mu$ gas pressure and then grinding to $<53-\mu$ particle size. The charcoal and coated particles were mixed with enough water to make the mixture similar to a viscous fluid. The mixture was mill-blended for $1 \mathrm{hr}$, and loaded into a 1/2-in. diameter by 4-in. long glass tube. The blend was vibrated to minimum volume at $\sim 1 \mathrm{~g}(120 \mathrm{cps})$, dried and vibrated again, and finally analyzed for coated particle content (by volume) and charcoal concentration. The finished blends appeared to be uniform. Radiographs will be taken to verify this.

The data from these measurements (see Fig. 3.9) show that the packing fraction remains at a maximum up to a charcoal content of $0.13 \mathrm{~g} / \mathrm{cm}^{3}$, beyond which the packing fraction is reduced with further increases in charcoal content. The packing fraction is reduced linearly with increasing charcoal content above about $0.20 \mathrm{~g} / \mathrm{cm}^{3}$. These data point out the possibility of using charcoal to reduce the packing fraction to a prescribed value. More tests are being made to better establish the curve.

A variation of this process will be used to prepare bonded particle beds. In this process a liquid such as furfuryl alcohol will be substituted for the water. The liquid will serve the double role of mixing agent and binder. 


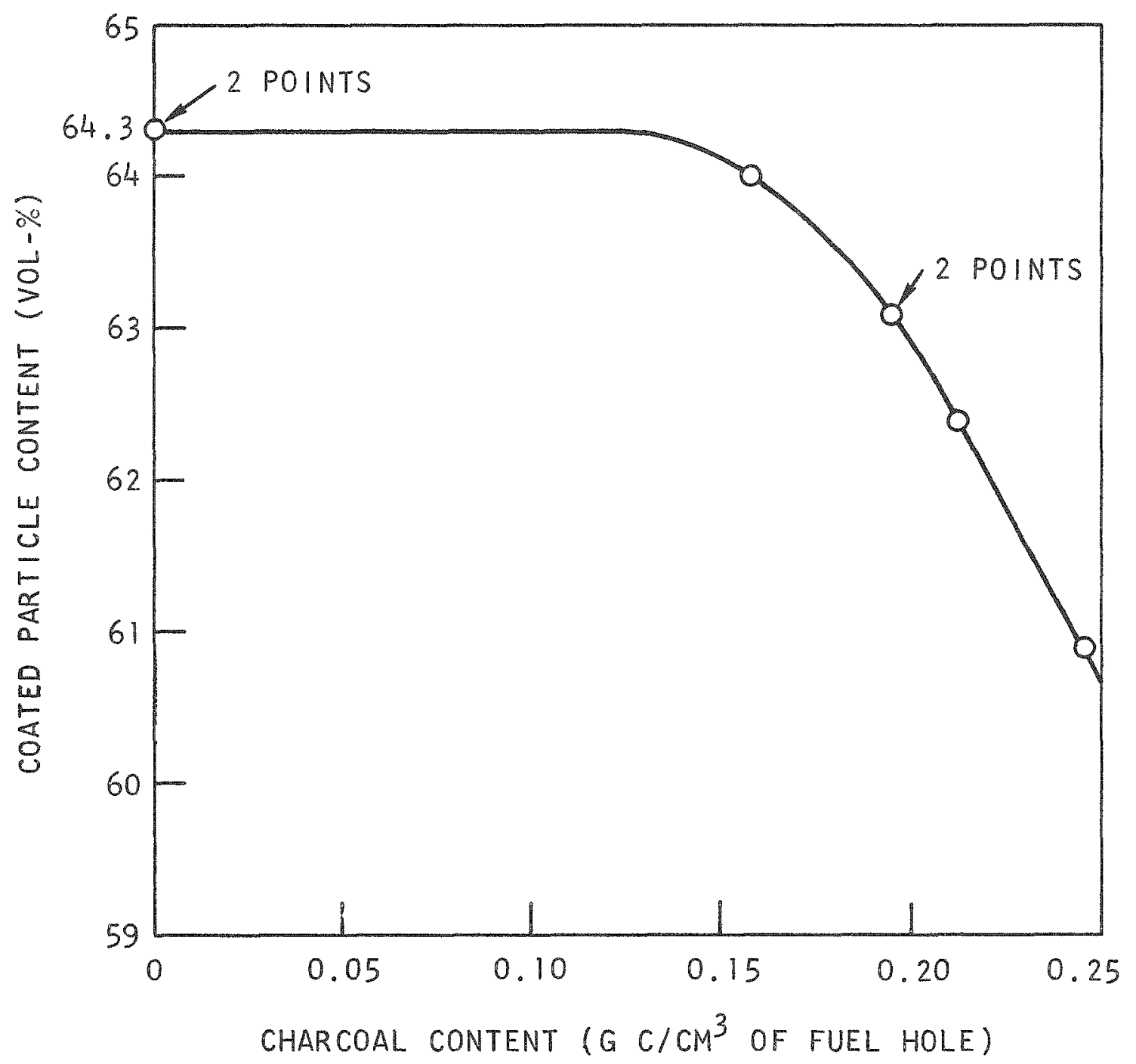

Fig. 3.9-macking fraction of reference fertile coated particles versus charcoal content 
Thermal Expansion. Thermal expansion measurements were made on reference fissile particles to supplement previous work. The technique involved measuring the expansion of a single row of particles in a narrow-bore quartz tube. Absolute measurements were made between room temperature and $1000^{\circ} \mathrm{C}$. The coefficient of thermal expansion increased with increasing temperature up to $400^{\circ} \mathrm{C}$ and was constant from there to $1000^{\circ} \mathrm{C}$. This constant value of $2.06 \times 10^{-6}{ }^{\circ} \mathrm{C}^{-1}$ was lower than expected because isotropic coatings have expansion coefficients of more than twice this value.

A value of $2.65 \times 10^{-6}{ }^{\circ} \mathrm{C}^{-1}$ had been previously measured for these particles in a TS-688 graphite tube and, since this graphite does not have a negative coefficient of expansion (except for minor shrinkage near room temperature), both of the above measurements cannot be valid. However, no further measurements to clarify these data are planned because of the present emphasis on bonded coated fuel particles.

Thermal Conductivity. Previous measurements have defined the thermal conductivity of beds of loose coated fuel particles. However, present considerations of bonding the particles together and adding charcoal to the bed necessitate further tests to determine the effect of a matrix on the thermal conductivity of particle beds. The apparatus used in the previous measurements was redesigned for use with bonded particles and will allow temperature measurement by an improved technique.

Sample containers for thermal conductivity measurement of bonded beds were designed, and the tooling and graphite parts fabricated.

\section{Bonded Particle Systems}

Studies on bonded particle systems are directed toward the development and evaluation of practical binders and bonding processes that will yield fuel systems satisfying PSC design requirements. Also, the addition of charcoal to the bonded particle-matrix system is considered highly desirable as a sorbent for metallic fission products.

A number of matrix samples were prepared for BET surface area measurements to determine their potential for fission-product absorption. The systems prepared were:

1. Furfuryl alcohol monomer with and without charcoal.

2. Furfuryl alcohol monomer plus $10 \%$ ethylcellulose with and without charcoal.

3. Barrett No. 30 pitch $\left(\mathrm{mp} \sim 100^{\circ} \mathrm{C}\right)$ with and without charcoal.

4. Pitch ( $\mathrm{mp} \sim 150^{\circ} \mathrm{C}$ ) with and without charcoal.

5. Coke from sugar.

6. Coke from Saran。

7. Activated charcoal with and without outgassing.

In systems containing pitch or furfuryl alcohol, the binder was impregnated at 150 psi into the pores between coated coke particles. The sugar and 
Saran specimens were made by coking the powdered material in a graphite crucible. All samples (except the activated charcoal) were carbonized at $900^{\circ} \mathrm{C}$, and all (including the charcoal) were outgassed at $1600^{\circ} \mathrm{C}$ 。

The matrix was ground away from the coated particles over a sieve so that the powdered matrix could be separated fxom the coated particles. The presently available BET data are summarized in Table 3.3. The most significant result is that the surface area of charcoal is drastically reduced upon impregnation with either furfuryl alcohol or Barrett No. 30 pitch (with initial evacuation). This constitutes a strong deterrent to the use of an impregnation process. The other results show that coking and outgassing sugar, pitch, and Saran does not produce a charcoal of surface area comparable to that of activated charcoal.

Test samples were prepared for irradiation in Capsule P14. For these samples, two grades of charcoal were mixed with coated particles and impregnated with pitch or furfuryl alcohol monomer. Samples were also made in which the charcoals alone were impregnated with these binders.

Samples are also being fabricated for Capsule P14B. Bonded samples wil1 be made using an admixture of furfuryl alcohol, charcoal, and coated fuel particles. One sample will be loaded directly into its graphite container. The other will be molded into a "fuel stick" that will be bonded into its graphite container. In addition, samples containing two grades of charcoal impregnated with furfuryl alcohol and pitch will be made.

Table 3.3

BET SURFACE AREA OF SOME CARBONACEOUS MATERIALS

Materiala

BET Surface Area $\left(\mathrm{m}^{2} / \mathrm{g}\right)$

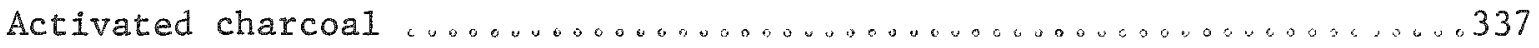

Activated charcoal impregnated with

furfuryl alcohol monomer $+10 \%$

ethylcellulose (coked at $900^{\circ} \mathrm{C}$ )

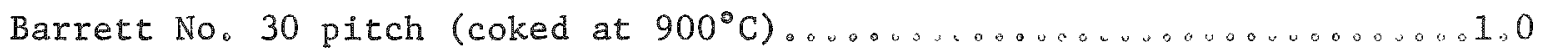

Activated charcoal impregnated with

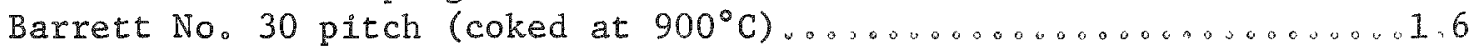

Activated charcoal impregnated

with furfuryl alcohol monomer

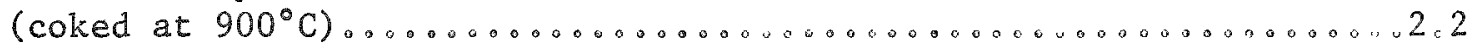

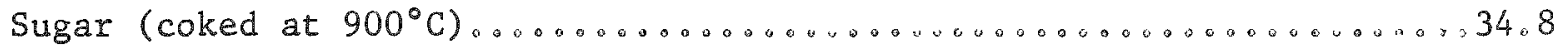

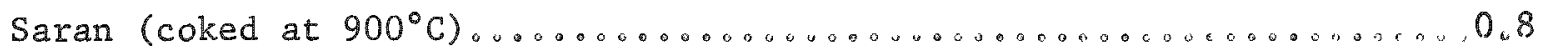

$150^{\circ} \mathrm{C}$ melting point pitch

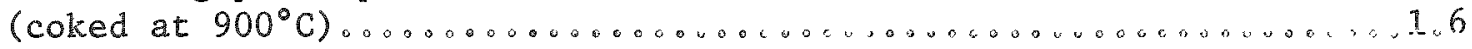

a All samples outgassed at $1600^{\circ} \mathrm{C}$. 
Graphite Development

The objective of this program is to evaluate various conventional needle-coke graphites for use in fuel elements. These graphites are obtained from various vendors and are being evaluated with respect to strength, purity thermal properties, and cost.

Graphite Evaluation. Conventional needle-coke graphites are currently being evaluated for use in fuel elements and as reflector graphites. The graphites of current interest are grades TS-688, $\mathrm{H}-327, \mathrm{H}-328$, and 9567. Tensile strength measurements were initiated to determine fracture stress, fracture strain, modulus of elasticity, and Poisson's ratio.

Additional tensile testing has been done by BNWL in conjunction with a cooperative testing program among General Atomic, BNWL, and UCC to determine the true tensile strength of TS-688 graphite. The additional data, along with the data obtained previously at General Atomic, are shown in Table 3.4. The data from BNWL confirm General Atomic data reported last quarter that this particular bar of TS-688 graphite is below the standards for this grade and does not meet the current PSc specifications (900 psi in the perpendicular direction and 1500 psi in the parallel direction).

Additional General Atomic data have been obtained using samples from another $20-i n$. by $20-i n$. by $20-f t$ log of TS-688 graphite. The results are shown in Table 3.5 .

These results indicate that this particular log has higher strength in the parallel direction and meets current specifications. However, the perpendicular strength is still too low. A slight variation in strength was observed between samples taken from either end. These data again confirm to some extent the inhomogeneity of this particular type of material.

Additional strength data were obtained on Grade 9567 in the direction parallel to extrusion. The results to eight tests indicate an average of 2230 psi, with a minimum of 2056, a maximum of 2400, and $\sigma$ of 104. These data further confirm previous data reported last quarter that this type of graphite is uniform and strong.

In summarizing the strength data obtained to date, it appears that Grade 9567 and Grade H-327 are satisfactory, with one qualification--that this high strength be maintained while producing 18-in. diameter logs. Since $H-327$ is now produced in 12-3/4-in. diameters, there is a good chance that it can be scaled up successfully. However, the 9567 material samples on hand are from a cross section of 4-3/4-in. $x$ 12-1/2-in. An order has been placed for a number of 18-in. diameter logs which are specified to have the same strength as 9567.

Thermal properties are being measured.

Surface Area Studies of Graphite. Work is being initiated to study the effect of high-temperature irradiation on the BET (nitrogen adsorption) surface area of reactor-grade graphites. This work should be useful in 
predicting the amount of metallic fission products that will be retained by the fuel element graphite, since the amount of sorbed material on graphite has been demonstrated to be a function of the surface area of the graphite.

Initial measurements will be made on samples of 780-S and NPR (needlecoke) graphites that were irradiated several months ago at temperatures of $500^{\circ}$ to $1000^{\circ} \mathrm{C}$. These samples will be compared with control (unirradiated) samples of the same graphite. If an appreciable change in surface area is observed, these studies will be extended to investigate TS-688 graphite as irradiated samples become available.

Effect of Steam-Graphite Reaction on Graphite Strength. An experiment is under way that will measure compressive and tensile strength of three graphites as a function of steamo oxidative burnoff.

Several samples have been exposed to steam at $1000^{\circ} \mathrm{C}$ resulting in weight losses up to $14 \%$. The specimens are being subjected to strength tests.

\section{Control Materials}

Control materials studies are being conducted to determine the availability of materials that meet the requirements of PSC. Liaison with manufacturers is being maintained and property evaluations are being conducted on suitable materials.

Modulus of rupture measurements have been made on samples of irradiated $\mathrm{B}_{4} \mathrm{C}$ graphite. These materials were irradiated to a total thermaland fast-neutron exposure of about $4.0 \times 10^{21} \mathrm{nvt}$ in the temperature range $300^{\circ}$ to $340^{\circ} \mathrm{C}$. The data (shown in $\mathrm{Table} 3.6$ ) do not comprise a complete set of systematic data before and after irradiation. However, two rather general conclusions can be made:

1. $\mathrm{B}_{4} \mathrm{C}$ graphite prepared by heating the $\mathrm{B}_{4} \mathrm{C}$ and graphite matrix together above $2500^{\circ} \mathrm{C}$ is relatively weak.

2. $\mathrm{B}_{4} \mathrm{C}$ graphite prepared by heating below $2500^{\circ} \mathrm{C}$ is relatively strong, and moderate neutron dosage does not adversely affect its strength.

\section{Irradiation Testing}

A series of irradiation experiments is being conducted to test reference BISO-coated particles under PSC design irradiation conditions. These experiments are intended to provide a guide to the selection of fuel materials that will meet the performance requirements of the PSC Reactor. BISO-coated carbide fuel particles have been selected as the reference design based on their good stability under high burnup and high temperature irradiation environments. Current tests are directed toward evaluating the optimum materials parameters for each layer of the BISO coating, with emphasis on evaluating the stability of these particles under highfast-flux exposures. 
Table 3.4

RESULTS OF COOPERATIVE TENSILE TESTS BY BNWL AND GENERAL ATOMIC ON TS-688 GRAPHTTE LOG 2369-30

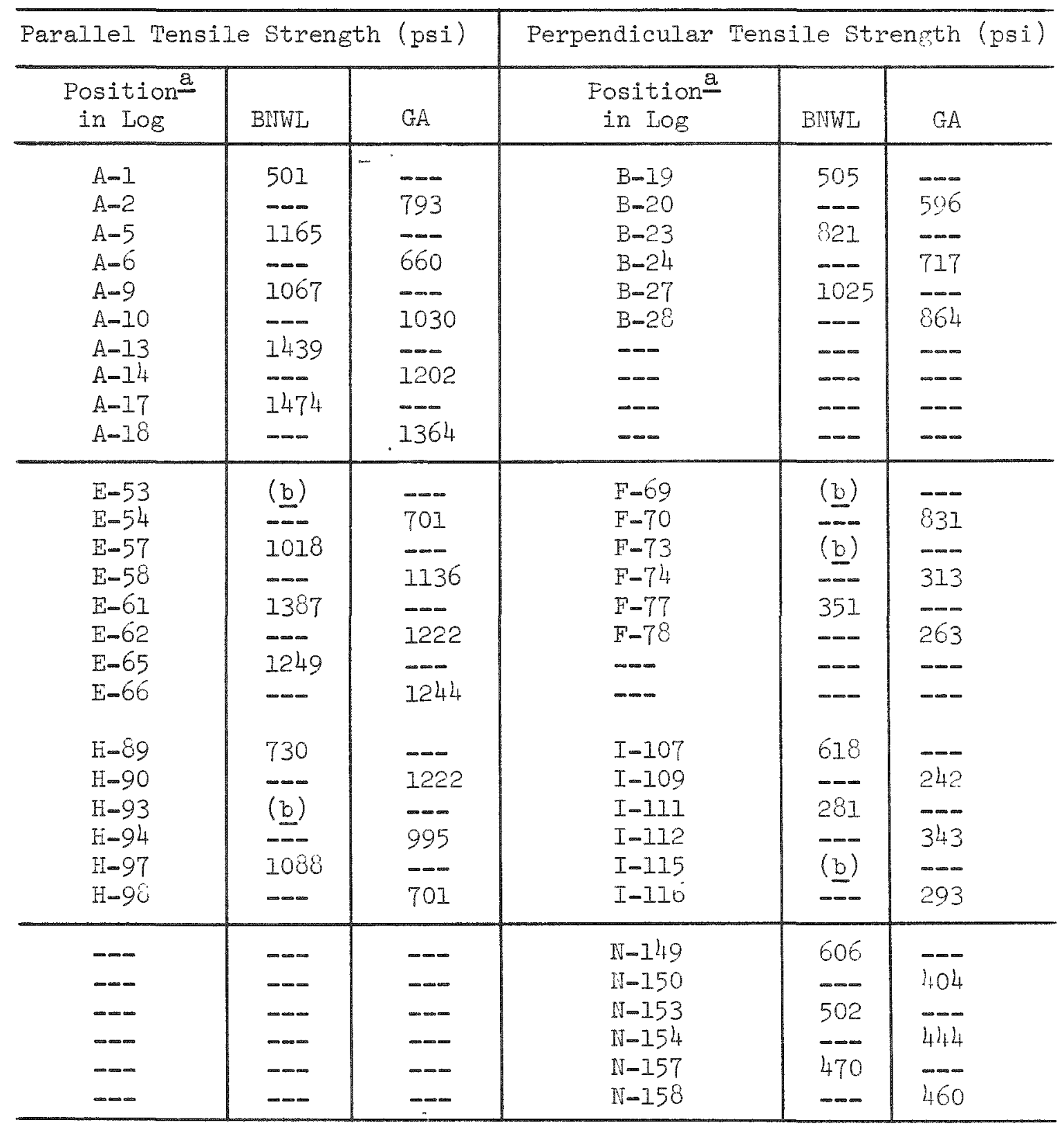

a see Fig. 3.19 of GA-6950 for position in log.

b Broken in machining, sample lost. 
Table 3.5

TENSILE STRENGTH OF TS 688 LOG $2369-74-B$

\begin{tabular}{|c|c|c|c|c|c|c|c|c|c|c|c|c|c|}
\hline \multirow{4}{*}{$\begin{array}{l}\text { Position } \\
\text { in Log }\end{array}$} & \multirow{4}{*}{$\begin{array}{l}\text { No of } \\
\text { Samples } \\
\text { Tested }\end{array}$} & \multicolumn{12}{|c|}{ Fracture Stress (psi) } \\
\hline & & \multirow{2}{*}{\multicolumn{4}{|c|}{ Parallel }} & \multicolumn{8}{|c|}{ Perpendicular } \\
\hline & & & & & & \multicolumn{4}{|c|}{$\mathrm{X}$} & \multicolumn{4}{|c|}{$Y$} \\
\hline & & Avg & Min & Max & $\sigma$ & Avg & $\operatorname{Min}$ & $\operatorname{Max}$ & $\sigma$ & Avg & Min & $\operatorname{Max}$ & $\sigma$ \\
\hline End & 5 & 1778 & 1710 & 1859 & 60 & 629 & 296 & 910 & 209 & 1189 & 980 & 1313 & 127 \\
\hline 1/3 from End & 5 & 1840 & 1641 & 2056 & 138 & 992 & 816 & 1228 & 139 & 867 & 812 & 990 & 68 \\
\hline End & 5 & 1900 & 1609 & 2132 & 181 & 804 & 735 & 1010 & 81 & 696 & 556 & 808 & 105 \\
\hline
\end{tabular}

a Five samples of each orientation.

$\underline{b}$ Directions $X$ and $Y$ are at $90^{\circ}$ to each other and $90^{\circ}$ to the parallel direction 
Table 3.6

MODULUS OF RUPTURE OF IRRADIATED $B_{4}$ C-GRAPHITE

\begin{tabular}{|c|c|c|}
\hline Sample Type $e^{a}$ & $\begin{array}{l}\text { Cross-section } \\
\text { Dimensions } \\
\text { (in.) }\end{array}$ & $\begin{array}{l}\text { Modulus of } \\
\text { Rupture } \\
\text { (psi) }\end{array}$ \\
\hline $\begin{array}{l}\text { Extruded, heated to } \\
<2500^{\circ} \mathrm{C} \text { during manu- } \\
\text { facture; unirradiated }\end{array}$ & $0.1162 \times 0.1165$ & 2430 \\
\hline $\begin{array}{l}\text { Hot molded with graphite } \\
\text { flour, } \mathrm{B}_{4} \mathrm{C}, \text { and pitch: } \\
\text { heated to } 1800^{\circ} \mathrm{C} \text { dur- } \\
\text { ing manufacture }\end{array}$ & $0.1233 \times 0.1247$ & 4700 \\
\hline $\begin{array}{l}\text { Hot molded with graphite } \\
\text { flour, } \mathrm{B}_{4} \mathrm{C}, \text { and pitch; } \\
\text { heated to } 1800^{\circ} \mathrm{C} \text { dur- } \\
\text { ing manufacture }\end{array}$ & $0.1242 \times 0.1247$ & 2800 \\
\hline $\begin{array}{l}\text { Extruded, heated above } \\
2500^{\circ} \mathrm{C} \text { during manu- } \\
\text { facturec }\end{array}$ & $0.1237 \times 0.1252$ & 560 \\
\hline $\begin{array}{l}\text { Extruded, heated above } \\
2500^{\circ} \mathrm{C} \text { during manu- } \\
\text { facture }\end{array}$ & $0.1251 \times 0.1252$ & 720 \\
\hline $\begin{array}{l}\text { Extruded nuclear } \\
\text { graphite }\end{array}$ & $0.1246 \times 0.1261$ & 7250 \\
\hline $\begin{array}{l}\text { Extruded nuclear } \\
\text { graphite }\end{array}$ & $0.1250 \times 0.1253$ & 7600 \\
\hline
\end{tabular}

a Samples all contained $30 \mathrm{wt}-\% \mathrm{~B}$.

b Test sections were 0.565 -in. 1ong.

c Graphite structure appeared to have recrystallized

during manufacturing process probably resulting from reactions of $\mathrm{B}_{4} \mathrm{C}$ and graphite.

Graphite irradiations on the PSC program are directed toward obtaining extensive data on a conventional needle-coke graphite over the complete temperature range and up to the lifetime dose of the PSC reactor. Recent design modifications have reduced the temperature range to $550^{\circ}$ to $900^{\circ} \mathrm{C}$ (it was previously $600^{\circ}$ to $1200^{\circ} \mathrm{C}$ ). Both physical-property and dimensional changes will be measured. The results will also be analyzed theoretically to aid in extrapolating these results to other similar nuclear graphites.

Capsule P14. Capsule P14 was intended to be a 3- to 6-cycle high-fastflux experiment in ETR to evaluate effects of BISO structural parameters on radiation stability and to test bonded particle beds. 
The capsule began irradiation in ETR cycle 78 during January. Before full power was reached, a gas leak developed between the lead tube pressurization system and the capsule secondary containment. Safeguards permission was obtained to operate the experiment despite the leak by closing off the secondary containment and using the primary gas control system to control the temperature. Fuel temperatures at full reactor power (with helium in all control gas gaps) were $700^{\circ} \mathrm{C}$ in the $10 w-t e m p e r a t u r e ~ c e 11$ and $950^{\circ}$ to $1000^{\circ} \mathrm{C}$ in the four high-temperature cells (design temperatures are $1000^{\circ}$ and $1400^{\circ} \mathrm{C}$, respectively). Shortly afterwards, plugs developed in the inlet gas systems of three of the high-temperature cells, which prevented the addition of argon to bring the cells up to the design temperature. In addition, an erroneously high reading on a secondary thermocouple brazed to the outside of the fourth high-temperature cell caused ETR personnel to prohibit the addition of argon to this cell until the cause of the the mocouple malfunction could be explained.

The low-temperature cell operated satisfactorily and could be raised to the $1000^{\circ} \mathrm{C}$ design temperature. However, with the other four cells at only $1000^{\circ} \mathrm{C}$, there was no reason to raise the temperature of this cell unless the others could also be increased.

Efforts to unplug the blocked lines by blowing gas in both directions at high pressure were unsuccessful. After about three weeks of operation, leaks apparently developed in several of the primary cell gas systems. There are some indications that these leaks may be outside the capsule as well as inside the capsule. Because of these leaks and the inability to obtain design temperatures, the capsule was removed from the reactor and shipped to General Atomic for analysis of the flow blockage and leak problems.

The results of burnup analyses indicate that the maximum burnups P14 could achieve would be $13 \%$ and $4 \%$ FIMA (for fissile and fertile particles, respectively) in four cycles compared with the design burnups of $20 \%$ and $6 \%$, This change in predicted burnups is caused by a revision in the flux data supplied by ETR.

Based on the operating experience with the P14 capsule, several design changes are being incorporated into subsequent coated particle capsules. It is felt that these changes will contribute significantly to the reliability of future capsules.

Capsule P15. Capsule P15 will be a 3- to 6-cycle ETR test to evaluate the buffer layer of reference BISO coatings. The fast-flux exposure will be $3-6 \times 10^{21}$ nvt at a design fuel temperature of $1400^{\circ} \mathrm{C}$ and design burnups of $20 \%$ and $6 \%$ FIMA. The Th:U ratios in the fuel particles will be adjusted so that these burnups can be achieved. Fabrication of capsule components is proceeding.

HTGR Reference Fuel Tests. HTGR reference coated particles (BISO-coated fissile and fertile particles in a packed bed) are being tested in ORNL Loop $1-15$ at a maximum temperature of $1400^{\circ} \mathrm{C}$ to a burnup of $216 \%$ FIMA. A low-temperature $\left(600^{\circ} \mathrm{C}\right)$ appendage capsule containing a small quantity of both 
loose and pitch-bonded coated particles is also included. The axial thermal gradient reported last quarter is gradually diminishing. Estimated fuel burnups are now $10 \%$ and 1.8\% FIMA for the fissile and fertile particles, respectively. Fission-gas release rates (calculated from equilibrium fission-gas levels in the $100 \mathrm{p}$ coolant) have been in the $10^{-5}$ to $10^{-6} \mathrm{R} / \mathrm{B}$ range, with some indication of an increase toward the end of the period. All impurities in the sweep gas have remained low The irradiation was concluded late in the quarter.

Capsule Gl1. A series of capsule experiments has been planned to irradiate conventional needle-coke graphites in the temperature range $550^{\circ}$ to $1000^{\circ} \mathrm{C}$ to a maximum dose of about $9 \times 10^{21}$ nvt (fast). The first of these capsules is Capsule G11, which was designed to receive an exposure in the ETR of about onewthird that of PSC design.

Detalls of material selection were reported previously The capsule irradiation started about January 25, 1966, Several gas leaks developed within the capsule shortly after startup. These gas leaks are within the capsule proper and involve mixing of the inner containment inert gases (He, Ne, or Ar) with inert gases in the lead tube or outer gas control container. Therefore, these leaks do not appear to pose a threat to the samples. The sample temperatures in the capsule range from $610^{\circ}$ to $850^{\circ} \mathrm{C}$, which is within the new design range. Since the prime objective of temperature is being achieved, it is therefore planned to continue the irradiation experiment as scheduled.

\section{CHEMISTRY}

The objective of this subtask is to determine:

1. The release behavior of solid fission products which might be important plateout sources and gaseous fission products from the fuel particles being considered for use in the plant as a function of time, temperature, and irradiation by means of analysis and postirradiation annealing and In-TRIGA furnace tests on irradiated fuel particles to determine the effects of such variables as particle diameter, coating thickness, and coating structure. The particles used in these tests will be irradiated under other subtests of this program or will be obtained from other sources.

2. The sorption and diffusion behavior of solid fission products in graphites being considered for use in the plant as a function of temperature and concentration by means of analysis and out-ofreactor chemical experiments on giaphite samples doped with "fissium."

\section{Fission-product Release}

Work has continued on the release of metallic fission-product nuclides of cesium, strontium, cerium, and barium from coated fuel particles. The purpose of this work is to obtain information for use in evaluating the retention properties of coatings and calculating the release of metallic 
fission products from PSC fuel elements. The work may be divided into two categories: (1) postirradiation determination of the fraction of metallic fission products retained during in-pile radiation and (2) postirradiation annealing experiments, in which release values are determined for particles irradiated to high burnup.

Retention of Metallic Fission Products During In-pile Irradiation. Fission-product retention measurements of $\mathrm{Cs}^{137}, \mathrm{Sr}^{89}$, and $\mathrm{Ba}^{140}$ retained during in-pile irradiation have been carried out on several irradiated samples of BISO-coated particles. Calculations have been refined to take into account shutdown times during the irradiation test. The data given in $\mathrm{Table} 3.7$ are based on gamma spectrometry ( $\mathrm{Cs}^{137}, \mathrm{Ba}^{140}$ ) using the lithium-drifted germanium crystal detector and radiochemical analyses ( $\mathrm{Sr}{ }^{89}$ ),

Table 3.7

FISSION-PRODUCT RETENTION OF PARTICLES IRRADIATED AT $1400^{\circ}$ TO $1500^{\circ} \mathrm{C}$ FOR $688 \mathrm{HR}$

\begin{tabular}{c|c|c|c|c}
\hline & \multirow{2}{*}{$\begin{array}{c}\text { No. of } \\
\text { Coating }\end{array}$} & \multicolumn{3}{|c}{ Fractional Release } \\
\cline { 3 - 5 } & Particles & $\mathrm{Cs}^{137}$ & $\mathrm{Ba}^{140}$ & $\mathrm{Sr}^{89}$ \\
\hline BISO $\left(2200^{\circ} \mathrm{C}\right.$, & 5 & 0.87 & 0.53 & 0.51 \\
thickness $98 \mathrm{H}$ & 6 & 0.88 & 0.55 & 0.51 \\
$\rho=2.12 \mathrm{~g} / \mathrm{cm}$ & 6 & 0.84 & 0.51 & 0.50 \\
\hline BISO $\left(2100^{\circ} \mathrm{C}\right.$ & 6 & 0.88 & 0.59 & 0.59 \\
thickness $105 \mu$, & 5 & 0.79 & 0.43 & 0.40 \\
$\rho=1.99 \mathrm{~g} / \mathrm{cm}^{3}$ & 5 & 0.82 & 0.55 & 0.49 \\
\hline
\end{tabular}

Additional measurements of $\mathrm{Cs}^{137}, \mathrm{Sr}^{89}, \mathrm{Sr}^{90}$, and $\mathrm{Ba}^{140}$ retained during inpile irradiation have been carried out on several samples from a later test. Tentative data show retentions of approximately $96 \%$ for $\mathrm{Cs}^{137}, 60 \%$ for $\mathrm{Ba}^{140}$, and $40 \%$ for $\mathrm{Sr}^{90}$.

Further calculations are being made to evaluate the influence of $U^{233}$ fissions on these data. The high thorium concentration of these particles and their long irradiation times were sufficient to produce an appreciable quantity of $\mathrm{U}^{2} 33$.

Annealing Experiments on Fuel Particles Irradiated to a High Burnup. Postirradiation annealing release studies have continued on particles irradiated to about 4\% FIMA burnup in the same capsule. Fuel particles of the BISO (buffer isotropic) type coating of two different densities were studied.

Results from annealing a sample of 177- to 250- $\mu$ (Th,U) $\mathrm{C}_{2}$ particles with a $98-\mu$ thick BISO-2200 coating, $\rho=2.12 \mathrm{~g} / \mathrm{cm}^{3}$ at $1300 \pm 25^{\circ}, 1400 \pm 30^{\circ}$, and $1750^{\circ} \pm 50^{\circ} \mathrm{C}$, yield $\mathrm{Cs}^{137}$ release fractions that are lower by a factor of 5 to 10 than values obtained for fuel particles from two earlier tests (170 $\mu$ thick BISO coating, $\rho=1.8 \mathrm{~g} / \mathrm{cm}^{3}$, and $102-\mu$ thick BISO coating, $\rho=$ $\left.2.02 \mathrm{~g} / \mathrm{cm}^{3}\right)$. On the other hand, the $\mathrm{Ba}^{140}$ and $\mathrm{Ce}^{144}$ release fractions are comparable with those obtained previously with the earlier particles. 
The initial release rates (the amounts released during the first ten hours of annealing) for $\mathrm{Cs}^{137}, \mathrm{Ce}^{144}$, and $\mathrm{Ba}^{140}$ are plotted against reciprocal temperature in Fig. 3.10. From the slope of the curves drawn through the data the apparent activation energies of $58 \mathrm{kcal} / \mathrm{mole}$ for $\mathrm{Cs}^{137}$, $73 \mathrm{kcal} / \mathrm{mole}$ for $\mathrm{Ce}^{144}$, and $55 \mathrm{kcal} / \mathrm{mole}$ for $\mathrm{Ba}^{140}$ are obtained. The $\mathrm{Ba}^{140^{\circ}}$ data show a wide scatter; accordingly, the activation energy for barium release should be regarded as very tentative.

Postirradiation annealing runs were also carried out on a sample of 177- to $250-\mu$ ( $\mathrm{Th}, U) \mathrm{C}_{2}$ particles with a 98- $\mu$ BISO-2100 coating, $p=1.99$ $\mathrm{g} / \mathrm{cm}^{3}$. The $\mathrm{Cs}^{137}$ release values at $1300^{\circ}$ and $1750^{\circ} \mathrm{C}$ are as $10 \mathrm{w}$ as those of the particles with the BISO-2200, $\rho=2.12 \mathrm{~g} / \mathrm{cm}^{3}$ coatings (above); also, both types of pyrolytic carbon coated fuel particles from this capsule show a substantial improvement in $\mathrm{Cs}^{137}$ retention over the fuel particles from earlier tests. There doesn't appear to be a significant difference in $\mathrm{Ba}^{140}$ and $\mathrm{Ce} 140$ retention characteristics of the different coatings. Also the different densities of the coatings (2.12 and $1.99 \mathrm{~g} / \mathrm{cm}^{3}$ ) appear to make little difference in their metallic-fission-product release characteristics.

Noble Gas Release. The steady-state release of short-1ived fission gases ( $\mathrm{Kr}$ and $\mathrm{Xe}$ nuclides) from a sample of BISO PyC-coated ( $\mathrm{Th}, \mathrm{U}$ ) $\mathrm{C}_{2}$ fuel particles irradiated to $4 \%$ FIMA was studied over the temperature range from ambient $(\because \mathrm{R}$.T. $)$ to $1700^{\circ} \mathrm{C}$ 。

The TRIGA Ring furnace used in these studies is designed to operate in the core of the TRIGA Mark I reactor to take advantage of the constant thermal-neutron flux necessary for steady-state experiments.

Results obtained for the irradiated particles are shown in Table 3.8 . The release values are of the order of values found previousiy in steadystate release tests on unirradiated BISO-coated particles. The release values appear to increase slightly with temperature between $1500^{\circ}$ and $1700^{\circ} \mathrm{C}$; however, in general, the release values are independent of temperature, within experimental error.

The lack of temperature dependence of the release values indicates that recoil release predominates. This is presumed to be due to $\mathrm{U}^{2} 35$ contamination of the coatings. A diffusion-controlled release would be temperature dependent and also would be proportional to the square root of the half life of the fission-gas nuclides. Fuel particles with cracked coatings would tend to show this type of behavior because diffusion of the gases from the carbide kernel would be rate limiting.

Accordingly, it is concluded that no deterioration of the coatings occurred because of the irradiation.

\section{Sorption and Diffusion of Fission Products}

Vaporization of Metallic Fission Products from Graphite. Measurements are continuing on the vapor pressures of metallic fission products sorbed in TS -688 graphite. The purpose of this work is to obtain basic data for use in calculations to predict the release of metal nuclides from PSC fuel elements. 


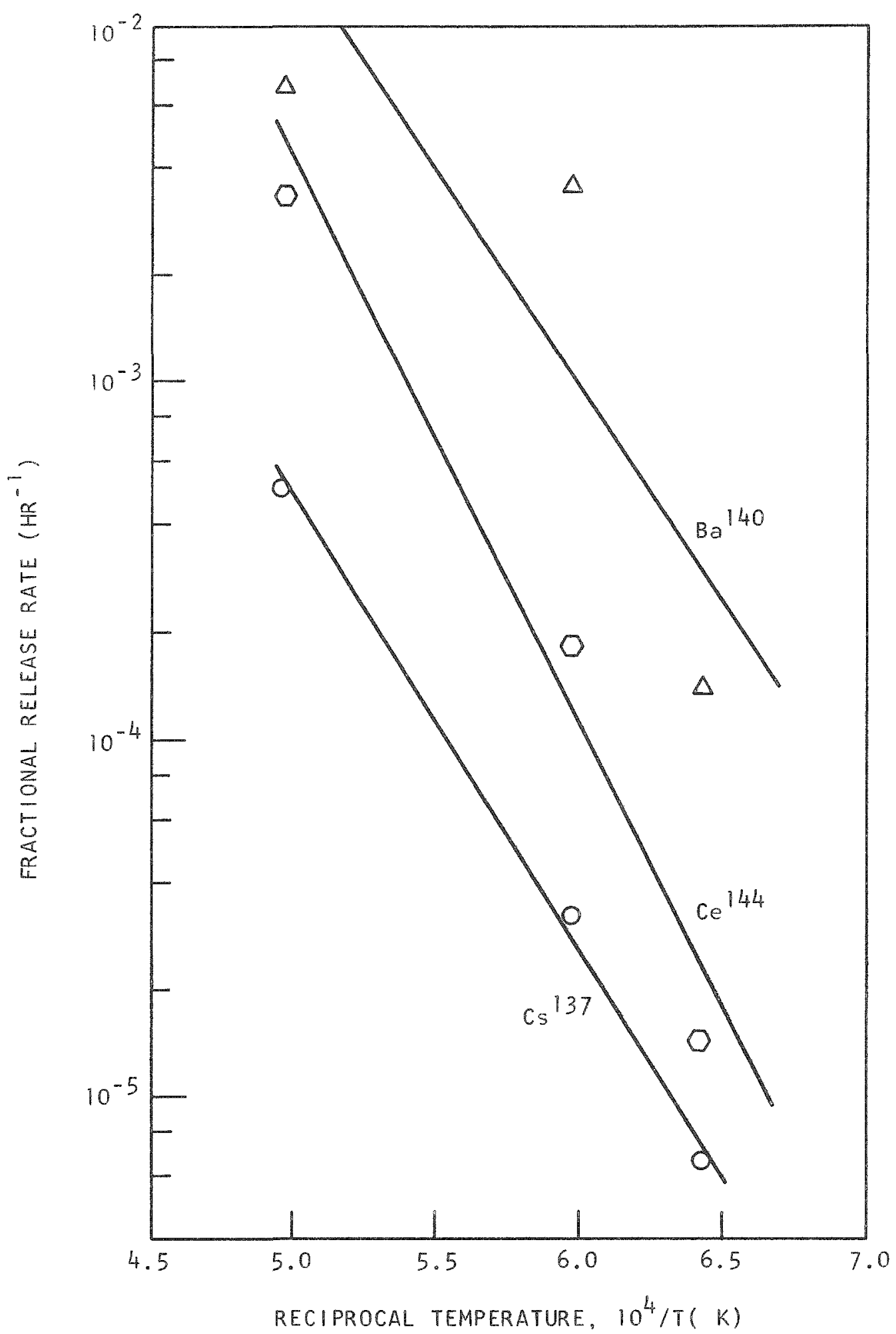

Fig. 3.10-Arrhenius plot of initial release rates of $\mathrm{Cs}^{137}$, $\mathrm{Ba}^{140}$, and $\mathrm{Ce}^{144}$ from coated fuel particles 
Table 3.8

STEADY-STATE FRACTIONAL RELEASE VALUES FOR IRRADIATED BISO-COATED $(\mathrm{Th}, \mathrm{U}) \mathrm{C}_{2}$ FUEL PARTICLES

\begin{tabular}{l|c|c|c|c|c|c}
\hline \multirow{2}{*}{$\begin{array}{c}\text { Temp } \\
\left(^{\circ} \mathrm{C}\right)\end{array}$} & $\begin{array}{c}\mathrm{Kr}^{85^{\mathrm{m}}} \\
(4.4 \mathrm{hr})\end{array}$ & $\begin{array}{c}\mathrm{Kr}^{88} \\
(2.8 \mathrm{hr})\end{array}$ & $\begin{array}{c}\mathrm{Kr}^{87} \\
(1.3 \mathrm{hr})\end{array}$ & $\begin{array}{c}\mathrm{Kr}^{89} \\
(0.053 \mathrm{hr})\end{array}$ & $\begin{array}{c}\mathrm{Xe}^{138} \\
(0.28 \mathrm{hr})\end{array}$ & $\begin{array}{c}\mathrm{Xe}^{139} \\
(0.011 \mathrm{hr})\end{array}$ \\
\hline $\mathrm{R} . \mathrm{T}$. & $9.4 \times 10^{-5}$ & $8.7 \times 10^{-5}$ & $8.4 \times 10^{-5}$ & $5.0 \times 10^{-5}$ & $5.6 \times 10^{-5}$ & $7.6 \times 10^{-6}$ \\
1100 & $2.6 \times 10^{-5}$ & $1.6 \times 10^{-5}$ & $9.9 \times 10^{-6}$ & $1.9 \times 10^{-5}$ & $2.4 \times 10^{-5}$ & $8.2 \times 10^{-6}$ \\
1300 & $7.6 \times 10^{-5}$ & $4.1 \times 10^{-5}$ & $4.6 \times 10^{-5}$ & $5.8 \times 10^{-5}$ & $6.2 \times 10^{-5}$ & $2.6 \times 10^{-5}$ \\
1500 & $7.0 \times 10^{-6}$ & $7.3 \times 10^{-6}$ & $8.7 \times 10^{-6}$ & $1.3 \times 10^{-5}$ & $1.1 \times 10^{-5}$ & $3.2 \times 10^{-6}$ \\
1700 & $1.3 \times 10^{-4}$ & $1.4 \times 10^{-4}$ & $1.3 \times 10^{-4}$ & $2.9 \times 10^{-5}$ & $2.5 \times 10^{-5}$ & $7.5 \times 10^{-6}$ \\
\hline
\end{tabular}

At present, studies of the strontium-TS-688 graphite system are being carried out using the mass spectrometric Knudsen-cell method. These measurements are comparable to vapor pressure measurements for barium sorbed on HLM-85 graphite, reported in GA-6830.

The present studies were made on a TS-688 graphite sample that was prepared by grinding up a representative portion of a graphite block. That it was representative was demonstrated by showing that the BET surface area from similar portions of the massive block were comparable.

The graphite sample (particle size range 37 to $74 \mu$ ) is impregnated with $\mathrm{Sr}\left(\mathrm{NO}_{3}\right)_{2}$ to the desired level by evaporating a mixture of the graphite and strontium nitrate solution to dryness. A portion of the loaded graphite is placed in a tantalum Knudsen cell, and in an inert atmosphere the cell is welded closed, except for the orifice. This cell is installed in the mass spectrometer and heated to convert the $\operatorname{Sr}\left(\mathrm{NO}_{3}\right)_{2}$ to sorbed strontium.

After the conversion process the cell is heated to a still higher temperature, until strontium vapor is effusing from the cell in appreciable quantities. This strontium beam is monitored by ionizing a portion of it in an ionization chamber and measuring the intensity of the strontium ion beam after mass analyzing. The intensity of the strontium beam is measured as a function of time and temperature. After the effusion process is halted, the strontium content of the remaining graphite is determined by activation analysis. This value is compared to the initial amount present. The difference is then related to the time-integrated ion signal from the mass spectrometer, and the ion signal is related to the strontium vapor pressure.

The data obtained is in the form of vapor pressure versus graphite loading at various temperatures. Reported barium data of this type have been interpreted in terms of a Freundlich adsorption isotherm; that is,

$$
\log P / P_{0}=(A+B / T) \log C / C_{0},
$$


where the empirically determined constants $P_{0}, C_{0}, A$, and $B$ can be determined from the data (see GA-6830).

In an orientation experiment, a great deal of material, which apparently was carbon, was transported to the inside cell surfaces. That is, at the end of the experiment the effusion orifice was, optically at least, closed. This effect, it was theorized, occurred because some portion of the material was not fully graphitized, and was thus considerably more volatile than graphite itself. For this reason, a prefired graphite was used in the next experiment. The prefiring treatment involved heating the graphite in a vacuum to over $2000^{\circ} \mathrm{C}$ for $30 \mathrm{~min}$. After this treatment, degassing of the graphite appeared to be minimal. A sample of this prefired graphite was then loaded with strontium nitrate, placed in the tantalum Knudsen cell, put in the mass spectrometer, and converted to $\mathrm{Sr}_{-\mathrm{C}}$; the effusion rates of strontium were then measured.

This experiment was deemed successful, in that a representation of strontium vaporization was obtained according to the Freundlich equation

$$
\log \mathrm{P} / 10^{4} .66=(0.079+4097 / \mathrm{T}) \log \mathrm{C} / 10^{3.75}
$$

where $\mathrm{P}$ is the strontium pressure in atm, $\mathrm{T}$ is the temperature in degrees Kelvin, and $C$ is the strontium concentration in $\mathrm{mg} \mathrm{Sr/g} C$. The graphite had a BET surface area of $5.87 \mathrm{~m}^{2} / \mathrm{g}$.

In the terms of the form of the Freundlich equation used in FREVAP calculation,

$$
\ln \mathrm{P}_{\mathrm{Sr}}=\left[\mathrm{a}+\mathrm{b} \cdot\left(\frac{10^{3}}{\mathrm{~T}}\right)\right]+\left[\mathrm{c}+\mathrm{d}\left(\frac{10^{3}}{\mathrm{~T}}\right)\right] \ln \mathrm{C}_{\mathrm{Sr}} \text {, }
$$

where $\mathrm{P}_{\mathrm{Sr}}$ is the equilibrium pressure of strontium (atm), $\mathrm{C}_{\mathrm{Sr}}$ is the concentration of strontium ( $\mu$ moles $/ \mathrm{m}^{2}$ BET area), $T$ is the absolute temperature $\left({ }^{\circ} \mathrm{K}\right)$, a is $10.00, \mathrm{~b}$ is -38.11 , c is 0.079 , and $\mathrm{d}$ is 4.097 (it should be noted that the corresponding constants for the $\mathrm{Sr}-$ HLM- 85 graphite system as previously determined were $a$ is $13.81, b$ is $-44.90, c$ is -1.42 , and $d$ is 6.73 ).

The pressure measurements were such that, when the $1800^{\circ} \mathrm{K}$ isotherm was displayed, the range of strontium pressures covered was nearly six orders of magnitude. In addition, a cell concentration range of essentially a factor of 300 was investigated. This is demonstrated in Fig. 3.11. The logarithms of the pressures can be fitted to a straight line when plotted against the logarithms of the concentrations. There is some variation of the data from this model, particularly the first and last points and some scatter, but, in general, the fit is quite reasonable. This then satisfies one requirement of the Freundlich adsorption isotherm.

The plot of the heat of vaporization of strontium (determined from log pressure versus reciprocal temperature plot) against the logarithm of the 


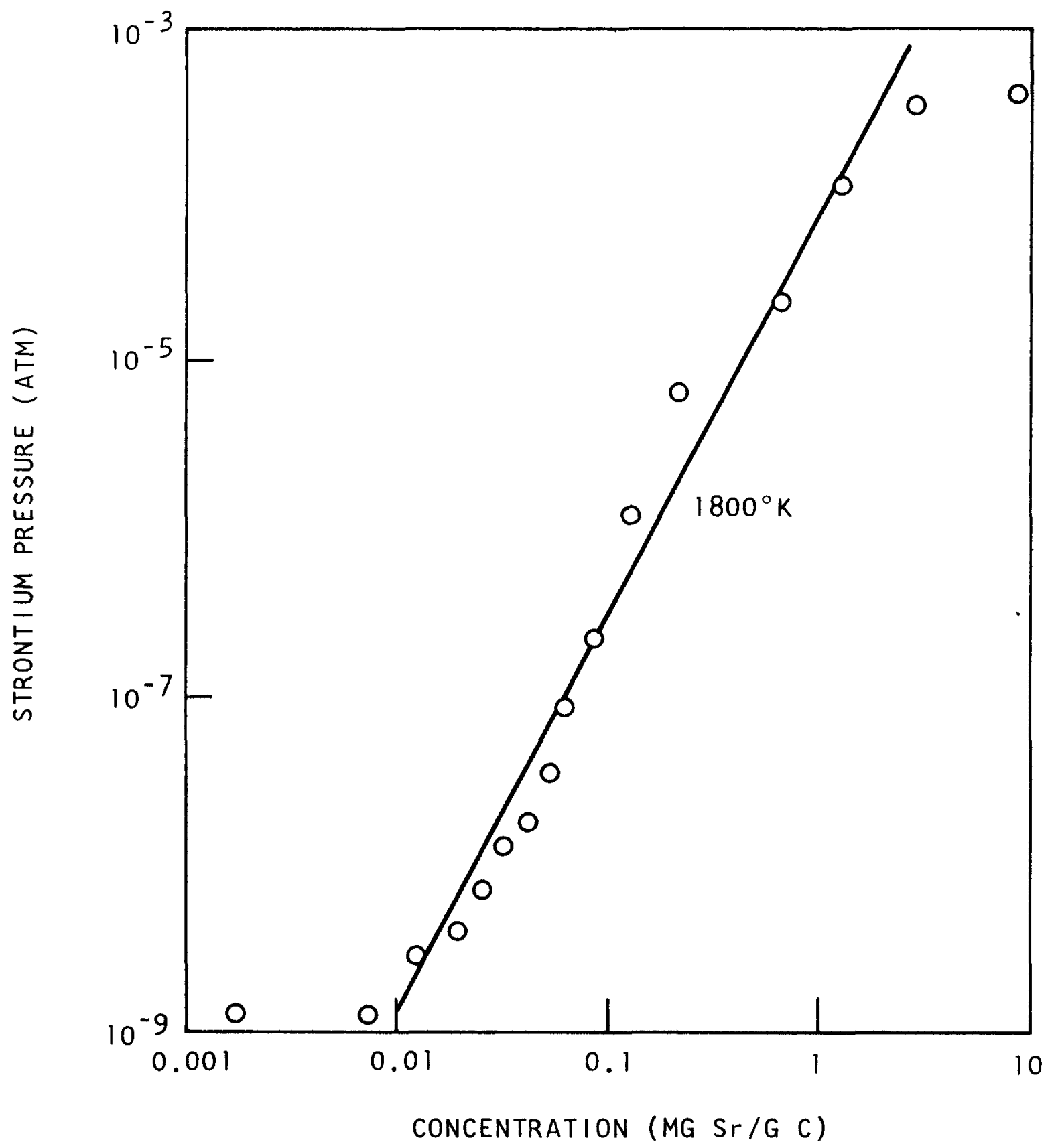

Fig. 3.11--Vapor pressure of strontium sorbed on TS-688 graphite at $1800^{\circ} \mathrm{K}$ versus loading 
concentration also could be reasonably fitted to a straight line, with the heat increasing as the logarithm of the concentration decreased. This is the other requirement of the Freundlich isotherm. Though there are also several early points and the one late point that do not fit well, the fit is generally quite satisfactory.

$\mathrm{R}$ 。 $\mathrm{H}$ 。 Flowers* has reported vapor pressure data for both $\mathrm{BaC}_{2}$ and $\mathrm{SrC}_{2}$. Using these data one can calculate the monolayer concentration on the basis of pressure; that is, one might assume that when the pressure of the metal carbide is obtained, the metal is present at a monolayer concentration. Also, one can calculate the monolayer concentration assuming that when the heat of vaporization is equivalent to that of the metal carbide the sample is loaded to a monolayer. One can also make a monolayer calculation on molecular size basis as a third method. Values for both $\mathrm{BaC}_{2}$ and $\mathrm{SrC}_{2}$ are calculated for each of these methods using Flowers' data as a reference and the values are given in Table 3.9 .

Table 3.9

MONOLAYER CONCENTRATION OF BARIUM AND STRONTIUM

\begin{tabular}{c|c|c|c}
\hline \multirow{2}{*}{ Element (M) } & \multicolumn{3}{|c}{ Monolayer Concentration $(\mathrm{mg} \mathrm{M} / \mathrm{g} \mathrm{C})$} \\
\cline { 2 - 4 } & Pressure & $\begin{array}{c}\text { Heat of } \\
\text { Vaporization }\end{array}$ & Geometry \\
\hline $\mathrm{Ba}$ & 21.0 & 5.5 & 11 \\
$\mathrm{Sr}$ & 4.2 & 7.3 & 7 \\
\hline
\end{tabular}

The geometry calculations were made assuming a $4.5-\AA$ diameter for barium (or $\mathrm{BaC}_{2}$ ?) and a 4.3- $\AA$ diameter for strontium. The agreement among these methods is striking, particularly for strontium.

Figure 3.12 shows the Freundlich isotherms for strontium sorbed on TS688 graphite. The irregularly shaped area indicates where the experimental data were obtained. The vapor pressures are similar in magnitude to vapor pressure values determined previously for strontium sorbed in HLM-85 graphite.

Sorption of Cesium and Rubidium on Graphite. Measurements using an isopiestic method are continuing on the sorption of cesium and rubidium on TS-688 graphite, including cosorption of cesium and rubidium (see the previous quarterly report for description of the experimental technique). The purpose of this work is to obtain data for use in calculations to predict the release of metal nuclides from PSC fuel elements.

The TS-688 graphite sample being used in this work was taken from a sample made up of cuttings taken from various locations on a large TS-688 graphite log. Surface area measurements indicate that the sample is representative of the bulk graphite. The anomalous behavior of the cesium isotherm reported in the previous quarterly report is not in evidence when

*R, H。 Flowers, AERE-R5011 


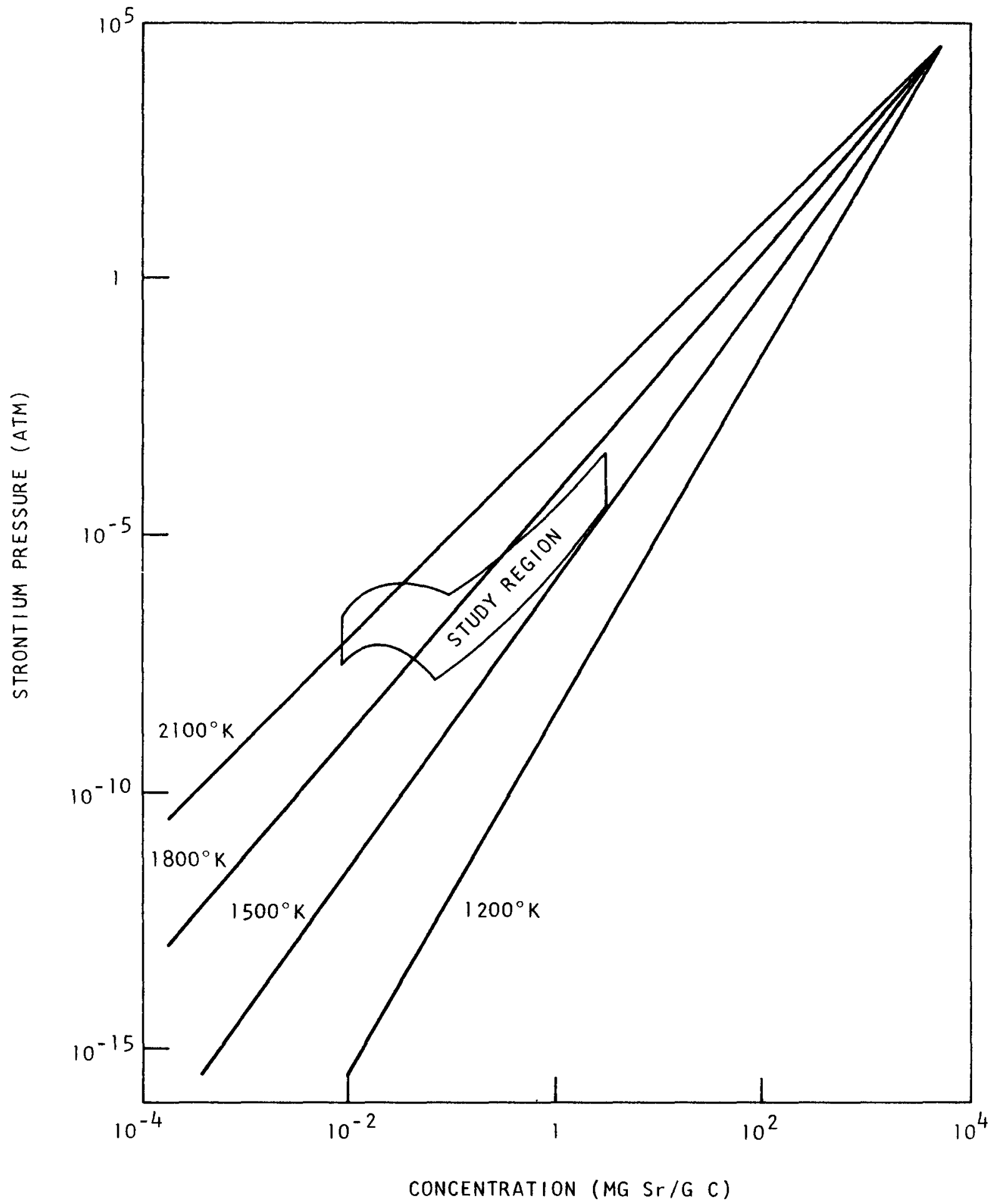

Fig。3.12--Freundlich isotherms for strontium sorbed on TS-688 graphite having a surface area of $5.87 \mathrm{~m}^{2} / \mathrm{g}$ 
measurements were made on the representative graphite sample. Figure 3.13 compares sorption isotherms at $900^{\circ} \mathrm{C}$ for various types of graphite and charcoa1. The TS -688 isotherm is located favorably in the predicted group relating to its method of manufacture.

Measurements of the sorption of cesium on TS -688 graphite have been completed. Cesium sorption isotherms have been obtained at $800^{\circ}, 900^{\circ}$, $1000^{\circ}$, and $1100^{\circ} \mathrm{C}$ over a cesium pressure range of $2 \times 10^{-8}$ to $10^{-4}$ atm. A Freundlich plot of the resulting isotherms is shown in Fig. 3.14. The apparent monomolecular layer coverage for cesium on TS-688 graphite is approximately $70 \%$ of that determined for HLM- 85 graphite. A comparison of the heats of sorption $(\Delta H) *$ on TS -688 and HLM-85 graphites is shown in Fig. 3.15 . The lower heat of sorption for cesium in TS-688 graphite at a given concentration is consistent with the lower cesium loadings observed at constant temperature and cesium pressure. Note that the straight-line plots indicate that in the case of each graphite the heat of sorption is proportional to the logarithm of cesium concentration (internal surface coverage). This is theoretically expected in the case of Freundlich isotherm behavior.t Since the lines are parallel, the same proportionality factor applies to each graphite.

Extrapolation of the heat curves to $\Delta \mathrm{H}_{\mathrm{s}}=0$ indicates the theoretical monomolecular layer coverage. These correspond to $10.7 \mu$ moles $\mathrm{Csm}^{2} \mathrm{HLM}-85$ graphite and $7.3 \mu$ moles $\mathrm{Cs} / \mathrm{m}^{2}$ HLM-85 graphite and $7.3 \mu$ moles $\mathrm{Cs} / \mathrm{m}^{2} \mathrm{TS}-688$ graphite. These values may be compared with the theoretical value of 5.94 umoles $/ \mathrm{m}^{2}$ graphite, assuming the area of the cesium atom to be $\sim 28 \AA . * \%$

The general equation for expressing the equilibrium pressure-compositiontemperature data for cesium on TS-688 graphite is given by

$$
\text { In } P(\mathrm{~atm})=\left[a+b\left(\frac{10^{3}}{\mathrm{~T}\left(\mathrm{O}_{\mathrm{K}}\right)}\right)\right]+\left[c+\mathrm{d}\left(\frac{10^{3}}{\mathrm{~T}\left(\mathrm{o}_{\mathrm{K}}\right)}\right)\right] \text { In } \mathrm{c}\left(\frac{\mathrm{\mu mole}}{\mathrm{m}^{2}}\right)
$$

where $a=26.6, b=-55.7, c=-14.5$, and $d=24.2$.

Rubidium sorption isotherms on TS -688 graphite have been obtained at $800^{\circ}, 900^{\circ}, 1000^{\circ}$, and $1100^{\circ} \mathrm{C}$ over a rubidium pressure range of $6 \times 10^{-8}$ to $10^{-4} \mathrm{~atm}$. A Freundlich plot of the resulting isotherms is shown in Fig. 3.16. These data appear to be lower by a factor of approximately 3 than rubidium sorption isotherms of HLM-85 graphite; however they show better conformance to the theoretical Freundich isotherm.

*As used here, heat of sorption is defined as the heat of vaporization for cesium sorbed in graphite minus the heat of vaporization of liquid cesium.

tD. O. Hayward and B. M.W. Trapne11, Chemisorption, 2d ed., Butterworths, Washington, 1964.

\% J. B. Taylor and I. Langmuir, "The Evaporation of Atoms, Ions, and Electrons from Cesium Films on Tungsten," Phys. Rev., Vo1. 44, 1933, p. 433. 


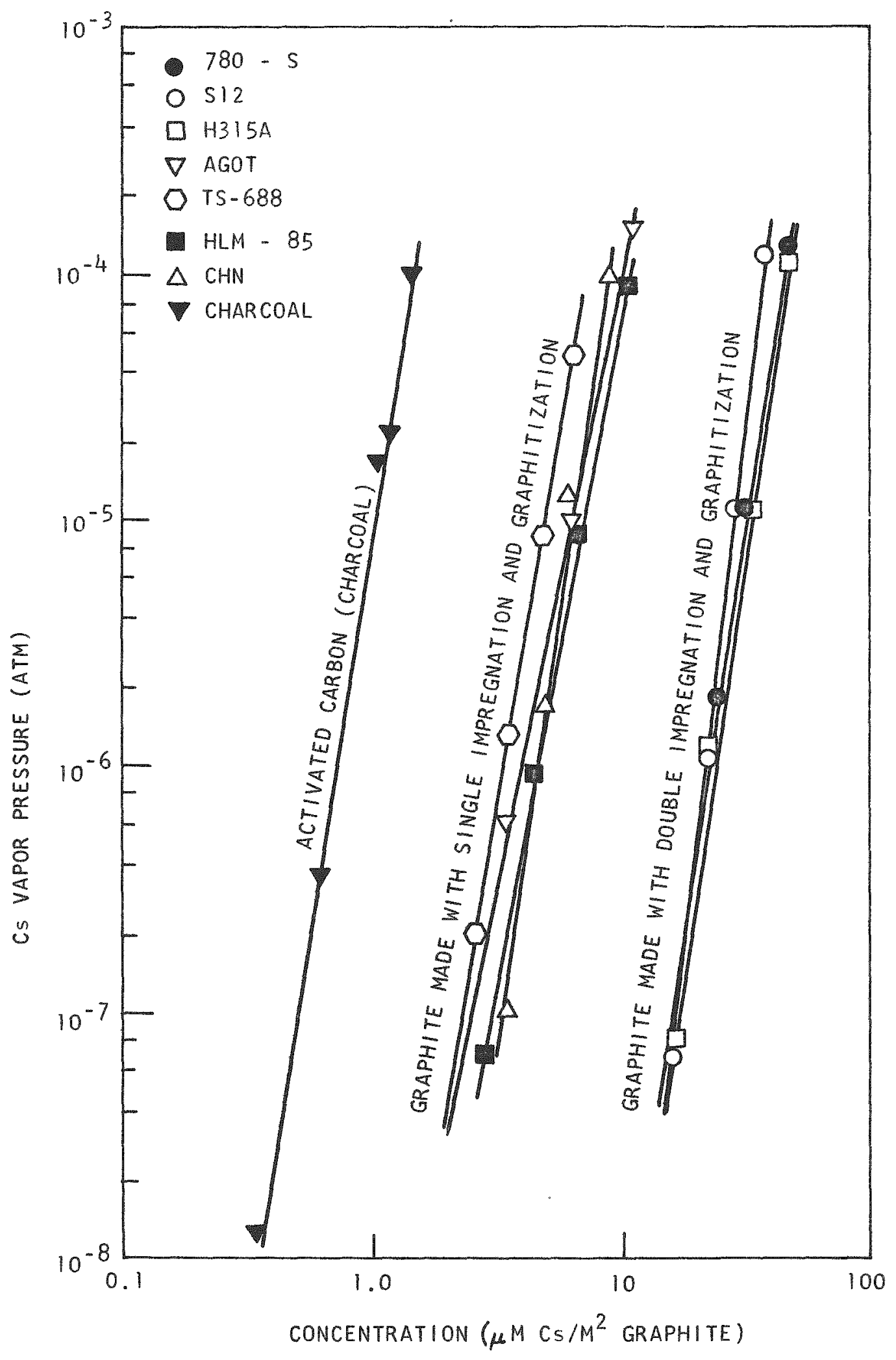

Fig. 3.13--Sorption of cesium on graphite and charcoal at $900^{\circ} \mathrm{C}$ 


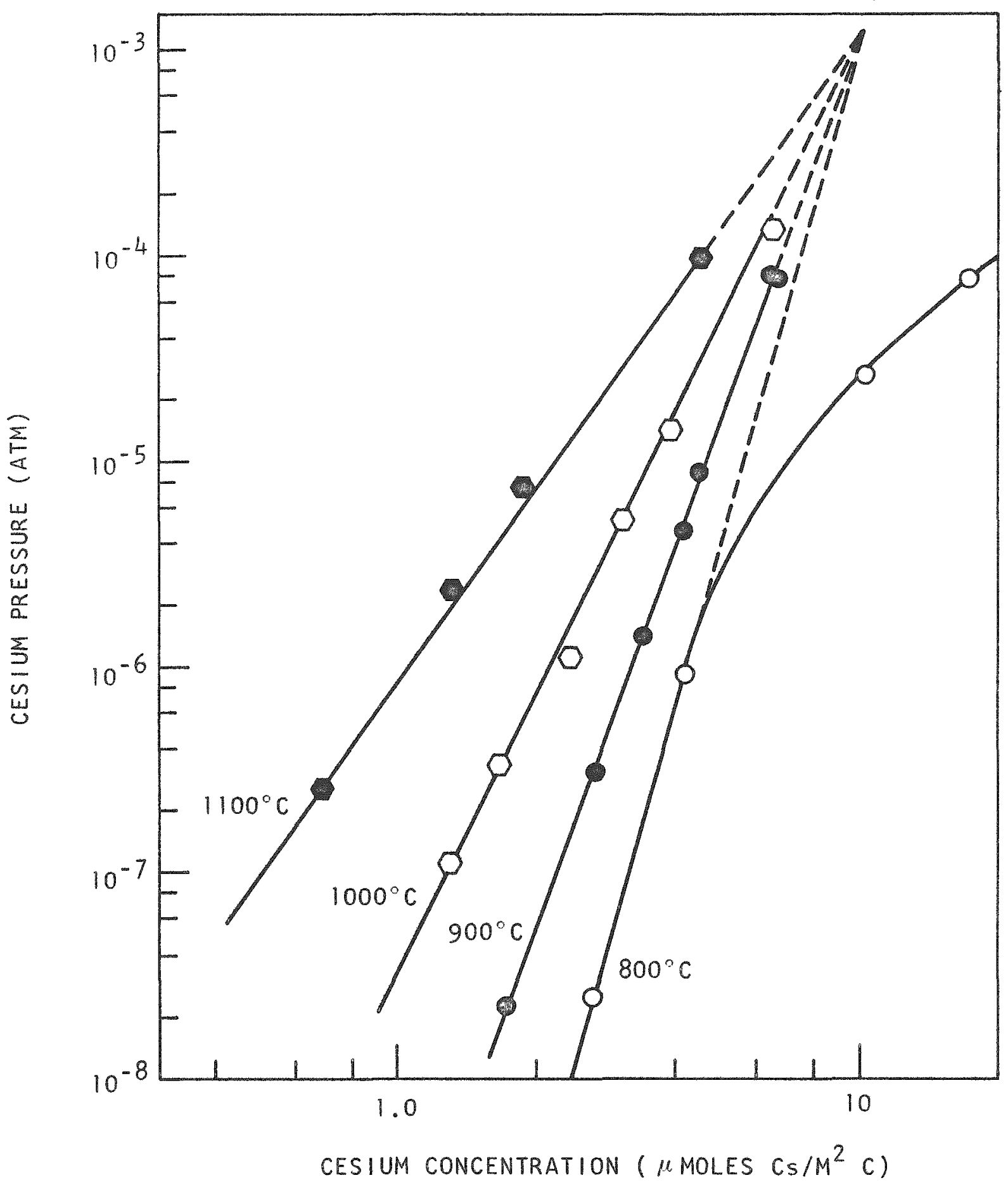

Fig. 3.14--Sorption of cesium on TS-688 graphite 


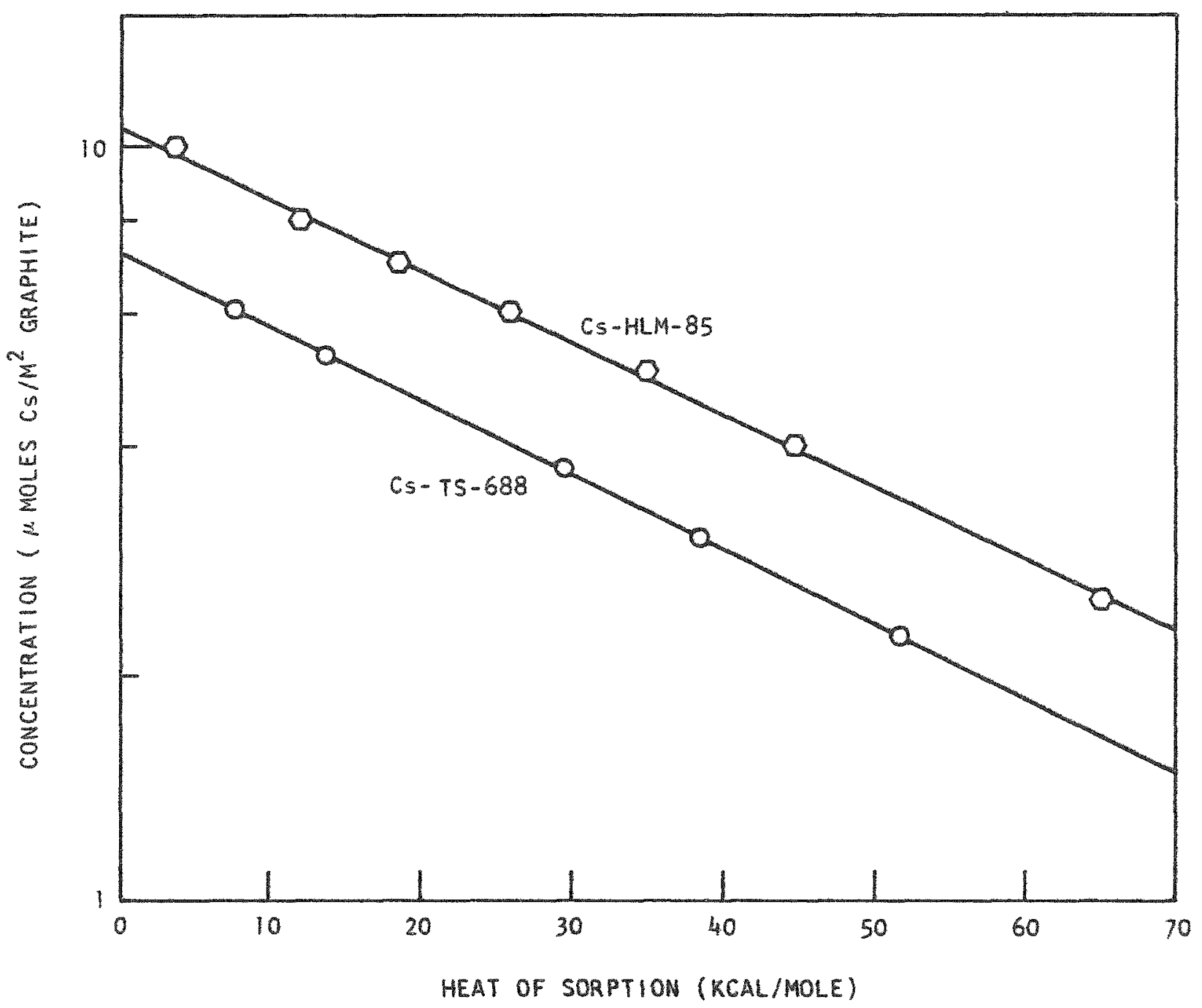

Fig. 3,15--Cesium concentration versus heat of sorption for the cesium - TS-688 and cesium - HLM-85 systems 
71

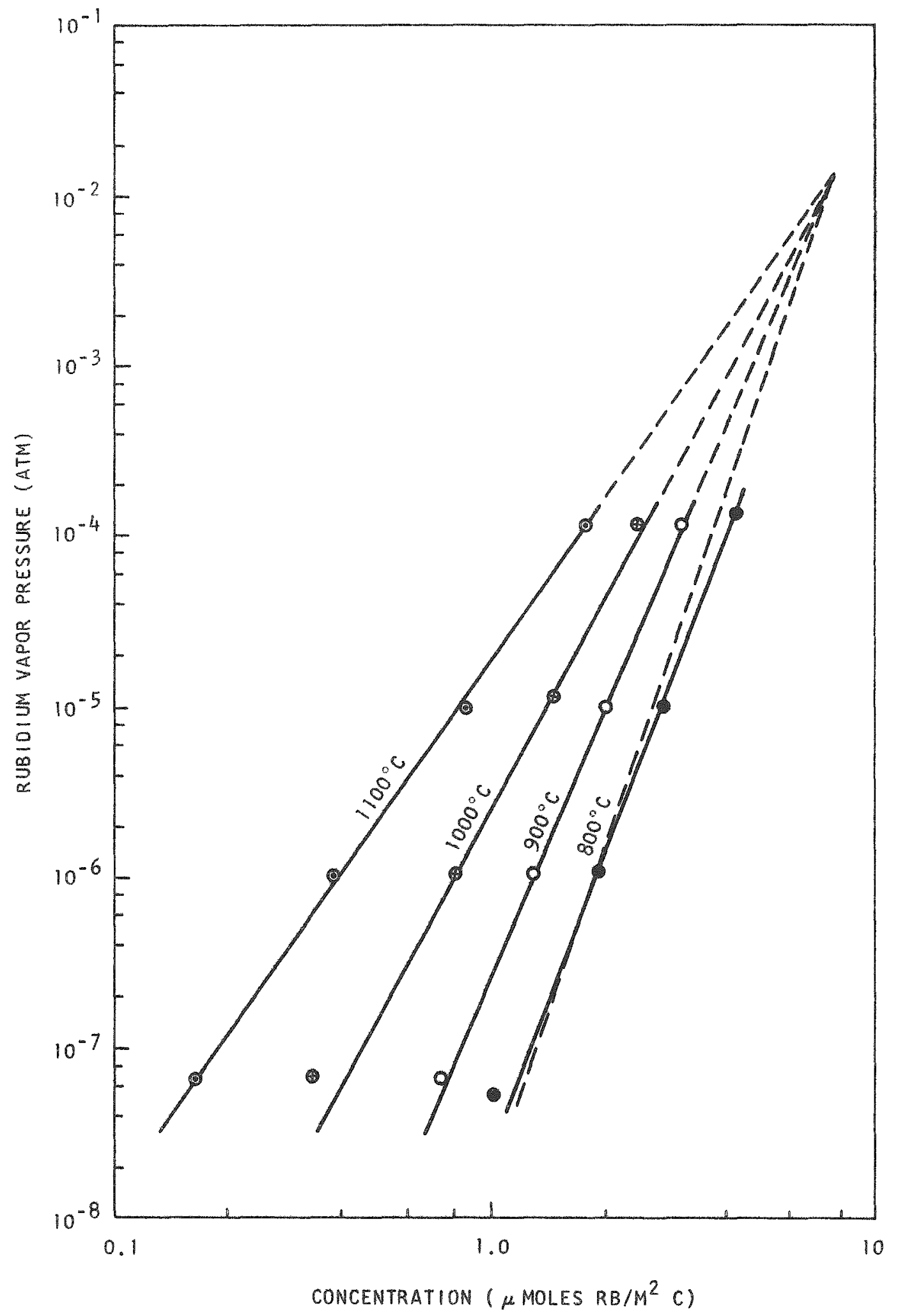

Fig. 3.16--Sorption of rubidium on TS-688 graphite 
These results may be interpreted by assuming that liquid rubidium is the adsorbed phase at the monlayer concentration. In this interpretation, the isosteric heat of adsorption is obtained by subtracting the heat of vaporization of liquid rubidium $(19.6 \mathrm{kcal} / \mathrm{mole})$ from the Clausius-Clapeyron heat of adsorption. Figure 3.17 shows a comparison of the heats of adsorption, $\Delta \mathrm{H}_{\mathrm{S}}$, (obtained by subtracting the heat of vaporization of sorbed in graphite) for rubidium on TS-688 graphite with values obtained for cesium on $\mathrm{TS}-688$ and HLM-85 graphite. Extrapolation to $\Delta \mathrm{H}_{\mathrm{S}}=0$ indicates a monolayer coverage of $4.4 \mu$ moles $\mathrm{Rb} / \mathrm{m}^{2}$ graphite, $1 / 2$ of the theoretical value. of 8.8 moles $\mathrm{Rb} / \mathrm{m}^{2}$ graphite, assuming the area of a rubidium atom is $19 \mathrm{~A}^{2}$.

The general equation for expressing the equilibrium pressure-compositiontemperature data for rubidium on TS -688 graphite is given by

$$
\ln P(a t m)=\left[a+b\left(\frac{10^{3}}{T\left({ }^{0} K\right)}\right)\right]+\left[c+d\left(\frac{10^{3}}{T\left({ }^{\circ} K\right)}\right)\right] \text { In } c\left(\frac{\mu \text { mole }}{m^{2}}\right),
$$

where $a=14.1, b=-34.1, c=-9.0$, and $d=16.8$.

Experimental work is also in progress to study the behavior of the cesium-rubidium-graphite TS-688 system. One run has been completed at $900^{\circ}$ and $1000^{\circ} \mathrm{C}$ using a cesium-rubidium metal source. In this run the source was prepared to yield approximately equal partial pressures of the metals, assuming the metals form an ideal (Raoult's law) solution. The results of this run indicate preferential sorption of cesium by the fact that the cesium loading is essentially unchanged from that observed in the cesiumgraphite system alone. The presence of the cesium, however, reduced the rubidium loading by a factor of about 2.5 .

Additional cosorption runs are being started with the mole fraction of the rubidium in the source adjusted to yield rubidium partial pressures of various multiples of the cesium pressure. In addition, a run is being made in which the cesium concentration is held constant and changes in rubidium concentration and partial pressure with temperature are observed.

Sorption of Strontium on Steel and Graphite Dust Particles. Measurements of the relative sorption of strontium on TS-688 graphite dust and Type 304 stainless steel are continuing. This work will be useful in predicting the distribution of fission-product strontium in the PSC reactor.

The transpiration type of experiment for measuring the plateout of strontium from a helium stream on Type 304 stainless steel, TS-688, and dust particles at $800^{\circ} \mathrm{C}$ was terminated after 93 days (the apparatus and procedure are described in GA-6830). Examination of the system indicated movement of strontium only $3 \mathrm{in.}$ downstream from the source with an average strontium vapor pressure of $4 \times 10^{-8}$ atm (determined from the loss of $\mathrm{Sr}$ from the source). The $1 / 2-$ in. OD stainless steel containment tube, held at $1050^{\circ} \mathrm{C}$ throughout the run, was cut into $1 / 2-i n$. lengths to determine the distribution of strontium along the tube. A sharp strontium gradient was detected, 


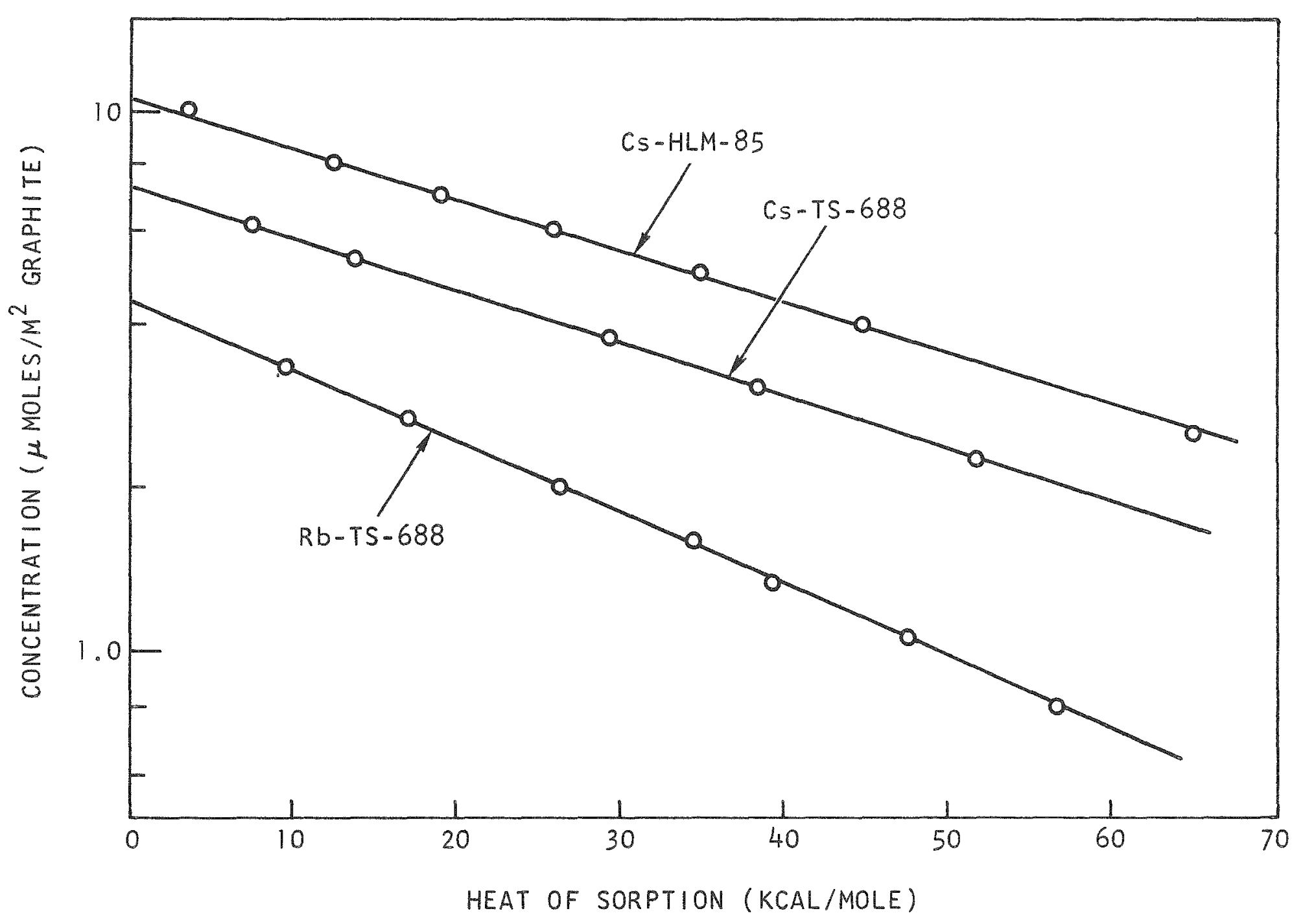

wै

Fig. 3.17--Heats of sorption for cesium and rubidium on HLM-85 and TS-688 graphites 
with an equivalent of 7000 monolayers on the steel tubing adjacent to the source and decreasing rapidly to 2.7 monolayers of strontium about 3-in. downstream (one monolayer $\mathrm{Sr} \simeq 0.10 \mu \mathrm{sr} / \mathrm{cm}^{2}$ surface area).

The high level of strontium plateout on apparently clean steel is rather surprising when compared to cesium plateout, which under comparable conditions is less than one monolayer The increased affinity for strontium over cesium is believed to be due to the stability of strontium oxide as compared to relatively unstable cesium oxides. This would also explain the inability of the strontium (or SrO) to be transported very far in a helium stream.

A further examination of the strontium-coated steel tubing revealed that $99.8 \%$ of the strontium could easily be removed with water. In addition, vacuum baking of a section of the tubing showed little removal of strontium at $800^{\circ}, 900^{\circ}, 1000^{\circ}$, and $1100^{\circ} \mathrm{C}$, illustrating the high stability of Sro.

A section of the tubing coated with 4000 monolayers of strontium was submitted for microprobe analysis to determine the extent of penetration of strontium into the steel. This analyis revealed that if there was any diffusion of strontium into the steel at all, it was less than 1 or $2 \mu$. $\mathrm{X}$-ray scanning pictures showed clearly that the strontium was present on the surface of the steel in a discontinuous coating 7-to 8- $\mu$ thick, raising the possibility of a combination of the strontium with one of the alloying constituents in the steel. This combination was disproved by examination of the coating for $\mathrm{Sr}-\mathrm{Fe}, \mathrm{Sr}-\mathrm{Cr}, \mathrm{Sr}-\mathrm{Ni}$, and $\mathrm{Sr}-\mathrm{Mn}$.

The conclusions drawn from this run indicate that the strontium probably was deposited on the steel as sro resulting from the combination of oxygen present in the helium stream and/or on the surface of the steel. Although the helium was gettered with zirconium at $1000^{\circ} \mathrm{C}$, an oxygen pressure of $>5 \times 10^{-8}$ atm is certainly a possibility. Oxygen on the surface of the stainless steel (as oxides of the constituents) very likely reacted with the Sr vapor. In general, the high heat of formation of Sro favors the reaction

$$
\operatorname{Sr}(g)+\frac{1}{y_{x}}{ }_{y} \rightarrow S r O+\frac{x}{y} \text {. }
$$

Oxygen may also have come to the surface by diffusion from the interior of the steel.

The relative sorption of strontium on steel and graphite is also being investigated using a Knudsen-cell technique. A preliminary experiment at $1000^{\circ} \mathrm{C}$ has been completed. In the experiment a sample of Type 304 stainless steel foil and a sample of TS -688 graphite powder (37- to 74- $\mu$ particle size of BET surface area $5.9 \mathrm{~m}^{2} / \mathrm{g}$ ) impregnated with strontium, tagged with $64-\mathrm{d}$ $\mathrm{Sr}^{85}$, were arranged in a tantalum Knudsen cell so that they were not in direct contact. The samples were allowed to equilibrate for about $20 \mathrm{hr}$ at $1000 \pm 50^{\circ} \mathrm{C}$ under vacuum. The vapor pressure was measured to be about $10^{-6}$ atm. At the end of the experiment, the cell and its contents were counted to determine relative concentrations. The concentration of strontium found 
on the stainless steel foil was $7 \mu \mathrm{g} \mathrm{sr} / \mathrm{cm}^{2}$ (based on the geometric area of the steel). This is equivalent to about 70 monolayers of strontium. The final strontium concentration in the graphite powder was found to be 0.078 $\mu \mathrm{g} \mathrm{Sr} / \mathrm{cm}^{2}$ (based on the BET surface area of the graphite). The distribution of strontium in the Knudsen cell was indicated to be $58 \%$ on the graphite, $6 \%$ on the stee 1 , and $36 \%$ on the tantalum cell.

Additional plateout measurements are in progress at $800^{\circ} \mathrm{C}$ using the knudsen cell technique. Several stainless steel Knudsen cells containing TS-688 graphite powder, loaded to $25 \mathrm{mg} \mathrm{Sr} / \mathrm{gC}$, and Type 304 stainless steel foll specimens are annealed simultaneously with periodic removal for strontium vapor pressure measurements and gamma counting of the steel specimens and graphite. It is hoped that equilibrium strontium plateout data can be obtained by this method in a relatively short time.

In order to correlate the sorption (plateout) of metallic fission products such as cesium and strontium on steel surfaces, it is highly desirable to know the oxide film thickness of the surface. Electropositive elements, such as cesium and strontium, should tend to react with the film as long as oxygen is present in the film and as long as the vapor pressure of the metal is above the equilibrium pressure of the metal over the resultant oxide. Thus, one might expect that the capacity of a steel surface to sorb these elements from the gas phase will be directly related to the oxide film thickness. Using an activation technique, further attempts are being made to determine the amount of oxygen present on the surface of stainless steel for use in correlating fission-product plateout data. This technique employs gamma irradiation ( $~ 25 \mathrm{Mev}$ ) of steel samples in the General Atomic Linear Accelerator, which results in the production of $2.2-\min 015$. The oxide film is rapidly stripped from the specimen by etching, and the etch solution is beta-counted as $0^{15}$ to determine the amount of surface oxygen on the steel.

The initial activation attempt was unsuccessful because of the high background resulting from excessive removal of the steel surface by the etch solution, although a 5-sec dip was used. A plot of the data yielded a curve that could not be resolved into components. Future runs will require a milder etch solution to avoid the removal of interfering metal ions.

Fission-product Diffusion Studies. In order to understand the factors that determine the retention of metallic fission products by PyC-coated fuel particles contained in graphite fuel elements and to make reasonably precise estimates of the release of these activities into the coolant stream, the two studies are being carried out.

The first study involves a determination of the diffusion coefficients of metallic-fission-product elements in well-characterized pyrolytic carbons that are essentially identical with carbons deposited on fuel particles. The effect of the variables temperature and concentration will be ascertained and correlation made with pyrolytic carbon structural parameters. The data will be used to obtain theoretical release rate coefficients that can be compared with empirical values. This comparison and a resolution of any differences that may be indicated should contribute substantially to the ability to understand and predict fission-product release from PyC-coated particles. 
The second involves determining diffusion coefficients and heats of transport related to the transport coefficients $\left(L_{h 1}\right.$ and $L_{h 2}$ ), which give the flow of a fission-product species (element) h in fuel element graphite in accordance with the Onsager equation *

$$
J_{h}=-I_{h 1} \operatorname{grad}\left(\frac{\mu_{h}}{T}\right)+L_{h 2} \operatorname{grad}\left(\frac{1}{T}\right)
$$

where $\quad J_{h}=$ the current of chemical element $\mathrm{h}\left(\mathrm{moles} / \mathrm{cm}^{2}-\mathrm{sec}\right)$ flowing through the graphite,

$I_{h 1}, I_{h 2}=$ transport coefficients that are functions of the temperature and of concentrations of the various chemical elements present in the graphite,

$\mu_{h}=$ chemical potential of $h$, a function of temperature and the concentrations ( $\mathrm{kcal} / \mathrm{mole}$ ), and

$\mathrm{T}=$ absolute temperature $\left({ }^{\circ} \mathrm{K}\right)$.

Diffusion of Metallic Fission Products in Pyrolytic Carbon. The diffusion of SR85-tagged strontium into an isotropic, PyC coating has been measured over the temperature range $1100^{\circ}$ to $1400^{\circ} \mathrm{C}$. The coatings used had been deposited on graphite wafers (5/16 in. diameter by $1 / 16$ in. thick) by the same techniques used to coat fuel particles.

For the diffusion anneal the samples were packed firmly into a bed of graphite powder on which $S r^{85}$ had been deposited. A constant (chemical) potential source comprising about $1 \times 10^{-4} \mathrm{~g} \mathrm{Sr} / \mathrm{g} \mathrm{C}$ is believed to have been attained by this arrangement.

The samples were annealed in screw-top tantalum containers in a helium atmosphere. After the anneal, sections were successively ground from the samples and the concentration of strontium was determined in each section. The data obtained were plotted as log concentration (activity per unit thickness removed) versus depth of penetration (thickness removed) and analyzed on the basis that Fick's law applies to the diffusion process. A typical concentration profile is shown in Fig. 3.18. The solid line gives the theoretical (Fick's law) concentration profile corresponding to $D=8.9 \times$ $10^{-10} \mathrm{~cm}^{2} / \mathrm{sec}$.

From an Arrhenius plot of diffusion coefficient versus reciprocal temperature the following equation for the diffusion coefficient was obtained:

$$
D=3.65 \times 10^{-2} \exp (-47,300 / R T)
$$

*K. C. Denbigh, The Thermodynamics of the Steady State, Methuen and Co., Ltd., London, 1958. 


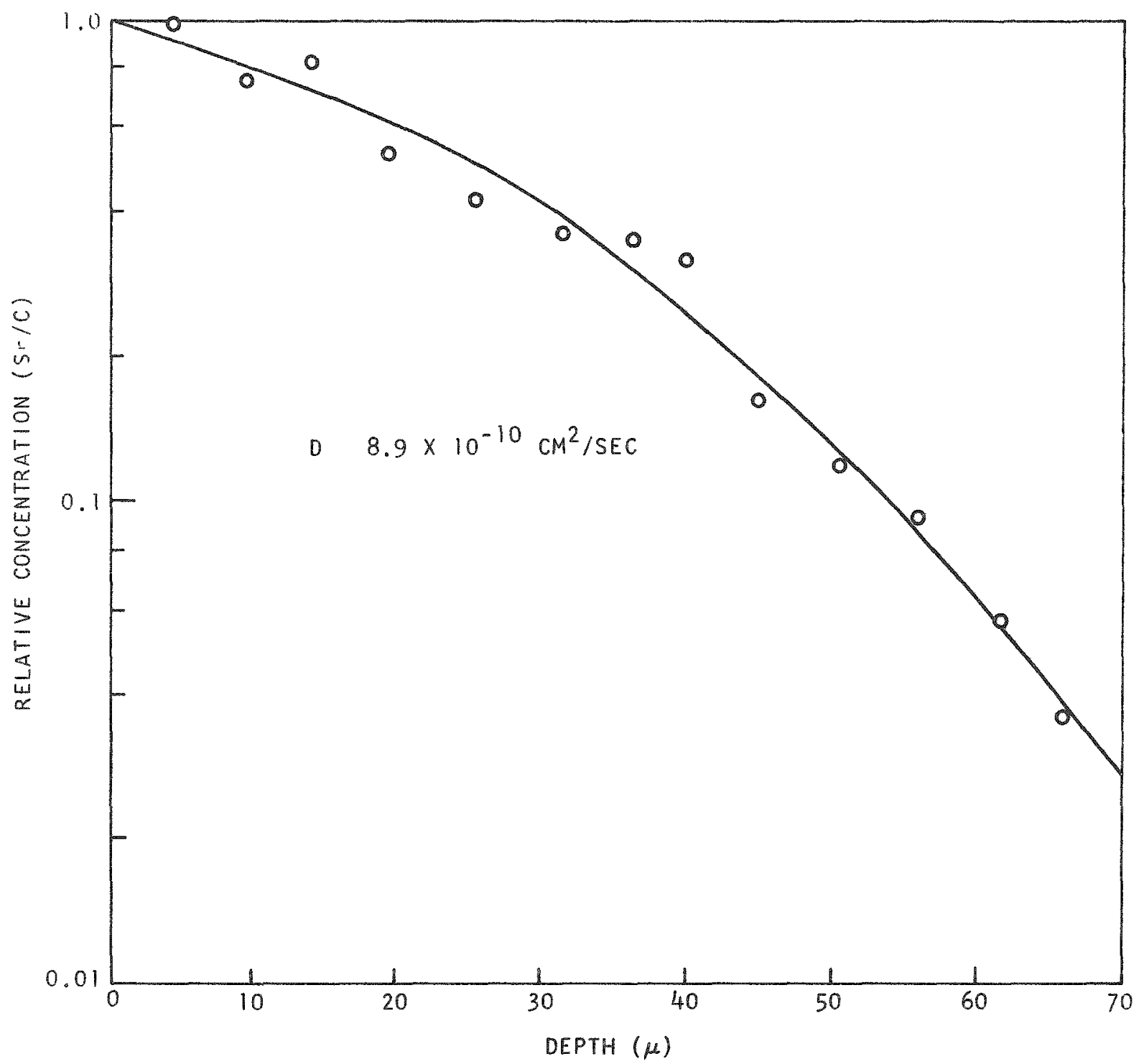

Fig. 3.18--Diffusion of strontium in isotropic pyrolytic carbon during a 2-hr anneal at $1100^{\circ} \mathrm{C}$ 
Using the same technique as for strontium diffusion, with the exception that the tantalum containers are welded closed to prevent the volatile cesium from escaping, several experiments have been performed with $\mathrm{Cs}^{137}$ tagged cesium. The annealing times proved to be insufficient to penetrate the carbon coatings. Since the time-temperature combinations were those that were adequate for $\mathrm{Sr}^{85}$ penetration, the general conclusion can be drawn that cesium diffuses (or dissolves) much less readily than strontium does in isotropic pyrolytic carbon.

Diffusion of Metallic Fission Products in Graphite. Two experiments were set up to determine the tracer diffusion coefficient for barium in TS-688 graphite where sleeves were preloaded with $\mathrm{Ba}^{13}$-tagged barium. The sleeve in the first experiment had a diffusion front profile and the sleeve in the second had a flat profile. The compacts were dismantled and carrierfree $\mathrm{Ba} 140$ was added to the compacts. The compacts were annealed at $1200^{\circ} \mathrm{C}$ until the $\mathrm{Ba}^{140}$ came out.

The first experiment has run $228 \mathrm{hr}$ at $1000^{\circ} \mathrm{C}$. Figure 3.19 shows a coring after $138 \mathrm{hr}$. The $\mathrm{Ba}^{133}$ front has continued to move and remains in front of the $\mathrm{Ba}^{140}$ front. The diffusion coefficient for $\mathrm{Ba}^{140}-\mathrm{La}^{140}$ has been calculated at $D \simeq 2.9 \times 10^{-9} \mathrm{~cm}^{2} / \mathrm{sec}$. This experiment is continuing.

The sleeve in the second experiment showed a flat profile of $\mathrm{Ba}^{133}$ in contrast to a frontal profile exhibited by the other. Because of the number of corings taken at the peak activity point, this sleeve broke before the $\mathrm{Ba} 140$ diffused out of the compact. Another sleeve with a flat $\mathrm{Ba} 33$ profile was loaded with the same compact. This sleeve has run a total of $100 \mathrm{hr}$ and is now being cored. This experiment is continuing.

A Soret (thermal diffusion) experiment of barium in TS-688 graphite has been initiated so that the distribution of fission-product barium in a graphite body (such as a PSC fuel element) having a significant temperature gradient may be estimated. This essentially involves determining the heat of transport of barium when it undergoes transport in graphite in a thermal gradient. The data obtained from this type of experiment provide necessary mathematical input for computer analysis of fission-product transport in fuel elements.

The experiment consists in part of a graphite rod approximately $2-1 / 2$ in. long by $3 / 8 \mathrm{in}$. diameter impregnated with $\mathrm{Ba}^{13}$-tagged barium as the nitrate. The impregnated rod will be heated to $600^{\circ} \mathrm{C}$ in helium to convert the nitrate to the oxide. The rod will then be encapsulated in a molybdenum cylinder and heated at a uniform temperature of $1300^{\circ} \mathrm{C}$ for a period of time sufficient to allow the barium or strontium to convert to the elemental form and diffuse uniformly throughout the graphite rod. The rod will then be repositioned in the heater tube of a small King furnace so that the temperature is about $1000^{\circ} \mathrm{C}$ at one end and $1300^{\circ} \mathrm{C}$ at the other. The rod will be periodically removed and scanned for $\mathrm{Ba}^{133}$ gamma activity through a $1 / 10$-in. slit. When the system has reached equilibrium, the rod will be removed and cored both axially and radially in order to establish the exact concentration gradient. 


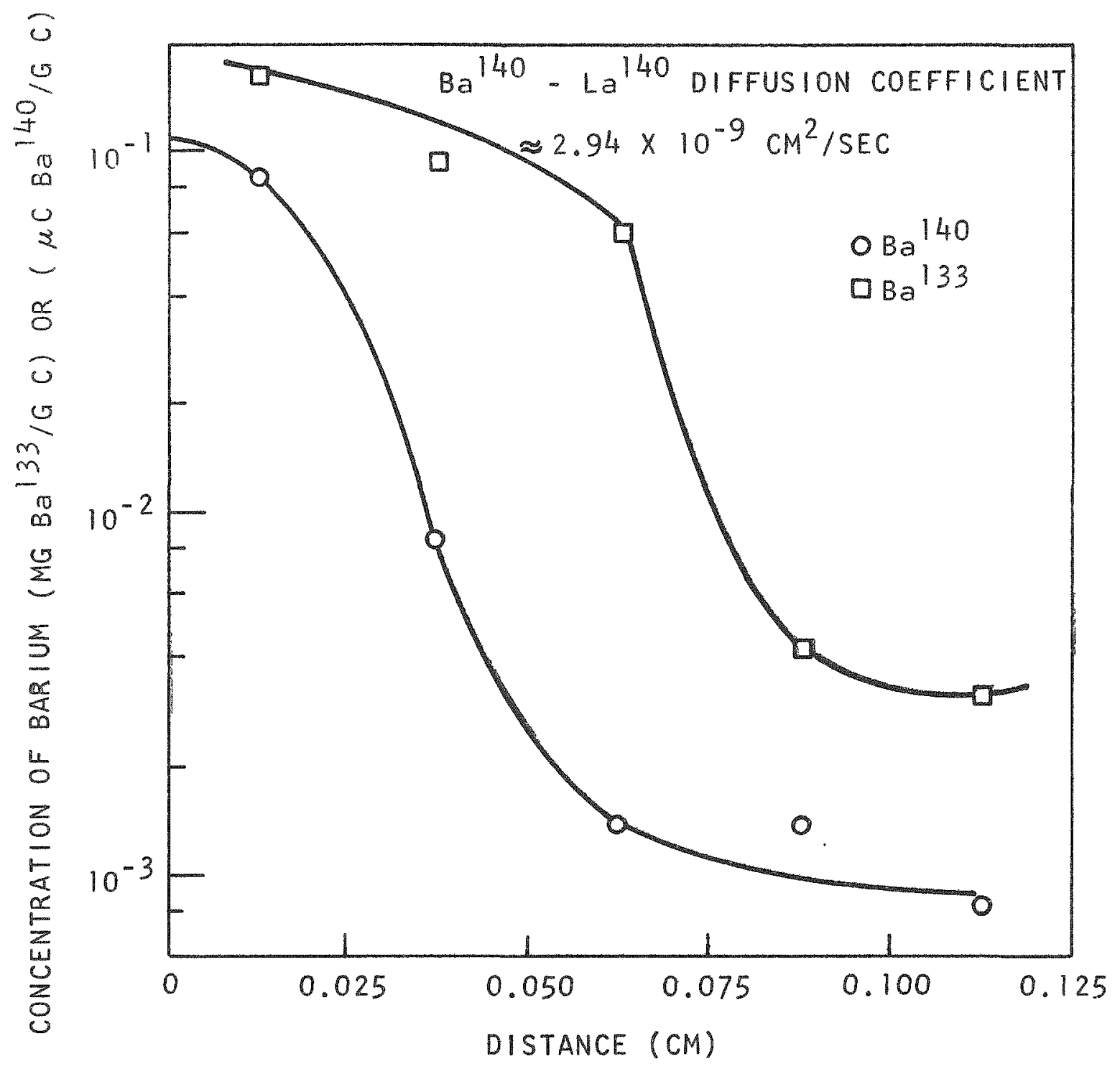

Fig。 3.19--Barium concentration profiles from sleeve coring $\left(1000^{\circ} \mathrm{C}\right.$, run time $138 \mathrm{hr}$ ) 
Mathematical Treatment of Metallic Fission-product Release from HTGR Fue1. The FREVAP-3 code has been revised so that it includes the option of a segment-by-segment calculation of the zeta factor (ratio of partial pressure of a given fission-product element in the coolant to its equilibrium pressure at the graphite boundary of the coolant channel).

The program has also been coded so that particles with different release characteristics can be considered. This has been applied to calculations where a certain percent of the fuel particles were assumed to be broken (in this case it was assumed in $R_{0}=0$ and $E_{a}=0$ )。

Work has begun on another modification that will permit more than one sorption region (such as activated carbon as well as graphite) to be considered.

\section{HELIUM PURIFICATION SYSTEM}

The objectives of this subtask are:

1. To determine operating conditions of the plant's low-temperature adsorption train as a function of bed size and temperature, coadsorbate interference, regeneration techniques, aerosol removal, and adsorption bed materials, by means of laboratory-type experiments.

2. To predict the extent of carbon transport and deposition in the plant's primary coolant system by means of analysis and out-ofreactor laboratory scale testing under the influence of variables such as temperature, materials, coolant gaseous impurities, and "fissium" concentration.

3. To determine the method of cleaning and protecting the steel components of the plant coolant system prior to startup, by reviewing available methods and testing selected candidates to verify their adequacy.

4. To develop processes for decontamination of the plant components to facilitate maintenance by means of analysis and testing of representative material on samples which have been exposed in a simulated plant environment.

5. To establish the suitability, reliability, and maintainability of the helium purification process for the plant for steady-state and transient operation by means of conceptual design and analysis utilizing data from other parts of the program and/or other sources.

6. To develop criteria for the final design of components naking up the helium purification system. 
Low-temperature Adsorption Studies

A high-pressure helium loop apparatus has been used for the study of equilibrium adsorption of tritium and hydrogen on activated carbon and molecular sieves at $-196^{\circ} \mathrm{C}$. After thoroughly purifying the adsorbent, usually by purging with clean helium at $300^{\circ}$ to $400^{\circ} \mathrm{F}$ for 2 to 3 days, a known volume of adsorbate is added to the system. The process gas is circulated through the 1iquid-nitrogen-cooled adsorbent trap until equilibrium sorbate pressure is attained. The sorbed phase concentration is determined by subtracting the amount of tritiun or hydrogen in the gas phase at equilibrium from the amount added originally. The gas-phase tritium levels are continuously monitored by an in-1ine lonization chamber to determine the attainment of equilibrium.

Adsorption isotherms for tritium and tritium plus hydrogen at liquidnitrogen temperature $\left(-196^{\circ} \mathrm{C}\right)$ are shown in $\mathrm{Fig} .3 .20$. The adsorbents tested are activated carbon, Type $B C-107,6$ to 10 mesh, and molecular sieve material, Type $5 \mathrm{~A}, 1 / 16$ in. pellets.

The results in Fig. 3.20 show that Type $5 \mathrm{~A}$ molecular sieve material possesses an adsorption capacity for tritium and hydrogen that is about twice as high as that of carbon.

The results of the present experiments using pure tritium as the adsorbate, or as a tracer for hydrogen, are in very good agreement with a hydrogen isotherm previously determined on activated carbon using a gas chromatographic technique.

Experiments using Type $4 \mathrm{~A}$ molecular sieve as the adsorbent are presently in progress.

\section{High-temperature Adsorption Studies}

Initial tests are under way in the helium-1oop system for studies of the dynamic behavior of fission products and carbon aerosols in a hightemperature activated carbon bed. The system is so designed that conditions of temperature, purge gas velocity, and helium pressure expected in the PSC high-temperature plateout trap can be simulated.

Tests presently planned for the high-temperature plateout trap (HITPOT) apparatus are:

1. Movement of in situ generated carbon aerosols through an activated carbon bed using $\mathrm{Ba}^{13}$-tagged carbon.

2. Movement through an activated carbon bed of tagged carbon dust injected from an external source.

3. Determination of iodine plateout profiles in an activated carbon bed using low lodine vapor pressures of an Il31-tagged source.

4. Determination of lodine plateout profiles in a cesium-impregnated activated carbon bed using low iodine vapor pressures of an Il31. tagged source. 


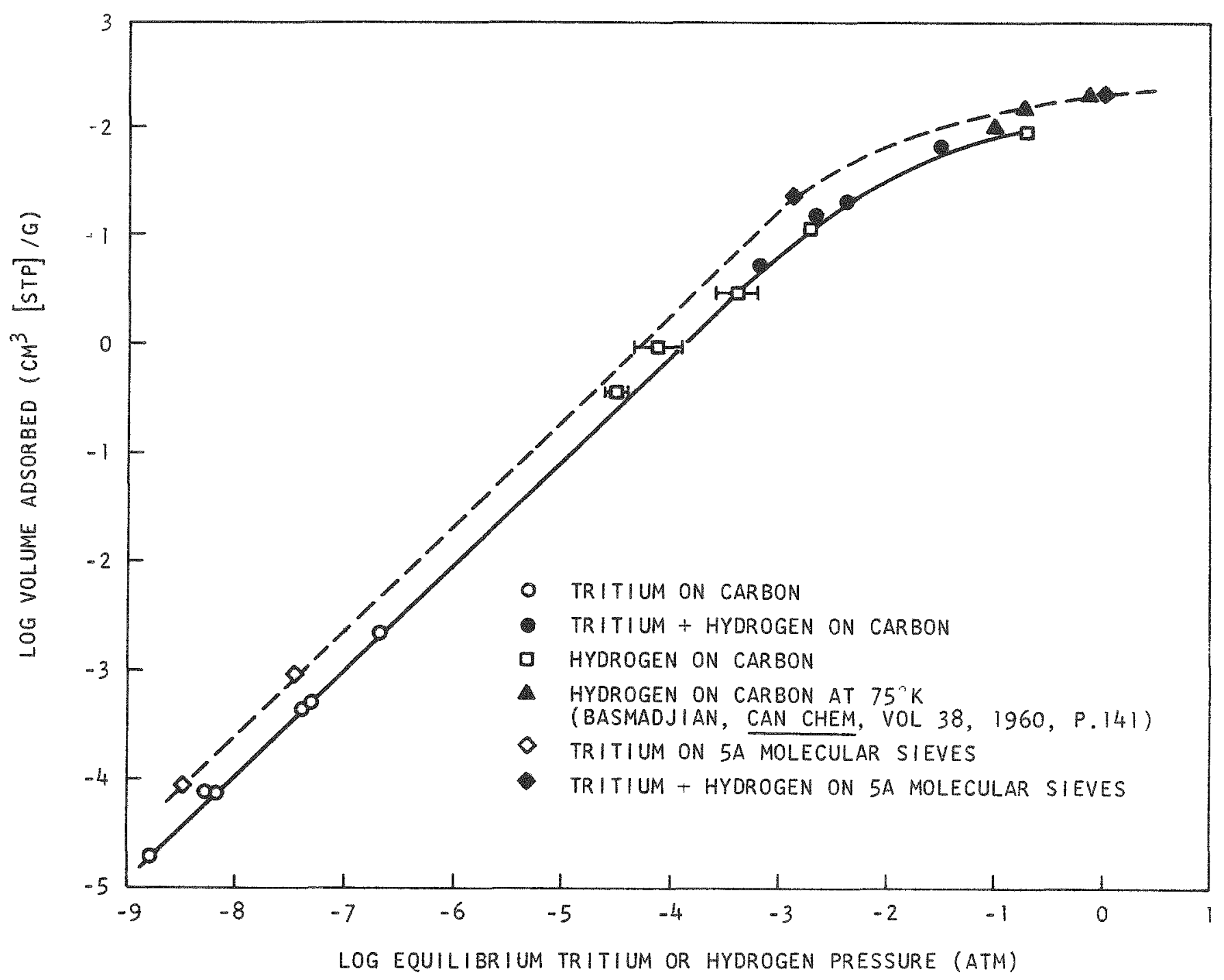

Fig. 3.20--lydrogen-tritium adsorption isotherms at $77^{\circ} \mathrm{K}$ 
The initial experiment is expected to determine the amount of in situ generated carbon dust (aerosols) transported through a carbon bed. Fissionproduct-laden dust may be generated in Situ in the PSC plateout trap by abrasion due to vibration and gas flow.

A small amount $(0.446 \mathrm{~g})$ of activated carbon (6 to 10 mesh) was tagged with 1 to $2 \mathrm{mC}$ of $\mathrm{Ba}^{133}$ activity by adding a nitrate solution of the activity to the activated carbon and allowing the solution to evaporate. The dry barium-activated carbon mixture was then placed in a closed graphite crucible and heated to $1000^{\circ} \mathrm{C}$ under vacuum for three days. This operation reduces the barium to the metal that is uniformly distributed during the heating throughout the activated carbon. After the heating operation, the tagged carbon was checked for uniform specific activity.

The steel furnace tube was inverted and filled to a depth of $3 \mathrm{~cm}$ with $5.7 \mathrm{~g}$ of activated carbon ( 6 to 10 mesh). This was followed by the $\mathrm{Ba}^{13} 3_{-}$ tagged carbon, which was loaded through a heavy-wall plastic tube inserted all the way to the previously loaded carbon. Thus, the tagged carbon was not allowed to come in contact with the walls of the furnace tube. After the tagged carbon was loaded into the tube, the plastic loading tube was carefully removed and checked for contamination, but none was detected.

The tagged carbon was followed by $185.9 \mathrm{~g}$ of activated carbon (6 to 10 mesh), which is held in place by a tack-welded support screen. The end cap was then screwed on and seal-welded. The tube was thereafter held in an upright position.

Before placing the tube in the loop system a Bal33 activity distribution scan was taken. This initial scan showed an unexpected profile that is assumed to be caused by fines associated with the tagged carbon having sifted down through the bed during the capping operations.

The test trap was then placed in the 1oop and the system pressurized to 575 psia with helium, Initially cleaned up using a liquid-nitrogen-cooled charcoal trap. After nine days of operation at $800^{\circ} \mathrm{F}$ with a flow rate of 52 std $1 / \mathrm{min}$, the test trap was valved off and removed from the system. Another activity profile scan was taken, with the results being virtually identical to those of the initial scan. A millipore filter downstream from the test trap was also removed at this time and was found to contain a very small amount of activity equivalent to less than $0.13 \mu g$ or less than $3 \times 10^{-\%} \%$ of the tagged carbon.

The test trap was then returned to the loop for continued operation. It will again be examined after about one month of continuous operation.

\section{Helium Purification System}

Consideration is being given to testing the full-size ltems of the helium purification system before they are shipped to the plant site for installation. This would permit testing not only the adsorption characteristics of the purification system, but also operating characteristics such as system pressure drop and the freezeout capacity of the low-temperature gas-to-gas exchanger for water vapor and $\mathrm{CO}_{2}$ 。 


\section{Carbon Deposition Studies}

An apparatus for use in a study of long-term reaction rates for carbon deposition on reactor metals of interest is essentially complete.

The experiment is designed to measure the rate of the reactions

$$
\begin{array}{r}
2 \mathrm{CO}=\mathrm{CO}_{2}+\mathrm{C}, \\
\mathrm{H}_{2}+\mathrm{CO}=\mathrm{H}_{2} \mathrm{O}+\mathrm{C},
\end{array}
$$

in the temperature range $450^{\circ}$ to $650^{\circ} \mathrm{C}$ for 3 metals (Type 316 stainless steel, Incoloy 800 , and $2-1 / 4 \mathrm{Cr}-1 \mathrm{Mo}$ ) and for two impurity concentration levels.

The test specimens will be loosely coiled 1-in. strips of 0.005 in. foil. This configuration will present the maximum surface area for reaction, thereby facilitating reaction rate measurements by gas analysis for $\mathrm{CO}_{2}$ and $\mathrm{H}_{2} \mathrm{O}$, as well as by weight change. The two gas impurity levels to be used are $1000 \mathrm{ppm}$ and $200 \mathrm{ppm}$ of both $\mathrm{CO}$ and $\mathrm{H}_{2}$ at $1 \mathrm{~atm}$ total pressure. The gas, which is premixed in cylinders, is passed through a hot carbon furnace and drying columns to ensure that all oxidizing impurities ( $\mathrm{CO}_{2}$, $\mathrm{H}_{2} \mathrm{O}$, and $\mathrm{O}_{2}$ ) are reduced to negligible levels (i.e., less than $1 \mathrm{ppm}$ ). ${ }^{2}$ The $\mathrm{CO}$ and $\mathrm{H}_{2}$ concentrations chosen for the tests correspond to 22- and 4.4-ppm impurity at the reactor pressure of $46 \mathrm{~atm}$. It is hoped that this experiment, along with other data, will determine the following:

1. The reaction order (concentration dependence) of the carbon deposition reaction.

2. The concentration dependence of the "incubation period."

3. The reaction rates for different alloys.

4. The temperature of maximum reaction rate for each alloy.

In addition, experiments are presently under way using the Cahn electromicrobalance. This apparatus is used for shorter term tests (in general using higher gas concentrations) and will be subjected to more drastic changes in experimental parameters. Some areas of interest that are to be explored are:

1. The effect of high hydrogen impurity levels ( $1 \%$ to $10 \%$ ) on the carbon deposition reaction rate.

2. The effect of varying the $\mathrm{H}_{2} / \mathrm{H}_{2} \mathrm{O}$ ratio.

3. The effect of surface pretreatment on carbon deposition.

4. The effect of metal plateout, such as $\mathrm{Cs}$ and $\mathrm{Ba}$. 
PART II

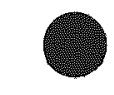


TASK I

FUEL TRANSFER MACHINE

The objective of this task is to establish the suitability and maintainability of the fuel transfer machine for use in the plant by means of testing (probably in air) of a full-scale prototype of the fuel transfer machine with a segment of a dummy core, and by carrying out tests in helium at the temperature and chemical impurity level expected in the plant of critical-service bearings used in the machine and other critical-service components as necessary.

\section{DESIGN}

A review was made of the criteria that govern the transfer machine design. It became apparent that a clear 19-in. bore would not be available in the fuel handling nozzle and that even if a transfer machine concept were based on the use of telescoping sections driven with ball screws, it might be severely prejudiced for lack of space. An alternative design was developed sufficiently to permit evaluation.

A detailed review is being made to determine the feasibility of concepts for a refueling machine capable of working within the 18.814-in. nominal pipe bore of the reference nozzle. It appears that an accurate temporary liner will be required during refueling. Although some attention is being given to mechanical details, it is intended that each component mechanism will be further evaluated and optimized as the design develops, within the general limitations of the bore and liner.

A development study of the fuel transfer machine head is in progress in order to determine the minimum possible working height, optimum grapple suspension, and sensor actuation for a machine meeting the reference design criteria.

A preliminary evaluation of the weight of the transfer machine for the purposes of establishing the requirements for a test facility was made.

A study to evaluate chain versus cable drives and the feasibility of pneumatic versus electric power sources was started late in the report period.

A fuel element shock load test showed the concept of an eccentric lifting ledge in the transfer machine pickup head to be inadequate. An alternative reversed-collet grapple that had previously been developed to fully utilize the available lifting ledge was adopted as the reference design, and tests involving it are scheduled. A design requirement to minimize the shock loading has been imposed on new pickup head development, and it is 
expected that these two approaches will restore adequate safety margins without resorting to significant fuel element changes.

\section{FUEL TRANSFER MACHINE TESTS}

Life testing of dry-film lubricants continued throughout the quarter with an evaluation of $D F-700$. This is a proprietary product of Marlin Rockwell Corp. It is a molybdenum sulfide base lubricant that has small quantities of graphite as an additive, and utilizes sodium silicate as the binding agent. The established testing conditions are as follows:

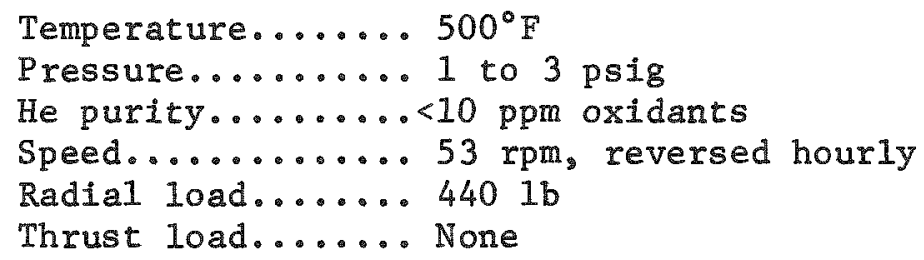

At the end of $600 \mathrm{hr}$ of testing under the above conditions, bearing number 6 , lubricated with $D F-700$, was exanined, and it was verified that only a slight change in radial play had occurred. Testing was resumed up to the first $1000 \mathrm{hr}$, but no significant torque increase was reached.

Testing has now been resumed with an identical bearing and lubricant for the purposes of comparison with the: original results. 
TASK II

SERIES-STEAM-TURBINE-DRIVEN CIRCULATOR

The objective of this task is to establish the suitability and maintainability and predicted reliability of the main helium circulators and steam turbine drives for use in the plant by means of analysis, component tests, and prototype testing (or, if the prototype is less than full scale, full-scale production unit testing) under conditions of temperature and speed expected in the plant and up to approximately $50 \%$ of design horsepower. Compressor blade and rotor vibration measurements will be made during these tests. The duration of the prototype or full-scale production unit testing will be approximately $200 \mathrm{hr}$.

The helium circulator development program has been modified to eliminate the separate rotor and aerodynamic tests. The objectives of these tests will be accomplished at the prototype test facility to be located at the Valmont Station of PSC. A rotor test will be performed at this facility, using the same components as in the prototype test。

The PSC plant reference design has been revised to include six main helium circulators. Four circulators would normally be in operation (two in each loop), while the remaining two circulators are held on standby. Each main circulator is equipped with an auxiliary drive to eliminate the requirement for auxiliary circulators.

At present, preliminary design and aerodynamic design of the new circulator have been completed, and a preliminary design of the prototype test facility has been prepared Mechanical Technology, Inc., has been selected to assist General Atomic with the design and analysis on the bearings and rotór system.

The present status of the circulator and test facility designs is described below.

\section{CIRCULATOR DESIGN}

The reference design for the series-steam-turbine-driven helium circulator is a single-stage axial-flow compressor driven by a single-stage steam turbine in series with the main turbine generator. In addition, each circulator will have a water turbine as an auxiliary drive. The auxiliary drive, which will be used if steam is unavailable for the main drive, will be capable of driving the circulator to $112 \%$ of design speed at atmospheric pressure, and to some fraction of design speed (about 25\%) at high pressure. Four machines are being designed to provide the flow required for the 330-Mw(e) PSC plant at a discharge pressure of 675 psia and a pressure rise of 14 psi. 
The rotating speed is $9550 \mathrm{rpm}$, and the tip diameter of the compressor rotor is $27.6 \mathrm{in}$. The aerodynamic design is based on the same parameters as was the previous design. The maximum continuous operating condition is set at a speed $12 \%$ above the design value. The development propram will determine the possibility of additional pressure rise capability, and thus the degree of conservatism of the aerodynamic loading parameter used in the design.

Water-lubricated bearings will be used and will be of the hybrid type (i.e., hydrostatic bearings with a high degree of hydrodynamic capability). These bearings will be capable of operating hydrodynamically at speeds in excess of $75 \%$ of the design speed. Both the journal and thrust bearings will be of the shrouded step pocket type. The thrust bearing will be mounted in a spherical seat to allow for misalimnent; this seat is hydrostatically lubricated at all times. The hydrostatic supply is provided from the pressure developed in the thrust bearing pocket when the thrust bearing is operating hydrodynamically.

Two seal concepts will be pursued: in one there will be a water-gas interface outboard of the compressor-side journal bearing, whereas in the other concept each of the bearings will discharge its lubricant flow into a scavenge chamber, so that the water-gas interface is outboard of the turbine side journal bearing. In both of these concepts, two shutdown seals will be used, one on each side and outboard of the journal bearings.

The circulators will require a water system for lubricant supply consisting of a pump and supply tank, pressurized to the reactor pressure level, and a water-helium separating system for separating the water-gas scavenged mixture. The water supply system for auxiliary drive turbine operation will consist of a motor-driven pump and supply tank, pressurized by gas to reactor operating pressure. The possibilities of combining the water supplies for both lubrication and auxiliary turbine operation and for using one water system to supply more than one circulator are being examined.

\section{AERODYNAMIC ANALYSIS}

The pertinent data on the aerodynamic design are given in Tables II.1 and II.2, for the compressor and steam turbine, respectively.

It is anticipated that the feasibility of higher aerodynamic loading parameters will be determined in the development program. For this reason, alternative compressor designs are being pursued in which the aerodynamic loading parameter (the diffusion factor) will be increased by $10 \%$ and $20 \%$. Although these higher values have been used and have heen found acceptable, the plant design has not been predicated upon them because they are not yet used in commercial practice; these values will, however, be evaluated as part of the development program to determine their suitability in this application.

PERFORMANCE

The operating characteristics of the circulator in the primary coolant system are shown on Fig. II.1 for the normal operating conditions. The 
Table II.1

HELIUM CIRCUIATOR DFSIGN SUMMARY

Dimensions:

Outer dlametex............................... in.

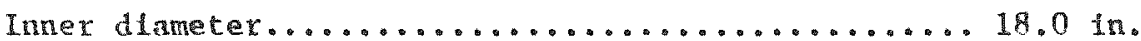

Diffuger outer diameter.......................... 19.

\section{Desinn Cond1tion}

Flow conditions:

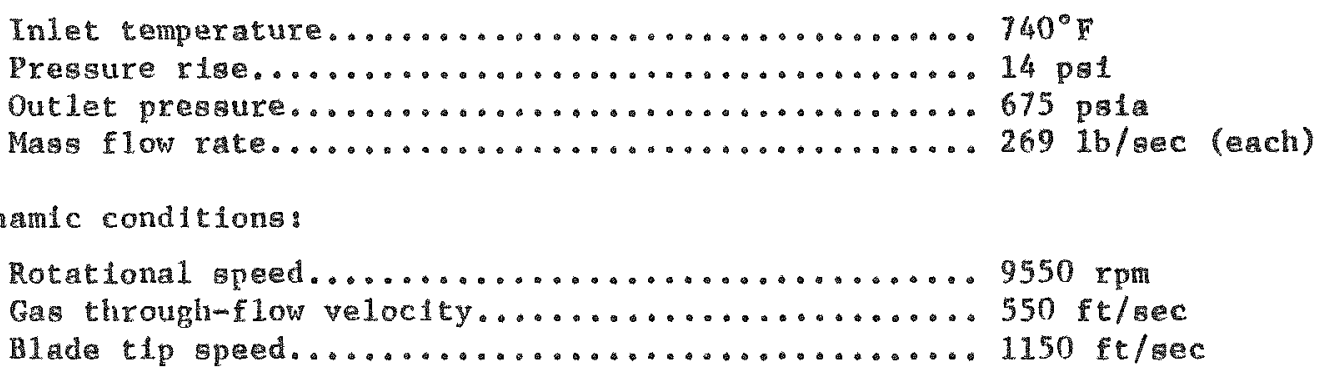

Masimum Cont1nuous operat1on

Wow conditione:

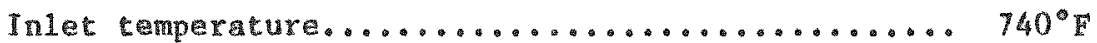

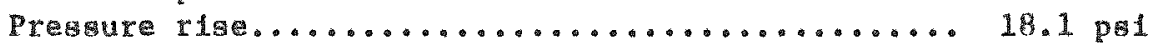

Out1et pressure..........................679.1 pala

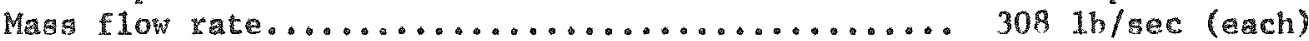

Dynamic condtions:

Rotatlonal speed........................ 10,800 rpm

Through-flow veloctty......................6. $622 \mathrm{ft} / \mathrm{sec}$

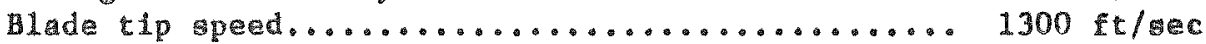

Table II. 2

STLAM TURBINE DESIGN SUMMARY

Flow conditions:

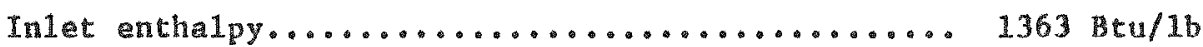

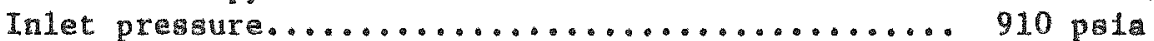

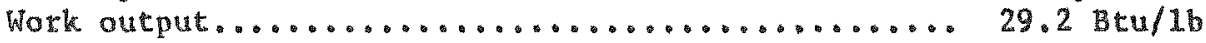

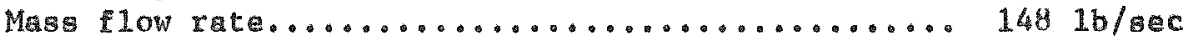

DLmenstorg:

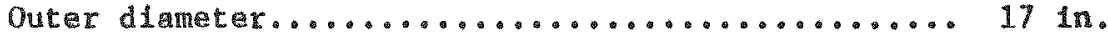

Inner diameter................................. 14.

Dynamic conditions:

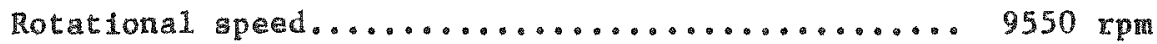

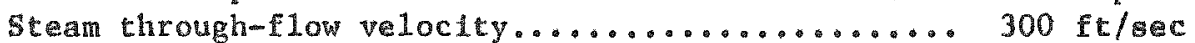

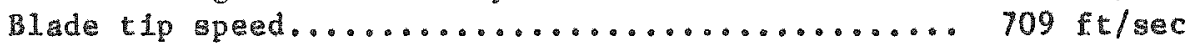




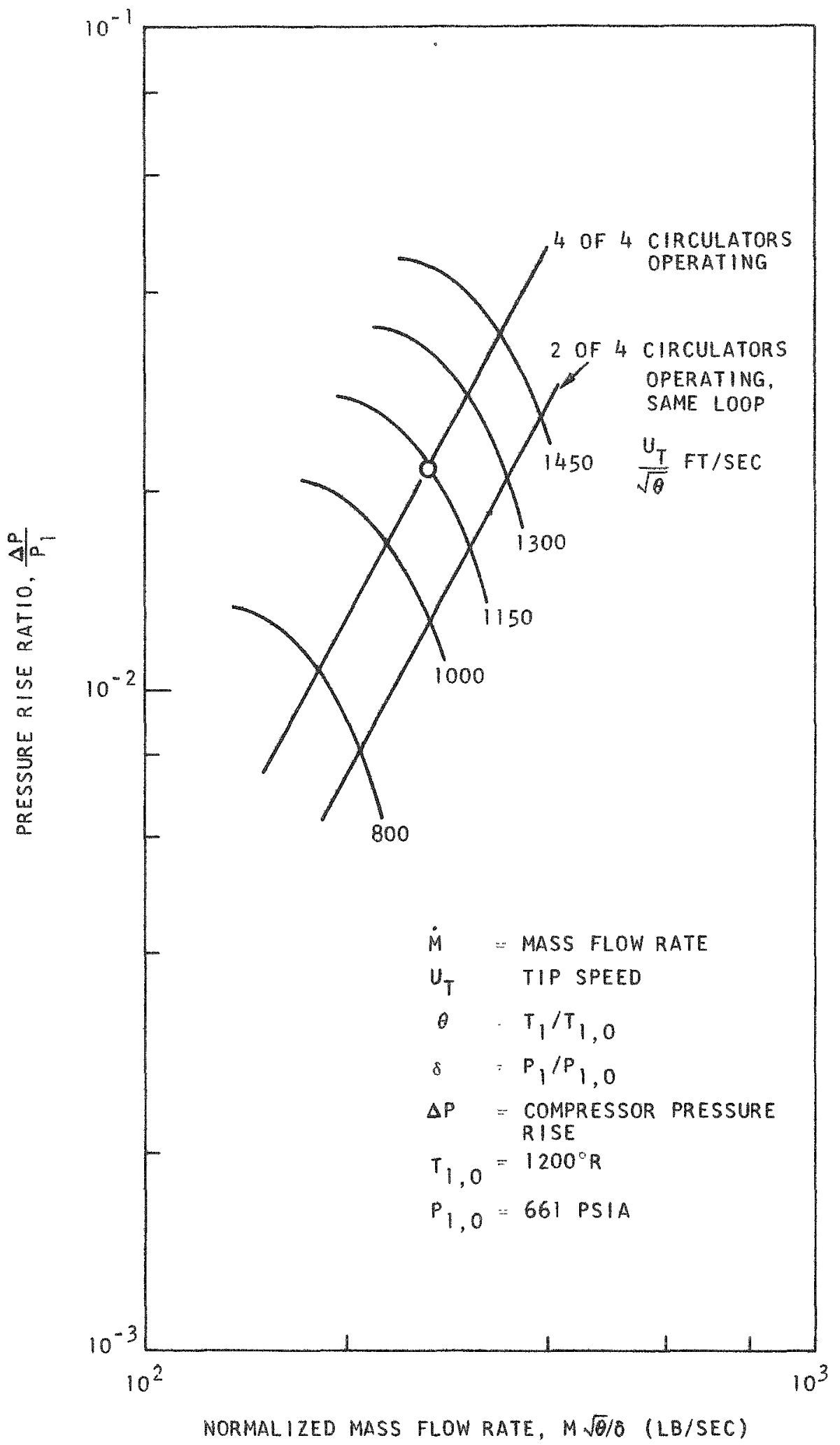

Fig. II.1-Compressor pressure-rise ratio versus normalized mass flow rate for various aerodynamic tip speeds; system operating curves superimposed for normal operation with 4 of 4 and 2 of 4 circulators operating 
pressure ratio of the compressor is the ordinate, and the flow rate, corrected for temperature and pressure, is the abscissa. The system pressure-flow characteristics for both 1oops operating and for one loop operating are linear on $\log -\log$ coordinates, since the pressure-loss curves are parabolic. The constant-speed lines for the compressor are shown parametrically. This figure covers the primary circuit operation under all loads.

The conditions during low-pressure operation are shown on Fig. II.2 with the same variables and parameters as Fig. II.1. Figure II.2 depicts the situation that will prevail under depressurization of the primary coolant system. The compressors can be driven by either the steam-turbine drive or the auxiliary water-turbine drive.

The design conditions for the auxiliary water turbine are determined by two operating conditions: the low-pressure conditions at the high-speed end and the high-pressure conditions at the low-speed end of the operating spectrum. The power requirements for the low-pressure operating conditions as a function of flow rate are shown in Fig. II. 3 for the case of one machine running in one loop, two machines running in different loops, and two machines running in the same loop. The variation in operating conditions that results is a function of the pressure losses that the different arrangements of operating machines impose.

The thrust conditions for the design of the thrust bearings are shown in Fig. II.4 for both normal operation and plant startup. In the startup condition, steam is supplied first from the auxiliary boiler and then from steam generated by nuclear heat before the main turbogenerator is started. These thrust loads form the basis for the bearing design.

\section{DEVELOPMENT PROGRAM}

The development program for the circulators is primarily focused on a prototype test facility to be constructed at the Valmont Station of PSC. A rotor inertia rig will be constructed from prototype parts in order to test the bearings, wheel attachment, rotor dynamics, bearing dynamics, and the lubrication system. This rig will also be used to obtain the limits of the torque-speed and flow-head characteristics of the auxiliary water-turbine drive; these are the stall and runaway conditions.

The prototype circulator will be installed in a large pressure vessel containing a heat exchanger to remove the heat of compression. This installation will serve as the vehicle for testing the seals and sealing system, the full-load performance of the compressor, the performance of the steamturbine driver, vibration characteristics of the blading, the mechanical integrity of the entire machine, the helium valve, and the containment seal. In addition, further tests will be run to simulate the flow asymmetry introduced by the reactor arrangement and to study their effect on circulator operation. The simulation of reactor operation will include starts, stops, part-load operation, etc., for both normal operation with steam and auxiliary operation with water. 


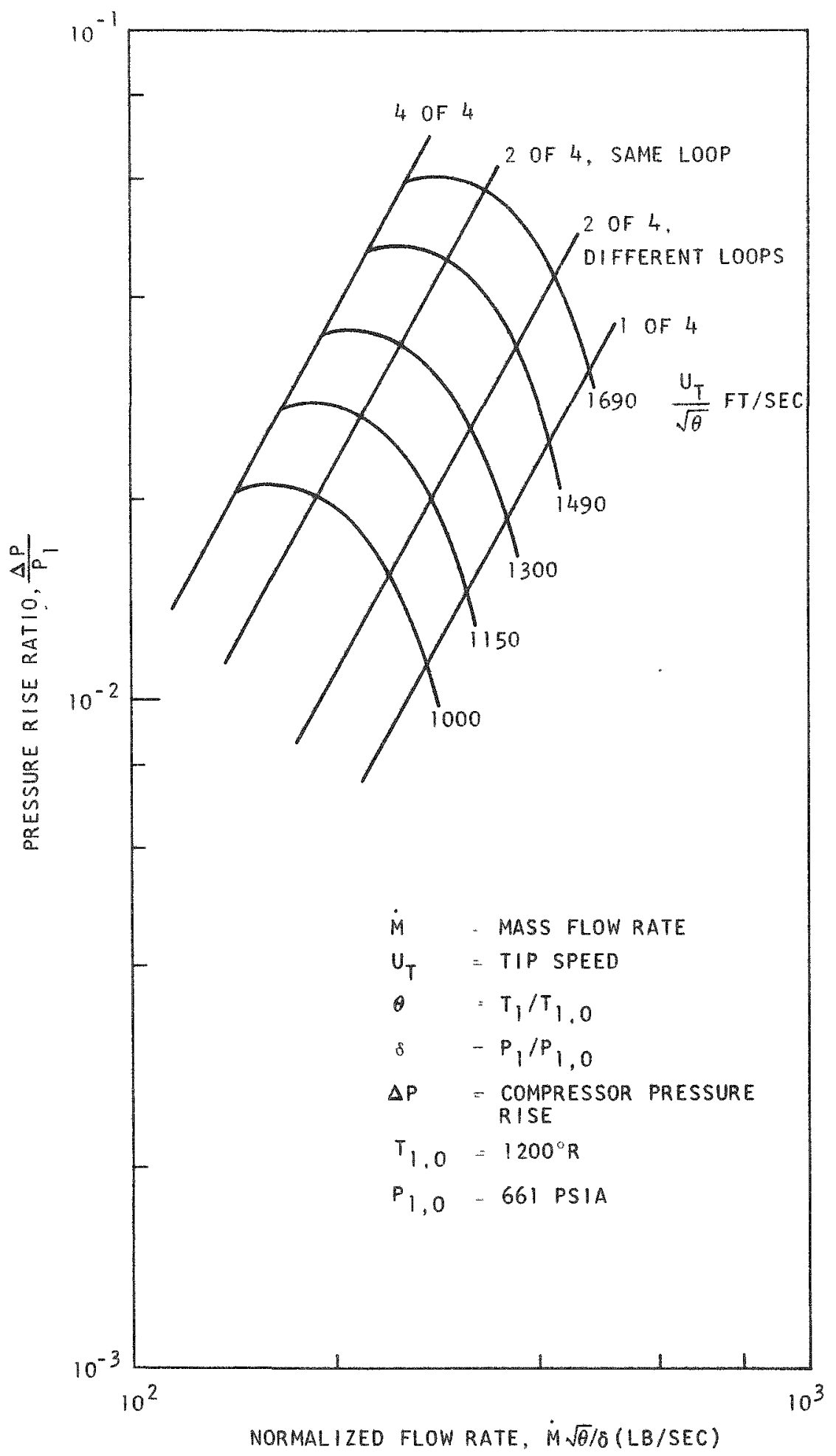

Fig. II,2--Compressor pressure-rise ratio versus normalized mass flow rate for various aerodynamic tip speeds; system operating curves superimposed for low-pressure auxiliary operation with 4 of 4,2 of 4 with 2 in same loop, 2 of 4 with each in different loop, and ' 1 " of ' 4 ' operating' 


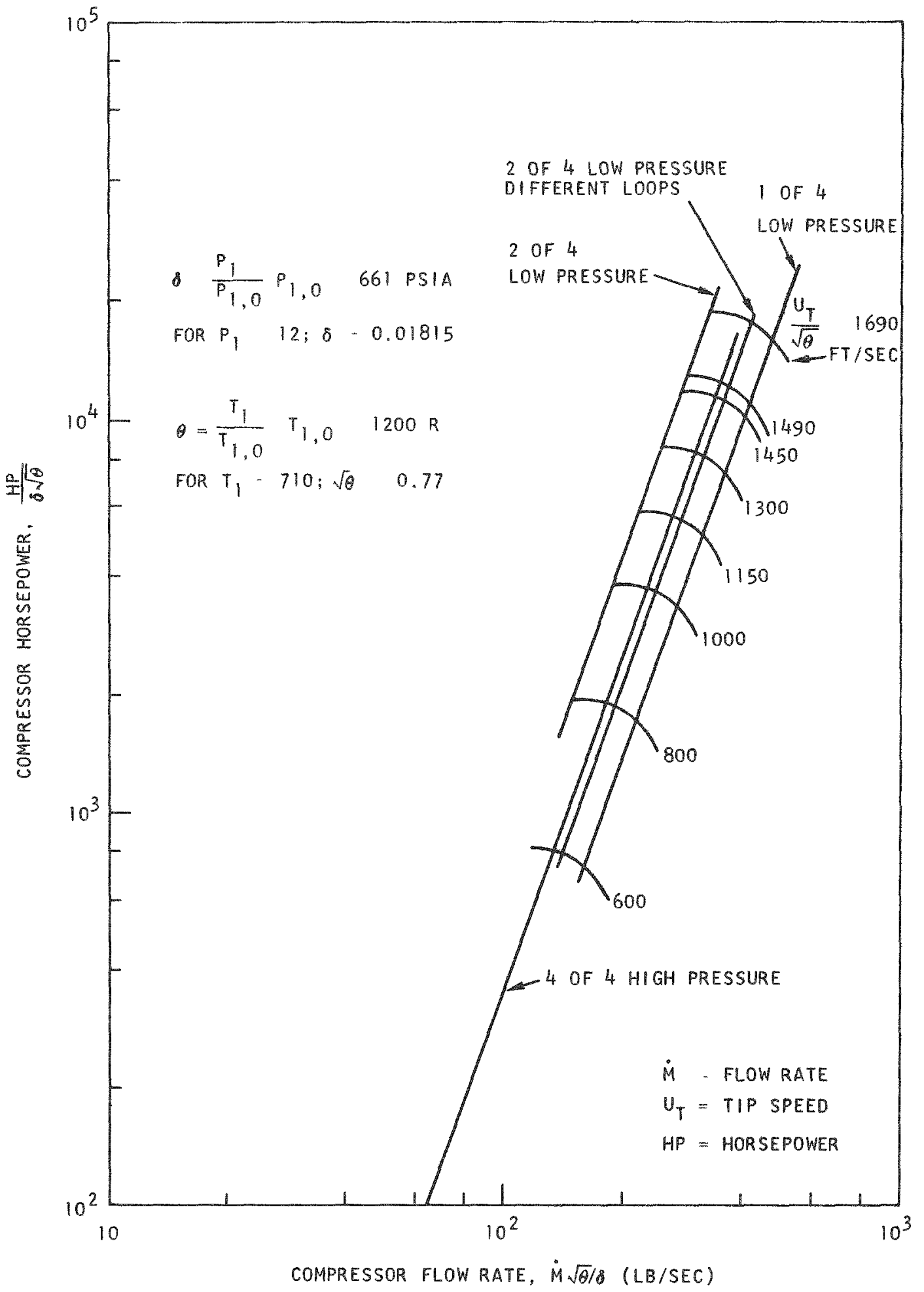

Fig. II.3--Normalized compressor horsepower versus normalized flow rate for various aerodynamic speeds superimposed on system power curves for 4 of 4 high-pressure operation, 1 of 4,2 of 4 different loops, and 2 of 4 same loop low-pressure operation 

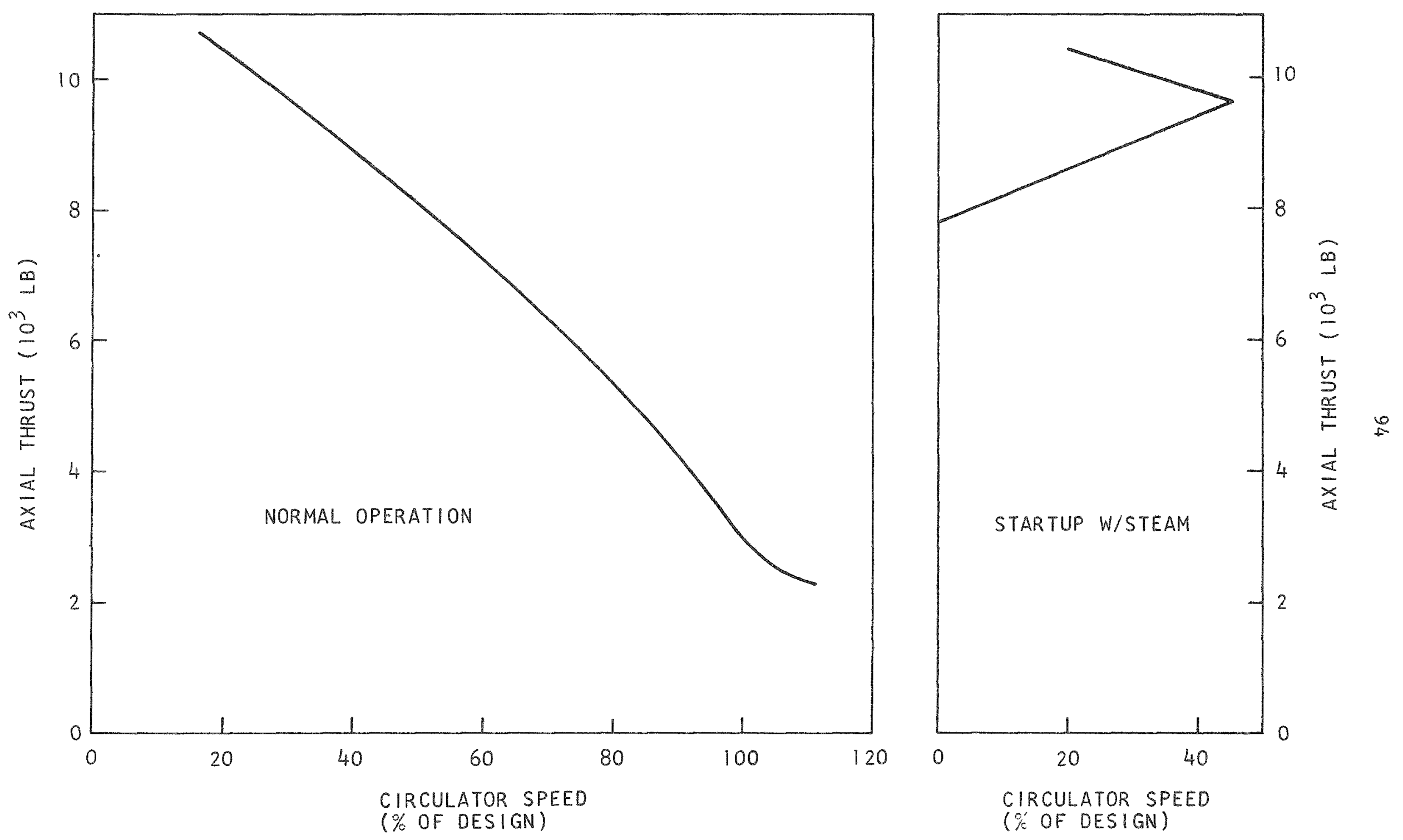

Fig. II.4--Resulting downward thrust loads for the series-steam-turbine-driven helium circulator with a 5-in. sháft. 


\section{TEST FACILITY}

A preliminary design of the test facility required for the prototype and component development testing has been completed. The helium test loop, which is contained in a large pressure vessel, is shown on Fig. II.5. Helium for filling the test $100 \mathrm{p}$ will be supplied from a helium gas trailer; a compressor will be used to pump the helium back into the trailer. Special instrumentation required for the test will be installed in an instrumentation trailer. Provision for assembly and disassembly of the circulator will be made in a separate clean room. The rotor inertia simulator test will be run on a separate test stand adjacent to the main facility. The means for driving this test is expected to be the auxiliary water turbine. The services required for the test are shown in Table II.3.

Table II.3

SERVICES REQUIRED FOR TEST

\section{Outside Services}

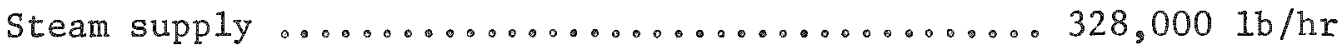

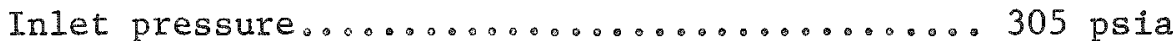

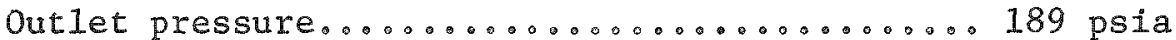

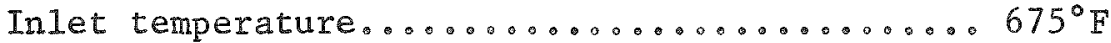

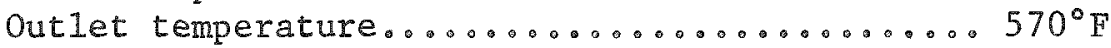

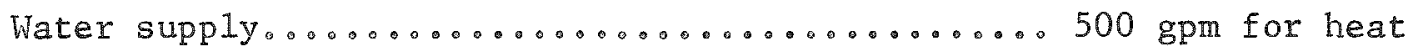 exchanger

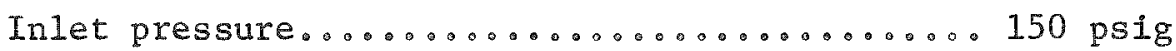

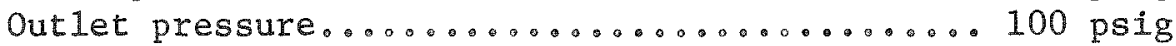
Inlet temperature...................

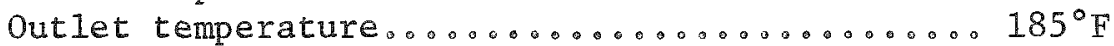

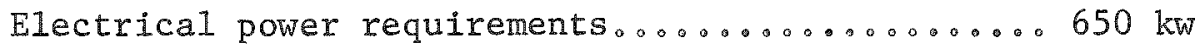
Closed Loop Services (inside test facility)

Water supply:

Seals and bearings $\ldots \ldots \ldots \ldots \ldots \ldots \ldots \ldots$ 50 $\ldots \ldots$ gal reservoir closed loop

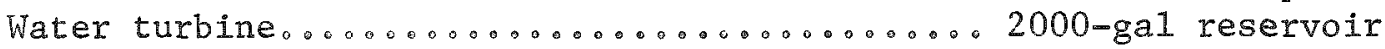
closed loop

Helium system

with helium cleanup circuit................... loop into and

out of tankage trailer

The pressure vessel will be a self-contained loop in which performance measurements for both the steam-turbine driver and the compressor will be made based in part on the heat rejection from the circulating gas. By designing the heat exchanger for relatively high water temperature differences, it will be possible to arrive at an accurate determination of the 


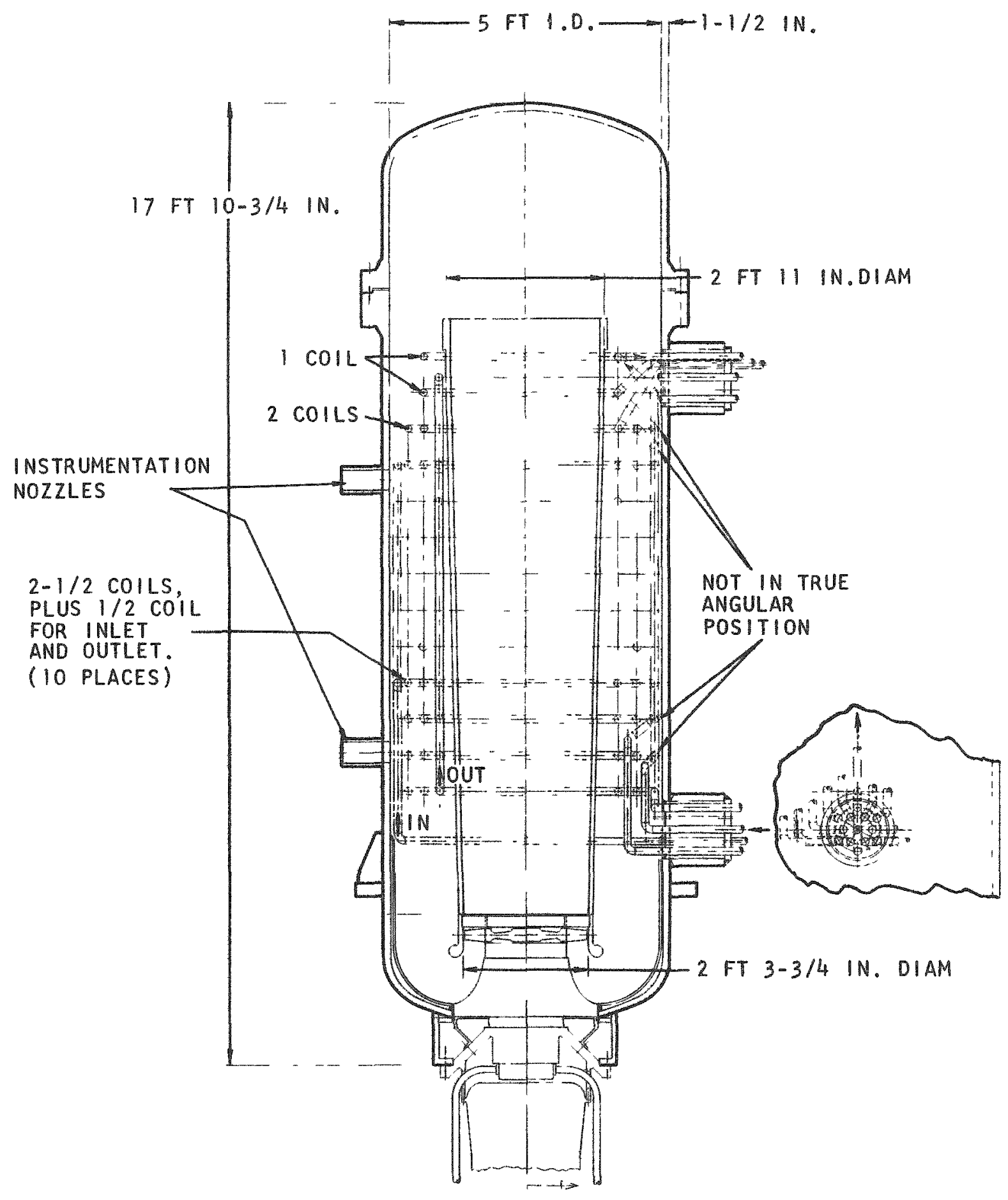

Fig。 II, 5-melium tes L loop 
power output through the measurement of temperature rise and water flow in the heat exchanger. Provision will be made for trimming the water flow to maintain the high temperature difference.

The preliminary design of the helium valve and the means for imposing a variable flow restriction on the compressor are still under study. 
TASK III

CONTROL ROD DRIVE

The objective of this task is to determine the suitability and maintainability and reliability of the control rod drives for the plant under the expected temperature and helium chemical impurity conditions predicted for the reactor by means of testing, including accelerated life testing, of a full-scale prototype of the control rods and drive.

In the first part of the period, the phase II environmental test of the control rod drive was somewhat retarded because of a periodic malfunction of the gas purification and analyzing systems. However, following installation of a new gas chromatograph and overhaul of the purification system, the total oxidizing impurity level was consistently held at less than $10 \mathrm{ppmv}$, and the test proceeded satisfactorily until the scheduled termination. No malfunction or deviation in performance of the control rod drive mechanism was observed.

The total test time logged in phase II was $4015 \mathrm{hr}$, during which time the mechanism was operated for $804 \mathrm{hr}$. A summary of the test functions performed up to the termination of the test is given below:

Function Number Rod Travel (ft)

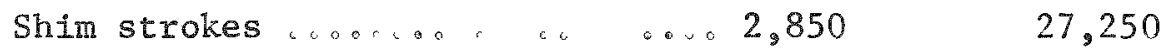

Scrams o o o . . o . . . . 848 8, 866

Postscram shim rod insertions...6 $638 \quad 6,036$

Oscillations ( 24 in。amplitude). 197,152 65,717

Cumulative rod travel .... $\quad \ldots \quad 107,169$ 
TASK IV

STEAM GENERATOR

The objective of this task is to establish the suitability and maintainability of the design of the steam generators for the conditions of temperature and pressure expected in the plant by means of conceptual design, analyses, and testing of the critical aspects of the design. The tests are expected to include gas flow distribution and pressure drops, helium-side heat transfer, tube vibration, and experimental investigation of material compatibility with coolant impurities. The development of a high-temperature design basis and investigation of experience relative to tube integrity is also planned.

\section{TUBE VIBRATION TEST}

Assembly of the tube vibration test facility and associated instrumentation was completed, and the Phase I testing program was performed for the first bundle arrangement. The tubes were oriented in a triangular-pitch pattern with respect to the direction of air flow. Upon completion of the test runs, analysis of the recorded results was initiated.

The natural frequencies of the tubes and tube bundle obtained from the test recordings correlated closely with the calculated values. The amplitudes of the tube bundle vibration as a result of air flow and the forcing frequencies caused by the air column pulsations from the flutter valve are also obtainable from the test results.

After determining the natural frequencies of the rig and the tube bundle, determination of the resonant frequencies of the inlet and outlet plena was investigated by use of microphones and an acoustical analyzer. Varying plena sizes and air flows were tried. After the recorded results were analyzed, it was determined that a modification to the test rig would be necessary to obtain the desired test results. This modification would provide continuous movement of the inlet and outlet plena reflecting flow screens. It is apparent from the test results that the plena air column resonant conditions for the various air flow ranges can only be located by continuous movement of the screens in a searching test. At present, methods of providing this modification are being considered. When this modification has been made, it is expected that the resulting data will indicate what combinations of unsupported tube length and plena volumes create resonant conditions for the test bundle arrangement. This information will permit the steam generator designer to prevent the resonant combination by knowing the range of lengths and plena volumes in which resonances occur. 
The computer cole DYNAM is now avallable for dynamic stability analyses of once-through boiler designs. Studies to date at General Atomic have heen restricted to various aspects of static instability. In brief, the dynamic analysis solves the linearized partial differential conservation equations using Laplace transformation of the temporal terms and integration of the spatial variations. The resulting equations represent the transfer functions for each spatial node. The computer code then employs frequency response techniques to develop the system transfer function. Stability criteria used in control system theory may then be applied to determine whether or not the boiling channel is unstable, i.e., whether flow oscillations rill appear. In this study, the Nyquist criterion for stability is used. If the magnitude of the system gain at $180^{\circ}$ phase shift is greater than unity, the system is unstable. The analysis is intended for use as a design tool to avoid the inception of oscillations and is not capable of predicting the severity of oscillations in an unstable design. Amplitule prediction would require treatment of nonlinearities, since only a nonlinear system can develop the characteristic limit cycle that appears in all the boiling experiments exhibiting instability. Since the analytical solution describing the system dynamics is built into the program, the code is not subject to numerical instabilities and does not require time-consuming iterations. Typical problem execution times range from 1 to 5 mhr on the IBM 7044.

The stability of a typical steam generator design was examined at ful1-1oad design conditions, $25 \% 10 a d$, and at 800 psia startup. The dynamic model describes the geometry of a single tube operating between headers, which includes the inlet lead, the active tube sections, the crossover connection within the split superheater, and the exit lead. The full-1oad operating case is unstable without additional damping, but is stabilized with the addition of a 10-psi orifice. Operation at $25 \%$ load requires slightly more orificing, equivalent to 16 psi at full load. The 800-psia startup case requires orificing equivalent to 270 psi at full load if fixed orificing is employed. Additional information on these cases is listed in Table IV.1. These findings must be considered preliminary and are not conservative, since no operational uncertainties are considered and no uncertainty factor has been applied representing the confidence level of the analysis. The latter uncertainty is difficult to estimate because of the paucity of comparative data from once-through experiments. When the operational uncertainties and the analytical confidence level have been established, then a safety factor (phase margin) may be used that describes the degree of excess damping designed into the system.

There are only two experiments available in the literature on oncethrough boiling flow oscillations at high pressure. A number of highpressure flow oscillation experiments have been carried out with partial evaporation at the channel exit and have been reported in a literature survey. Data from one of the experimental programs has been compared with code predictions. Good agreement was found at the inception conditions of oscillations, and agreement between measured and predicted frequencies was excellent. Comparison between prediction and one of the two experimental once-through results is shown in the Table IV. 2 . 
Table IV.I

RESULTS OF STABILITY CALCULATIONS

\begin{tabular}{l|c|c|c|c|c}
\hline & $\begin{array}{c}\text { Pressure } \\
\text { (psia) }\end{array}$ & $\begin{array}{c}\text { Exit } \\
\text { Temp。 } \\
\left({ }^{\circ} \mathrm{F}\right)\end{array}$ & $\begin{array}{c}\text { Inlet } \\
\text { Resistance } \\
\text { Factora }\end{array}$ & $\begin{array}{c}\text { Flow } \\
\text { Oscillation } \\
\text { Frequency } \\
\text { (cps) }\end{array}$ & $\begin{array}{c}\text { Gain at } \\
180^{\circ} \text { Phase } \\
\text { Shift }\end{array}$ \\
\hline Ful1 load & 2700 & 1000 & 0 & 0.13 & 1.74 \\
Ful1 load & 2700 & 1000 & 50 & 0.14 & 0.57 \\
$25 \%$ load & 2400 & 1000 & 0 & 0.041 & 2.60 \\
$25 \%$ load & 2400 & 1000 & 80 & 0.043 & 0.84 \\
$\begin{array}{c}\text { Startup } \\
\quad \text { (fundamenta1) }\end{array}$ & 800 & 790 & 1400 & 0.055 & 0.60 \\
$\begin{array}{c}\text { Startup } \\
\quad \text { (Ist harmonic) }\end{array}$ & 800 & 790 & 1400 & 0.175 & 0.95 \\
$\begin{array}{c}\text { Startup } \\
\quad \text { (2nd harmonic) }\end{array}$ & 800 & 790 & 1400 & 0.35 & 0.97 \\
\hline
\end{tabular}

a Number of inlet velocity heads dissipated.

Table IV.2

COMPARISON BETWEEN PREDICTION AND APDA PROTOTYPE LIQUID-METAL STEAM GENERATOR EXPERIMENT

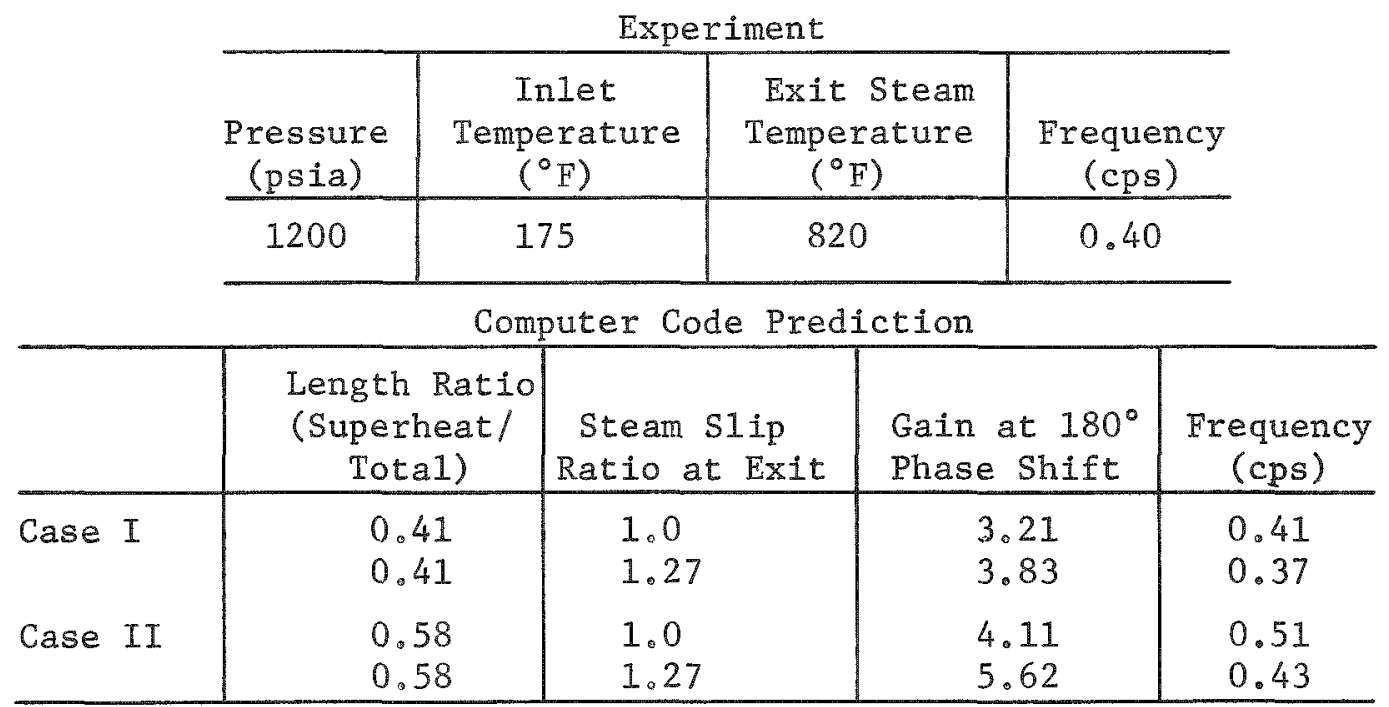

Predicted results in all instances shown in Table IV.2 are unstable. Case I and II represent the probable bounds on the heating distribution which, of course, is difficult to ascertain because of the high heat-transfer coefficient on the liquid metal side. It is also difficult to determine an appropriate model for steam slip in the evaporator region, because cruciform spacers were located in the tubes at 3-ft intervals over their 
entire length. The spacers tend to act as turbulence promoters, thus causing development of a flow regime more nearly homogeneous than annular. Cases I and II with the moderate slip values indicated are felt to be reasonable models of the experiment

Table IV, 3

CONPARISON OF PREDICTION WITH WAPD HEAT TRANSFER PROGRAM

Experiment

\begin{tabular}{|c|c|c|c|c|c|c|}
\hline & $\begin{array}{c}\text { Heat Flux } \\
\begin{array}{c}(B t u / \\
\left.h r-f t^{2}\right)\end{array}\end{array}$ & $\begin{array}{c}\text { Resistance } \\
\text { Factor- }\end{array}$ & $\begin{array}{l}\text { Inlet } \\
\text { Temp } \\
\left({ }^{\circ} \mathrm{F}\right)\end{array}$ & & $\begin{array}{l}\text { t steam } \\
\text { Temp } \\
\left({ }^{\circ} \mathrm{F}\right)\end{array}$ & $\begin{array}{c}\text { Pressure } \\
(\text { psia })\end{array}$ \\
\hline \multirow[t]{3}{*}{$\begin{array}{l}\text { Stable operation } \\
\text { Unstable (frequency } \\
\text { unknown) }\end{array}$} & $\begin{array}{l}104,000 \\
117,000\end{array}$ & $\begin{array}{l}04 \\
0.4\end{array}$ & $\begin{array}{l}651 \\
651\end{array}$ & & $\begin{array}{l}690 \\
710 \\
\end{array}$ & $\begin{array}{l}2400 \\
2400 \\
\end{array}$ \\
\hline & \multicolumn{4}{|c|}{ Computer Code Prediction } & & \\
\hline & $\begin{array}{c}\text { Heat Flux } \\
\begin{array}{c}(B t u / \\
\left.h r-f t^{2}\right)\end{array}\end{array}$ & $\begin{array}{l}\text { Exit } \\
\text { Resistance } \\
\text { Factora }\end{array}$ & \multicolumn{2}{|c|}{$\begin{array}{l}\text { Frequency } \\
\text { (cps) }\end{array}$} & \multicolumn{2}{|c|}{$\begin{array}{l}\text { Gain at } 180^{\circ} \\
\text { Phase Shift }\end{array}$} \\
\hline $\begin{array}{l}\text { Stable operating } \\
\text { conditions } \\
\text { Unstable operating } \\
\text { conditions } \\
\text { Unstable conditions } \\
\text { with } \mathbb{K}_{e} \text { as a } \\
\text { parameter } \\
\text { Unstable conditions } \\
\text { with } \mathrm{K}_{e} \text { as a } \\
\text { parameter }\end{array}$ & 110,000 & $\begin{array}{l}0.4 \\
0.4\end{array}$ & 090 & & $\begin{array}{l}\text { Overda } \\
\text { respo }\end{array}$ & $\begin{array}{l}\text { nped } \\
\text { ise }\end{array}$ \\
\hline
\end{tabular}

a Number of exit velocity heads dissipated,

A comparison between the computer code predictions and the other experiment is shown in Table IV 3. The close agreement found in this table may be fortuitous. The prediction is exceedingly stable at conditions corresponding to the low-power stable experimental run. This result is indicated by the predicted overdamped response wherein the frequency response curve reflected such extreme damping that a crossing did not occur at $180^{\circ}$ phase shift. The prediction for the high-power unstable experimental run is descriptive of a barely stable system in which oscillation will slowly converge with time An increase in the estimated value of the exit resistance factor from 0.4 to 0.5 results in an unstable prediction. Since the exit loss pressure drop is only $3 \%$ of the total, the unstable prediction is well within the experimental uncertainties involved.

These comparisons do not add much support for reliance on the oncethrough dynamic analysis applied to high-pressure cases. In the first 
instance, the stable performance could not be reproduced, and in the second, the superheat is so small that the case is not a proper test of once-through performance. Considering other uncertainties arising from two-phase stratification in curved tubes and boiling heat transfer, one must conclude that it is hardly possible to develop an uncertainty factor for the analysis without additional experimental data.

\section{STEAM GENERATOR DESIGN STUDIES}

The steam generator supplier conceptual design studies have been completed during this period, and discussions with the suppliers were held to review the designs. These designs are now under evaluation.

\section{STEAM GENERATOR TUBE PLUGGING MACHINE}

Development of the weld-preparation tool head has proceeded satisfactorily. Cutting tests on typical tube-to-tubesheet weldments have produced clean, parallel counterbores into which the plugs are inserted and welded. No tool chatter was observed at design cutting speeds and cutter wear was minimal, a 1-1/8-in. diameter counterbore 5/8 in. deep taking approximately 16 min.

Development to date has been based on Types 304 and 316 stainless steel tubes and tubesheets. The use of other materials, such as Incoloy 800, is currently being considered; fabrication of weld specimens in that material has therefore been initiated.

A preliminary study was performed to assess tube plugging machine requirements for concentric header arrangements. In such arrangements, it appears feasible to utilize a single turret to service both inlet and outlet tube ends; a small secondary turret would carry only a single tool head for leak detection purposes and possibly a seal surface cleanup tool. 
TASK V

COATED PARTICLE DEVELOPMENT

The objective of this task is to determine the process variables for fabrication of coated fuel particles suitable for use in the plant by means of investigation of various methods of fabricating fuel particles, investigation of coating process variables, and preirradiation evaluation of coated particles.

\section{BUFFER COATING STUDIES}

An intensive study of the inner layer of the reference two-layer BISO-coated particles is being conducted. This inner layer is interposed between the fuel particle and the outer, dense coating layer to accommodate swelling of the fuel particles and to absorb fission recoils. The objective of the study is a more complete understanding of the properties required for the inner layer to enhance the radiation stability of the coated fuel particle. Information gained during this study will aid in optimization of the reference coating process.

Three approaches to producing a coating that will satisfy the requirements of the inner layer of the BISO fuel particles are being considered. First, the proven concept of using a soft, low-density isotropic coating (true buffer coating) is being systematically studied. Second, the use of a low-density isotropic coating that is not soft is being evaluated. Third, the concept of a laminar inner coating that contains the core particle loosely within its central void will be evaluated.

The systematic studies of the true buffer coating have been completed. Al1 of the coatings were deposited at temperatures ranging from $900^{\circ}$ to $1200^{\circ} \mathrm{C}$ and in concentrations ranging from $60 \%$ to $100 \%$ of acetylene. In all cases, buffer density decreases with increasing acetylene concentration. Over the range of parameters studied, the minimum buffer density achieved on fissile size particles ( 150 - to $250-\mu$ diameter) was 0.7 to $0.8 \mathrm{~g} / \mathrm{cm}^{3}$ 。 Methods of characterizing the mechanical strengths of these coatings are under study.

The study of the use of other gases for the deposition of the buffer structure was expanded into a systematic study. Complete characterization of the structures produced during this study is under way. Partial results show that low-density coatings $\left(0.7\right.$ to $\left.0.8 \mathrm{~g} / \mathrm{cm}^{3}\right)$ equivalent to true buffer coatings can be deposited from other sources.

A method for determining the density of the buffer coating directly on particles has been developed. The buffer density is calculated from the over-all density and carbon analysis of the particles both before and 
after coating. Densities of nonporous PyC coatings calculated in this manner agree within $5 \%$ with those measured by the sink-float technique on the PyC slabs removed from graphite disks coated along with the fuel particles. However, when this new technique is applied to buffer coated particles, the error involved may be larger, because it becomes difficult to measure the true bulk density of the buffered particles.

This new density measuring technique is being applied to all of the buffer studies. The numerical results confirm the qualitative results inferred from metallography; however, there is a significant disagreement between the values obtained by this technique and those obtained by the $\mathrm{X}$-ray absorption technique. The reason for this disagreement has not yet been determined.

\section{HIGH-DENSITY ISOTROPIC COATINGS}

A study of high-density isotropic PyC coatings is also being conducted. The results of the $G 9$ irradiations on pyrocarbon indicate that this structure should have the best radiation stability of the structures tested to date. The objective of this work, therefore, is an understanding of the high-density isotropic coating region and optimization of the coating process necessary to obtain the high-density structure.

Previous work was concerned with methane as the hydrocarbon source. Current work has been expanded to include deposition from other gases. Characterization of the coatings produced are not yet complete。

\section{COATED PARTICLE PREPARATION}

Irradiation testing of promising types of reference coated particles is being carried out in connection with the PSC program at General Atomic. Supporting irradiation tests are also being conducted at ORNL and Dragon (DFR). Coated particles for the irradiations are being prepared as part of this task. The irradiation tests are intended to guide the development of BISO coatings with optimum radiation stability and retentivity and minimum fabrication costs. During the past reporting period, coated particles were prepared for the following experiments.

Capsule P14B

One sample of coated particles was prepared for Capsule $\mathrm{P} 14 \mathrm{~B}$, the replacement capsule for $\mathrm{P} 14$. The coating produced had an anisotropy factor of 1.6 , which was needed to fill a gap in the anisotropy series originally prepared for P14.

Capsule P15

A tentative selection of the coatings for Capsule $P 15$ has been made. Capsule P15 primarily will be a study of the inner (buffer) coating layer. True buffer, high-temperature buffer, and low-density isotropic coatings will be tested as materials for this inner layer. 


\section{ORNL Irradiations}

Two additional BISO coated particle samples were prepared for the ORNL 41-28 irradiation. The samples previously reported were not acceptable, because the anisotropy of the overcoat was too high. The properties of the particles sent to ORNL are shown in Table V.1.

Table V.1

COATED PARTICLE SAMPLES FOR ORNL 41-28 HIGH BURNUP IRRADIATION EXPERIMENT

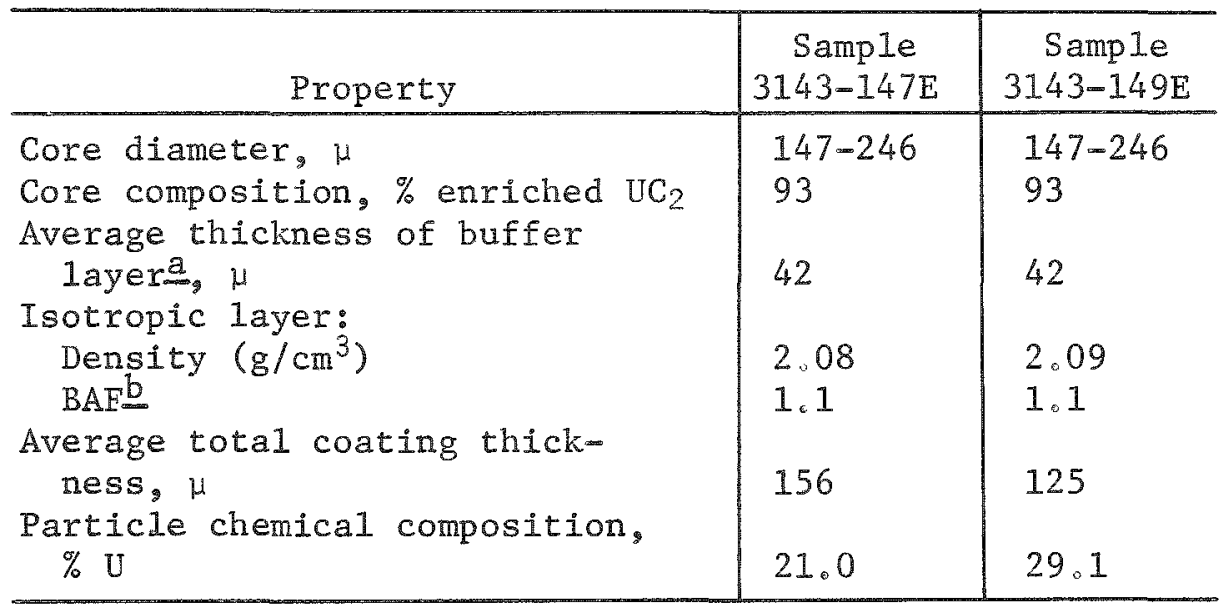

a Both samples were overcoated from the same lot of buffer particles.

b Bacon anisotropy factor.

\section{COATING EVALUATION TECHNIOUES}

Characterization of pyrolytic carbon coatings is necessary for predicting and understanding the performance of coated particles under irradiation and thermal testing. These studies are intended to improve and add to existing techniques used in determining coating parameters.

Development of a new technique for determining densities by $\mathrm{X}$-ray absorption has reached a useful stage. This method is based on the difference in $\mathrm{X}$-ray absorption exhibited by coatings having various densities. Experimentally, the thicknesses of the PyC coating samples are measured mechanically, and these samples are placed along with standards of known density on a photographic plate. This plate is exposed to an X-ray beam, developed, and scanned with a densitometer. The densitometer readings of the known samples are plotted to yield a standard curve. The densities to be determined absorb the same amount of X-rays as the known amount of carbon, allowing determination of the weight of carbon per square centimeter of sample; the density can be calculated from this value and the measured thickness. 
An experiment is currently in progress to check the $X$-ray density against the sink-float (standard) density. Twenty-seven samples were radiographed along with two standard wedges made of carbons with densities of 1.5 and $2.0 \mathrm{~g} / \mathrm{cm}^{3}$ (determined by sink-float). Typical results are shown in Fig. V.1. The data show that this method yields accurate density values.

Work has also been done on enlarging the original photographic plate so that coating thicknesses less than $50 \mu$ (the limitation of present equipment) can be analyzed. It was shown that the plate could be enlarged, and the new standard curves from the enlargement showed excellent agreement with the original curves.

\section{THERMAL STABILITY STUDIES}

Three samples of the reference BISO coating are undergoing a long-term thermal stability test at $1400^{\circ} \mathrm{C}$. These particles were previously shown to have good irradiation stability in P-capsule tests. After $1300 \mathrm{hr}$ at $1400^{\circ} \mathrm{C}$, the three samples showed no significant change from the as-coated average migration values of 0,4 , and $11 \mu$. The samples are now being examined after $2500 \mathrm{hr}$ at $1400^{\circ} \mathrm{C}$.

\section{FISSION-PRODUCT RELEASE}

Postactivation fission-product release studies have been performed on unirradiated BISO-coated fuel particles. The release rates of $\mathrm{Sr}^{91}$ and $\mathrm{Ba}^{140}$ for these samples are given in Table V.2.

Table V.2

FRACTIONAL RELEASE FROM BISO-COATED FUEL PARTICLES a

\begin{tabular}{|c|c|c|c|c|}
\hline $\begin{array}{c}\text { Sample } \\
\text { Description } \\
\end{array}$ & $\begin{array}{l}\text { Annealing } \\
\text { Time } \\
\text { (hr) }\end{array}$ & $\mathrm{Xe}$ & $\mathrm{Ba}^{140}$ & $\mathrm{Sr}^{91}$ \\
\hline $\begin{array}{l}(T h, U) C_{2} 250-350 \mu, \\
85 \mu\end{array}$ & 1.0 & $-\infty$ & $1.0 \times 10^{-2}$ & $3.9 \times 10^{-2}$ \\
\hline $\begin{array}{l}\text { BISO 2000, } \\
\quad 1.86 \mathrm{~g} / \mathrm{cm}^{3}\end{array}$ & $\begin{array}{l}3.0 \\
4.5 \\
8.5\end{array}$ & $\begin{array}{c}--- \\
8.5 \times 10^{-7} \\
\ldots-\end{array}$ & $\begin{array}{l}3.8 \times 10^{-2} \\
9.9 \times 10^{-2} \\
1.5 \times 10^{-1}\end{array}$ & $\begin{array}{l}7.2 \times 10^{-2} \\
1.2 \times 10^{-1} \\
1.4 \times 10^{-1}\end{array}$ \\
\hline $\begin{array}{l}(\mathrm{Th}, \mathrm{U}) \mathrm{C}_{2} 250-350 \mu, \\
99 \mu \\
\text { BISO } 2000^{\circ}\end{array}$ & -- & $3.4 \times 10^{-7}-\frac{b}{b}$ & -- & -- \\
\hline $1.95 \mathrm{~g} / \mathrm{cm}^{3}$ & $\begin{array}{l}1.0 \\
3.0 \\
4.8 \\
8.4\end{array}$ & $2 . \overline{9 \times 10^{-5}}$ & $\begin{array}{l}1.6 \times 10^{-3} \\
6.2 \times 10^{-3} \\
2.5 \times 10^{-2} \\
3.2 \times 10^{-2}\end{array}$ & $\begin{array}{l}1.3 \times 10^{-2} \\
2.8 \times 10^{-2} \\
5.3 \times 10^{-2} \\
6.4 \times 10^{-2}\end{array}$ \\
\hline
\end{tabular}

a Determined by postactivation annealing experiments conducted at $1400^{\circ} \mathrm{C}$.

b Recoil (preannealing) release. 


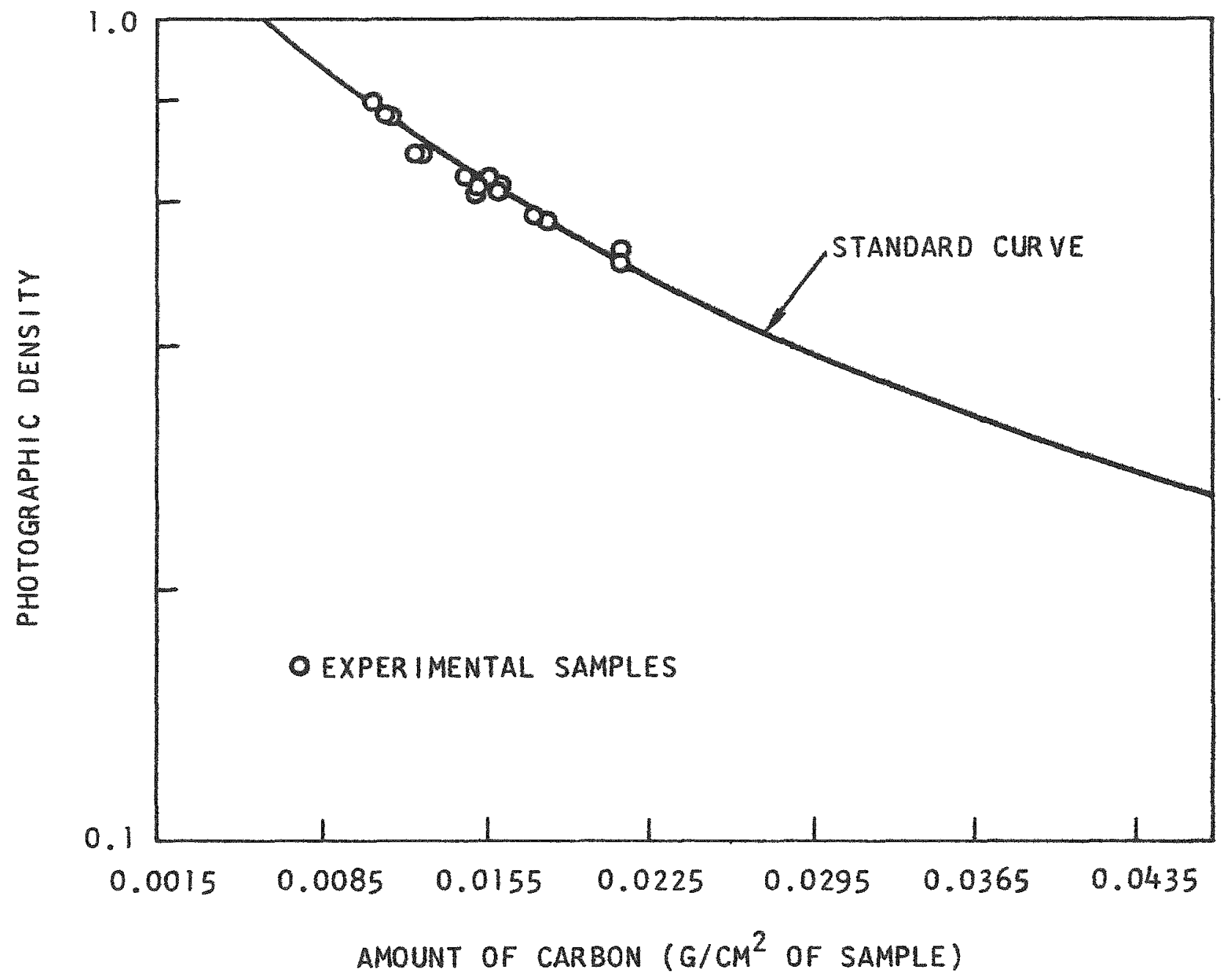

Fig. V。1--Log plot relating the intensity of the X-rays transmitted through a carbon specimen to the number of $\mathrm{g} / \mathrm{cm}^{2}$ of carbon; a standard wedge of carbon was examined by the $\mathrm{X}$-ray technique to make the standard curve. Carbon specimen densities determined by the sink-float method are plotted on the standard curve to show a comparison 
There appeared to be no definite correlation between the fraction of fission products released and coating parameters. $\mathrm{Xe}^{135}$ release fractions are also given. These indicate slight $U^{235}$ contamination of coatings but no breakage.

The results, in general, show that (1) all the particles released strontium and barium to an appreciable extent, (2) the total release increased with time, as might be expected for a diffusion-controlled process, and (3) strontium releases were higher than barium releases, indicating a higher diffusivity for strontium in agreement with the results of postirradiation experiments. 